\title{
WestVirginiaUniversity
}

THE RESEARCH REPOSITORY @ WVU

Graduate Theses, Dissertations, and Problem Reports

2002

\section{Design and construction of a zinc pot bearing material wear tester}

Ryan Ware

West Virginia University

Follow this and additional works at: https://researchrepository.wvu.edu/etd

\section{Recommended Citation}

Ware, Ryan, "Design and construction of a zinc pot bearing material wear tester" (2002). Graduate Theses, Dissertations, and Problem Reports. 1900.

https://researchrepository.wvu.edu/etd/1900

This Thesis is protected by copyright and/or related rights. It has been brought to you by the The Research Repository @ WVU with permission from the rights-holder(s). You are free to use this Thesis in any way that is permitted by the copyright and related rights legislation that applies to your use. For other uses you must obtain permission from the rights-holder(s) directly, unless additional rights are indicated by a Creative Commons license in the record and/ or on the work itself. This Thesis has been accepted for inclusion in WVU Graduate Theses, Dissertations, and Problem Reports collection by an authorized administrator of The Research Repository @ WVU. For more information, please contact researchrepository@mail.wvu.edu. 


\title{
Design and Construction of a Zinc Pot Bearing Material Wear Tester
}

\author{
By \\ Ryan Ware \\ THESIS \\ Submitted To \\ The College of Engineering and Mineral Resources \\ West Virginia University \\ In partial fulfillment of the requirements \\ For the degree of \\ Master of Science in Mechanical Engineering \\ John Loth, Ph.D., Chair \\ Gary J. Morris, Ph.D. \\ Xingbo Liu, Ph.D. \\ Department of Mechanical and Aerospace Engineering

$$
\text { Morgantown, West Virginia }
$$ \\ 2002
}

Keywords: Contact Pressure and Velocity, Galvanizing, Friction Coefficient, Torque 


\begin{abstract}
Design and Construction of a Zinc Pot Bearing Material Wear Tester

By

Ryan Ware
\end{abstract}

There are more than fifty galvanizing lines in the U.S.A. producing galvanized steel sheet by the method of pulling a steel sheet over a roller that is submerged in a liquid zinc bath. Although highly competitive, this product is very lucrative for the Steel Industry. The objective of this research is to assist the U.S. Steel Industry in becoming more competitive with foreign imports by reducing line stoppage for bearing replacement, which currently might be as long as one week to a month.

A great variety of wear and corrosion resistant zinc-pot bottom roller bearing metals and ceramics have already been developed. A small, laboratory-size testing machine was designed to measure wear and friction coefficient on new bearing materials as a function of contact pressures, velocities, and time. It was designed for safety and ease of use. Once the friction coefficient and the wear of the material have been determined, possible correlation between these two parameters may be found in the future. 


\section{Acknowledgements}

I would like to express my special thanks to my research advisor Dr. John Loth, for giving me the opportunity as a graduate student to work with him. I would also like to express my thanks to my academic advisor Dr. Gary Morris. I would like to thank Cliff Judy, Chuck Coleman, and Dr. Mike Palmer for helping with this project. I would like to thank my friend and colleague Jay Snider for assisting me with this project. A special thanks to my friend, Thomas Burke, who help me throughout my years at WVU. I would like to thank my grandmother, Dolly Smith, and for giving me the support needed to achieve my degree. I would like to give my deepest and most appreciative thanks to my mother and father, Susie and Tom Ware for giving me the motivation and assistance necessary thru the duration of my masters degree program. Mom and Dad thanks for always being there.

I appreciate being supported by the DOE Contract DE-PS07-001D13964 throughout this effort. 


\section{Table of Contents}

Title Page

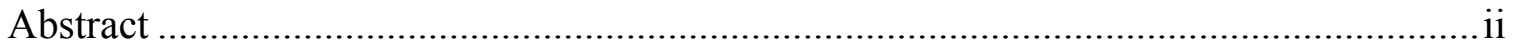

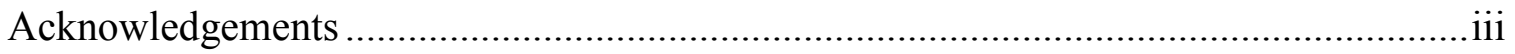

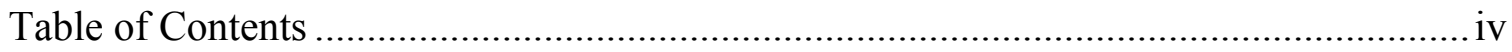

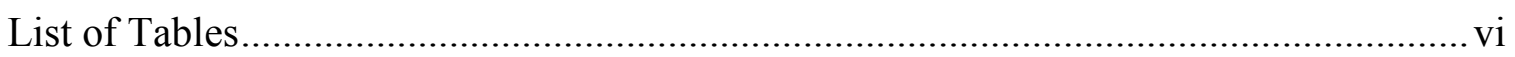

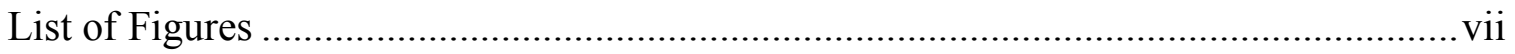

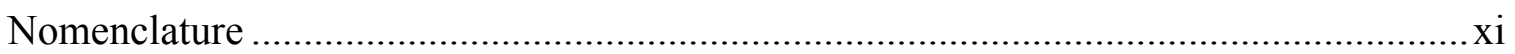

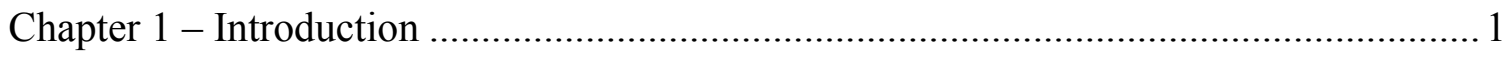

Chapter 2 - Review of Relevant Literature ............................................................... 3

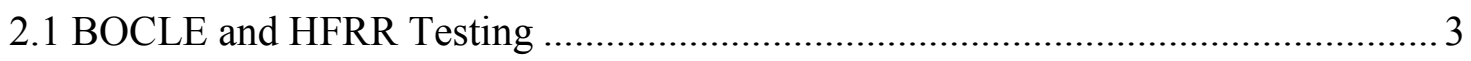

2.2 Teck Cominco's Continuous Galvanizing Line Submerged Hardware Research .... 4

2.3 WVU's Lubricity Research and Testing Apparatus................................................ 9

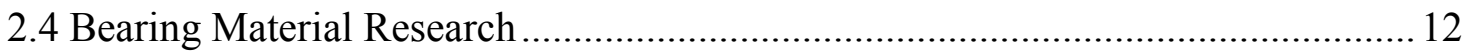

Chapter 3 - Steel Mill Operating Conditions.............................................................. 16

3.1 Steel Mill Zinc Pot Bearing Operating Conditions ................................................... 16

3.2 Laboratory Simulated Operating Conditions ........................................................ 18

Chapter 4 -Bearing Material Wear Tester Design ...................................................... 22

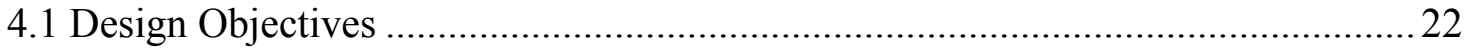

4.2 Zinc-Pot Bearing Material Wear Tester Design Aspects ........................................ 24

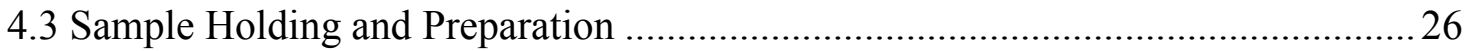

Chapter 5 - Construction of Bearing Material Wear Tester ...........................................2 28

5.1 Vertical Mill, Melting Pot, and Testing Facility ………………............................28 
5.2 Bearing Track Assembly

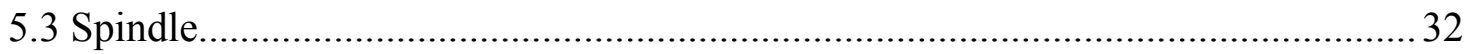

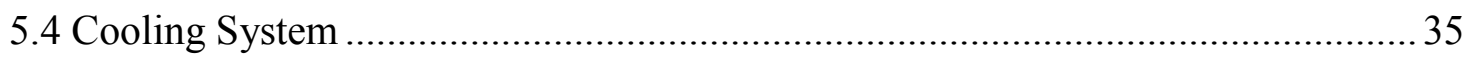

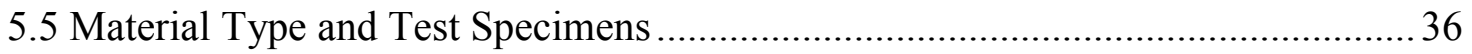

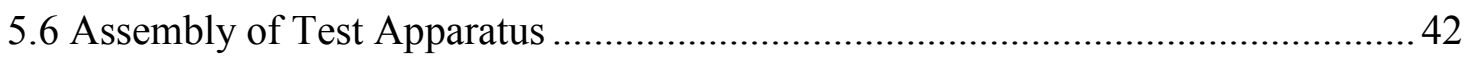

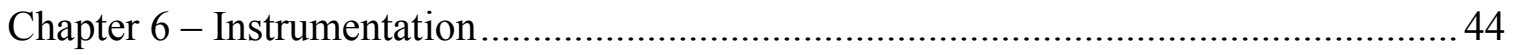

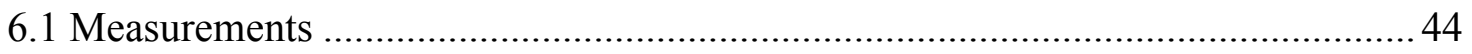

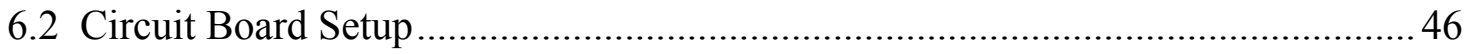

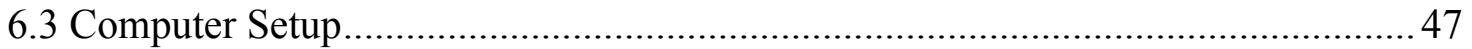

Chapter 7 - Preliminary Tests and Test Results ..................................................... 48

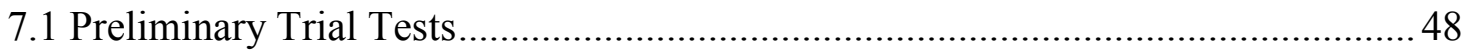

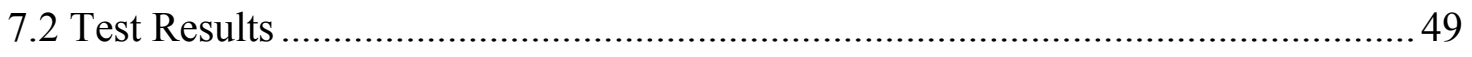

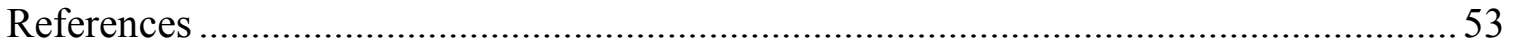

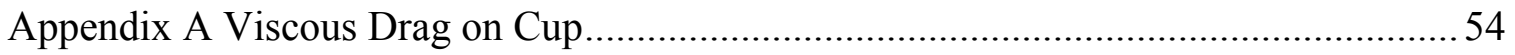

Appendix B Drawings of Test Apparatus ......................................................... 57

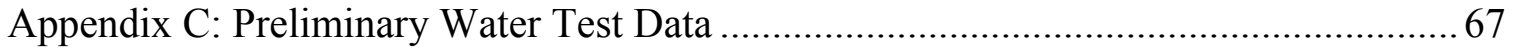

Appendix D: Raw Test Data Hot Zinc Pot Tests ................................................. 72

Appendix E Wiring Diagram for Power Supply ................................................... 81

Appendix F Zinc Composition for Testing ....................................................... 82

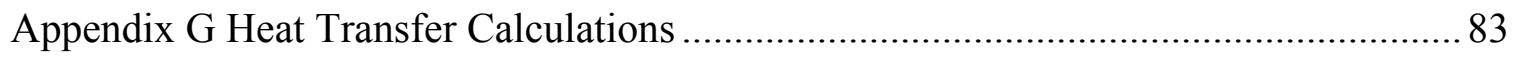

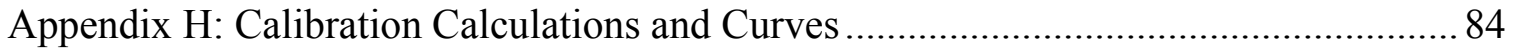




\section{List of Tables}

Table 2.1: Teck Cominco's study of friction and wear results for different material

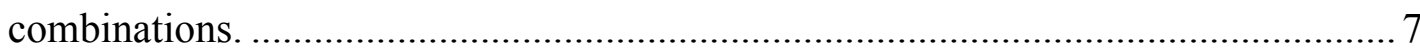

Table 2.2: Teck Cominco's static immersion (dissolution) tests. ..................................... 7

Table 2.3: Results of EDS analysis of the various alloy layers on the 316L bushing ........9

Table 2.4: Results of EDS analysis of the alloy layer on the Stellite \#6 sleeve..................

Table 2.5: Friction coefficient data from WVU's test apparatus prior and after

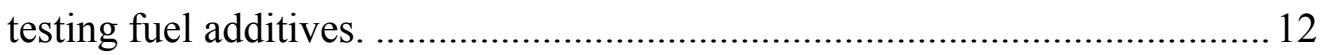

Table 3.1: Weirton Steel operational galvanizing lines data ranges ................................ 17

Table 3.2: Steel mill bearing pressures and velocities in actual galvanizing lines ........... 18

Table 3.3: Test ball on seat contact load and RPM range for testing.............................. 20

Table 5.1: Initial test series material combination matrix ............................................... 38

Table 7.1: Data obtained during preliminary water testing of stainless steel ball ........... 48

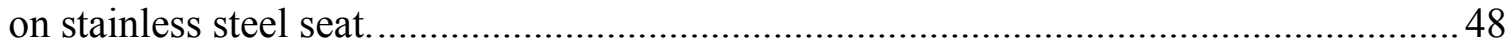

Table 7.2: Hot zinc pot load, RPM, and temperature ranges for testing......................... 49

Table 7.3: Hot zinc pot test data obtained from testing a WC-LC ball on a

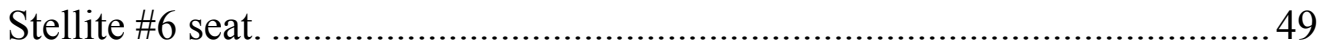

Table F.1: Chemical composition analysis for molten zinc used in testing.................... 82 


\section{List of Figures}

Figure 2.1: Teck Cominco's diagram of pin-on-disk test apparatus [5] .......................... 5

Figure 2.2: Graph of Teck Cominco's friction coefficient data of pin and disc

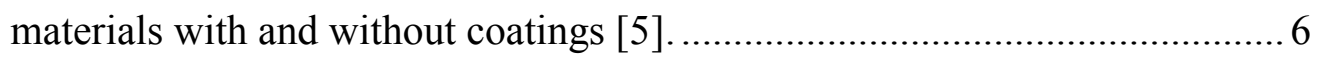

Figure 2.3: WVU lubricity test apparatus used to measure friction coefficient................. 11

Figure 2.4: Flow-chart of powder production by HIP for the consolidation of 10 different samples.

Figure 3.1: Schematic of galvanizing lines roller and bearing submerged in molten zinc. 16

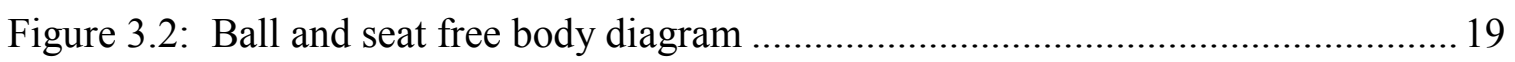

Figure 3.3: Contact velocity versus spindle RPM......................................................2 20

Figure 3.4: Contact pressure versus spindle load ..................................................... 21

Figure 5.1: Linear bearings, bearing track and cup torque transfer plate.......................... 30

Figure 5.2: Cross section of the bearing track assembly................................................ 31

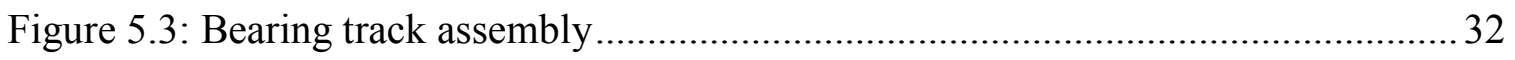

Figure 5.4: Initial spindle setup for the testing apparatus, prior to update....................... 33

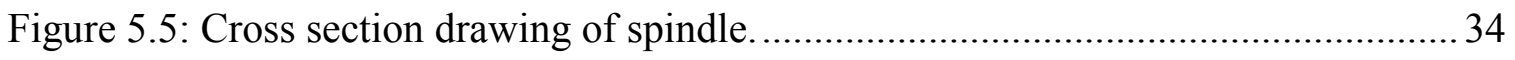

Figure 5.6: Copper water lines mounted to the V-groove ring, base plate, spindle.......... 35

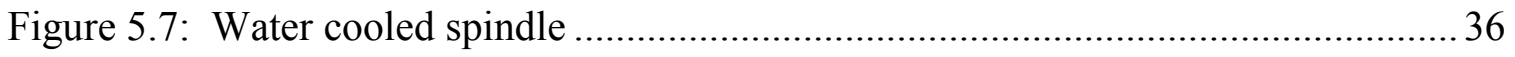

Figure 5.9: Upward sand casting mold designed at ORNL............................................ 39

Figure 5.10: Downward sand casting mold designed at WVU ........................................ 40

Figure 5.11: Polished stellite \#6 seat sample .................................................................. 40

Figure 5.12: Specimen pressed into the strut channel clamp ………….......................... 41 


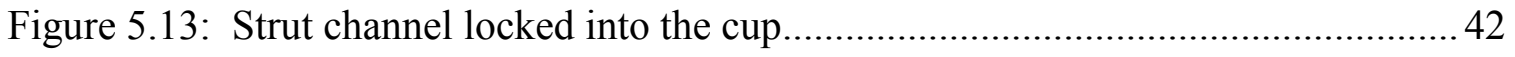

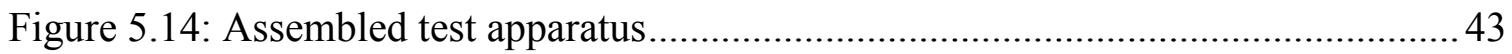

Figure 6.1: Instrumentation setup for the test apparatus ....................................... 45

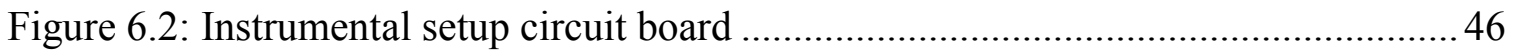

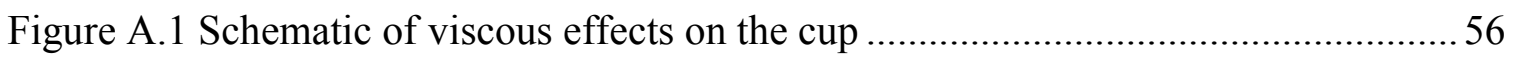

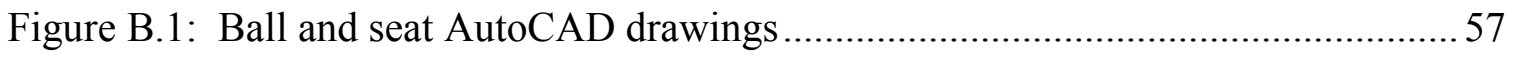

Figure B.2: Bearing track assembly dimensions ....................................................5

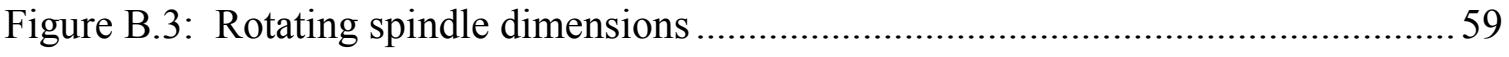

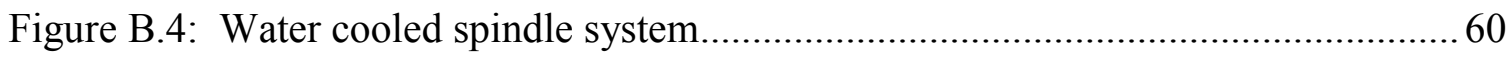

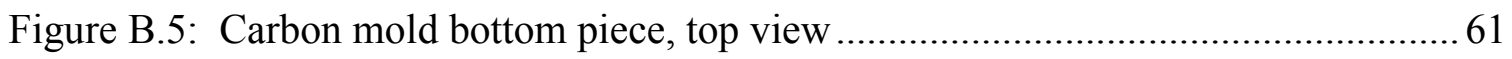

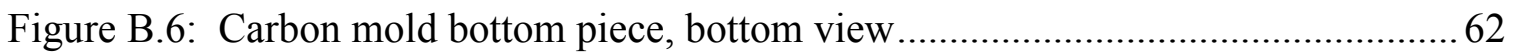

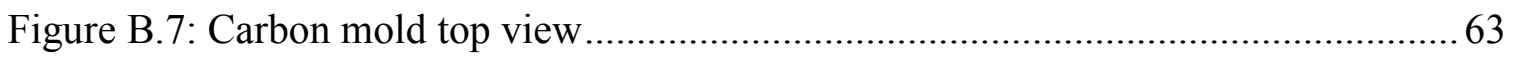

Figure B.8: Layout of cope and drag sand casting technique ..................................... 64

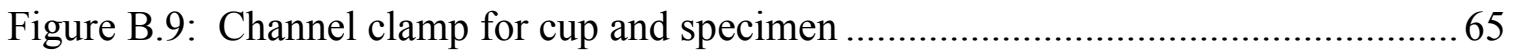

Figure B.10: Tapered ball and seat specimen for sand casting .................................. 65

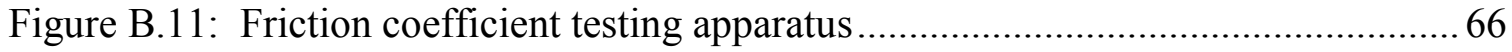

Figure C.1: Ball/seat load output voltage as a function of time in preliminary water test.

Figure C.2: Torque strain gage output voltage as a function of time in preliminary water test.

Figure C.3: Ball/seat load as a function of time in preliminary water test......

Figure C.4: Torque strain gage load as a function of time in preliminary water test....... 69 
Figure C.5: Zinc pot bearing material friction coefficient as a function of time, for test $1 \mathrm{~A}$ in preliminary water test. 70

Figure C.6: Zinc pot bearing material friction coefficient as a function of time, for test $1 \mathrm{~B}$ in preliminary water test. 70

Figure C.7: Zinc pot bearing material friction coefficient as a function of time,

for test $1 \mathrm{C}$ in preliminary water te 71

Figure D.1: Ball/seat load output voltage as a function of time in hot zinc test

$2 \mathrm{~A}, 2 \mathrm{~B}$, and $2 \mathrm{C}$

Figure D.2: Ball/seat load output voltage as a function of time in hot zinc test

2D, $2 \mathrm{E}$, and $2 \mathrm{~F}$.

Figure D.3: Torque strain gage output voltage as a function of time in hot zinc test

$2 \mathrm{~A}, 2 \mathrm{~B}$, and $2 \mathrm{C}$.

Figure D.4: Torque strain gage output voltage as a function of time in hot zinc test $2 \mathrm{D}, 2 \mathrm{E}$, and $2 \mathrm{~F}$. .74

Figure D.5: Ball/seat load as a function of time in hot zinc test $2 \mathrm{~A}, 2 \mathrm{~B}$, and $2 \mathrm{C}$. 75

Figure D.6: Ball/seat load output voltage as a function of time in hot zinc test $2 \mathrm{D}, 2 \mathrm{E}$, and $2 \mathrm{~F}$. .75

Figure D.7: Torque strain gage load as a function of time in hot zinc test $2 \mathrm{~A}, 2 \mathrm{~B}$, and $2 \mathrm{C}$. .76

Figure D.8: Torque strain gage load as a function of time in hot zinc test 2D, $2 \mathrm{E}$, and $2 \mathrm{~F}$. .76

Figure D.9: Temperature as a function of time in hot zinc test 2A, 2B, 2C, 2D, $2 \mathrm{E}$, and $2 \mathrm{~F}$. .77 
Figure D.10: Zinc pot bearing material friction coefficient as a function of time, for test $2 \mathrm{~A}$ in hot zinc test.

Figure D.11: Zinc pot bearing material friction coefficient as a function of time,

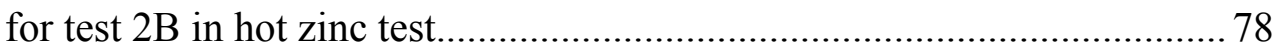

Figure D.12: Zinc pot bearing material friction coefficient as a function of time,

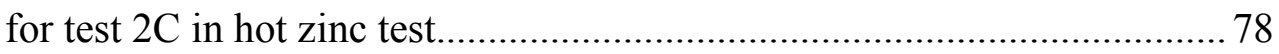

Figure D.13: Zinc pot bearing material friction coefficient as a function of time, for test $2 \mathrm{D}$ in hot zinc test.

Figure D.14: Zinc pot bearing material friction coefficient as a function of time, for test $2 \mathrm{E}$ in hot zinc test

Figure D.15: Zinc pot bearing material friction coefficient as a function of time,

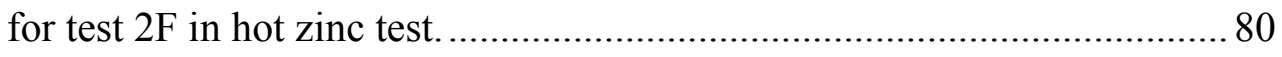

Figure E.1: Wiring diagram for power supply ….......................................... 81

Figure H.1: Calibration curve for strain gage beam $\mathrm{F}_{\text {Gage }}$ with moment arm $1_{\text {Gage }}=6.75$-inch .84

Figure H.2: Calibration curve for load cells 85 


\section{Nomenclature}

$\begin{array}{ll}A_{B} & \text { Steel mill bearing area } \\ A_{\text {Hor }} & \text { Horizontal projection of laboratory ball on seat contact area } \\ A_{\text {Seat }} & \text { Laboratory test sample actual slanted seat area } \\ \mathrm{C}_{1} \& \mathrm{C}_{2} & \text { Algebraic constants } \\ \mathrm{F}_{\mathrm{B}} & \text { Steel mill bearing contact force } \\ \mathrm{F}_{\text {Gage }} & \text { Force applied to the strain gage beam } \\ \mathrm{F}_{\text {Load }} & \text { Laboratory vertical spindle load by ball on seat } \\ \mathrm{F}_{\text {Sheet }} & \text { Sheet tension in galvanizing line } \\ \mathrm{F}_{\text {Wall }} & \text { Shear force acting on the cup outer wall } \\ \mathrm{F}_{\perp} & \text { Component of } \mathrm{F}_{\text {Load }} \text { perpendicular to test sample contact surface } \\ \mathrm{P}_{\mathrm{B}} & \text { Steel mill bearing pressure } \\ \mathrm{P}_{\mathrm{C}} & \text { Laboratory ball on seat contact pressure } \\ \mathrm{r} & \text { Radius } \\ \mathrm{TQ}_{\mathrm{Q}} & \text { Torque } \\ \mathrm{V}_{\mathrm{B}} & \text { Steel mill bearing contact surface velocity } \\ \mathrm{V}_{\mathrm{C}} & \text { Laboratory ball on seat contact velocity } \\ \mathrm{V}_{\text {Sheet }} & \text { Velocity of sheet in galvanizing line } \\ \mathrm{V}_{\theta} & \text { Velocity of zinc in cup due to spindle rotation } \\ \mu & \text { Viscosity } \\ \mu_{\mathrm{F}} & \text { Friction coefficient } \\ \tau_{\mathrm{r}, \theta} & \text { Shear stress inside zinc bath swirl } \\ \tau_{\text {Wall }} & \text { Shear stress acting on the cup outer wall } \\ \omega_{\mathrm{o}} & \text { Angular velocity } \\ \ell & \\ \ell & \text { Mean contact radius of ball on seat } \\ \ell & \text { Moment arm from spindle centerline to contact with strain gage beam } \\ & \end{array}$




\section{Chapter 1 - Introduction}

The objective of this project is to assist the U.S. steel Industry in becoming more competitive in galvanized sheet products by improving submerged zinc pot bearing materials. One significant operating and energy cost is frequent shutdown due to failure of the submerged zinc pot bearings. Aside of the short life of the bearing surfaces there is corrosion of the supporting structure and the roller surface, which contributes to dross build up which blemishes the surface finish of the galvanized sheet. Research by others has shown that wear and life of the bearings varies for each galvanizing line and is a function of pot chemistry/dross content, temperature, corrosion/erosion, contact pressure, contact velocity and vibrations.

This DOE research project is a cooperative effort by teams from West Virginia University, Industries of the Future of WV, International Zinc Research Organization, Oak Ridge National Laboratory, and various Steel Industries. All those are working together to develop new materials, to achieve a significant improvement in bearing life. The performance of zinc pot bearing materials and coatings is a function of pot chemistry, temperature, line tension, line speed and other operational constrains. Such a large number of variables increases the size of the test matrix. Therefore, a large joint effort will be required to achieve the ultimate objective of developing a computerized design guide for sheet mill operators to determine the most cost effective selection of zinc pot bearing materials/coatings, which may be different for each galvanizing line.

The objective under Task 2 of the contract is to determine wear on future zinc pot bearing materials as a function of contact pressures, velocities, and time. A small laboratory size-testing machine is designed for this purpose. It is designed for safety and 
ease of use. The design objective is to measure, in real time, the wear and friction coefficient between two bearing materials. The material test samples selected are in the shape of a 1-inch diameter hemisphere and the other is in the form of a matching seat. The seat can be cast or machined, using new bearing materials. In the middle is a 5/8-inch diameter hole, with an approximately $1 / 8$-inch wide seat for the 1 -inch ball in the center. During the test the ball is lowered onto the seat, which is submerged in molten zinc at a closely controlled temperature. The load, torque and RPM of the test samples is measured and the data transferred into a database. From measurements of the torque on the bearing, the sliding friction coefficient of the material being tested can be calculated. The wear of the material is determined by measuring the change in diameter of the seat before and after testing. Once the friction coefficient and wear of the material has been determined, the correlation between these two can be investigated. 


\section{Chapter 2 - Review of Relevant Literature}

\subsection{BOCLE and HFRR Testing}

A review of available literature on dynamic wear testing of materials, showed that most wear and friction testing was done with the materials being dry or lubricated. "The wear of lubricated bearing surfaces (Bond, et, al [1]) depends not only on the lubricant, but also on the materials used, the bearing load, surface finish and velocity at the point of contact. Lack of sufficient lubricating properties increases wear, which alters the surface finish and produces loss of material from the surface. One can experience four types of wear: corrosion, adhesive wear, abrasive wear and surface fatigue. Wear can be reduced by the presence of lubricants and corrosion inhibitors at the point of contact of the wear bodies. Many testing machines have been built to perform these duties, like the four balls wear test, single particle wear test and the BOCLE test. Many have been developed

to characterize lubricating fluids. The three most common test methods are: BOCLE (Ball-on-Cylinder Lubricity Evaluator), the HFRR (High Frequency Reciprocating Rig), and field-testing."

The BOCLE (American Society for Testing and Materials, 1999 [2]) test was designed for testing the lubricity of diesel and jet fuel. The test consists of placing a $1 / 2$ inch diameter ball on cylinder rotating at $244 \mathrm{RPM}$, submerged in the test fluid at $25^{\circ} \mathrm{C}$. Each test starts with a new ball loaded with a 9.81 Newton force and lasts 30 minutes. Upon completion of the test, the scar on the ball is measured to the nearest $0.01 \mathrm{~mm}$.

A variation of this test is called the Lubrizol Scuffing BOCLE (Lubrizol Corporation, 2000 [3]). This test is similar to the before mentioned test but applies a 
steady load provided by a 7 kilogram mass. The test is run on the cylinder for 2 minutes. The average scar diameter is then measured and used to compare lubricating qualities.

The HFRR (Rabinowicz, et, al [4]) test uses a $1 / 2$-inch ball, which is rapidly vibrated back and forth over a flat surface. A load of 200 grams is placed on the ball and moved back and forth with a $1-\mathrm{mm}$ stroke. The time necessary to wear a scar into the ball is measured; the size of the scar gives the lubrication qualities of the fuel being tested. Field-tests are the most reliable tests, because all of the operating conditions are duplicated exactly. However, this type of testing is usually very expensive and can be impractical.

The BOCLE [1] "has been used for some time, but there are only a few of these machines available at specialty fuel testing labs. HFRR has been accepted by ISO, Society of Automotive Engineers (SAE) and is commonly used in Europe for testing diesel fuel lubricity. The drawback of HFRR is that, there are very few of these testing machines available in North America. Field-testing is good but very expensive."

\subsection{Teck Cominco's Continuous Galvanizing Line Submerged Hardware Research}

At the Teck Cominco Product Technology Center in Canada, extensive test have been done in the past decade on characterizing zinc pot materials in friction and wear. Tests in molten zinc were conducted under simulated operating conditions. The objective of study at Teck Cominco (Teck Cominco, 1996 [5]) was to improve the life and performance of bearings submerged in molten zinc in the galvanizing lines. To study the friction and wear characteristics of bearing materials, with and without coatings, a pinon-disk testing machine was designed and built, see Figure 2.1. The machine was used to 
test various promising bearing materials for use in journal bearings of galvanizing lines. An electric motor drives a shaft that supports the testing materials. The testing materials in the form of three pins were installed in a hub that rotated on a fixed plated submerged in a zinc bath. Motor current was measured to determine friction torque of the materials under test. Cylinder weights on the shaft provided contact load to the pins. These tests were performed over a temperature range from $450-470^{\circ} \mathrm{C}$. Wear was determined by measuring the loss of length of the pins and/or the depth of the wear groove on the disc.

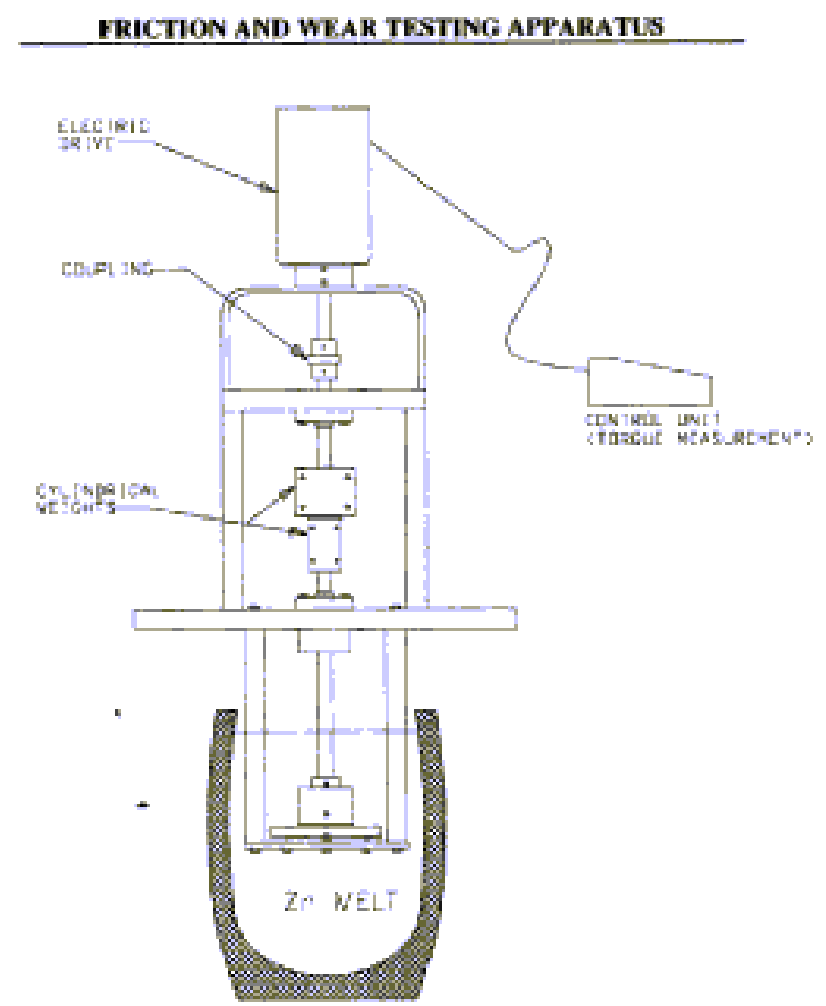

Figure 2.1: Teck Cominco's diagram of pin-on-disk test apparatus [5]

Materials used by Teck Cominco in their study were: 316L S.S., Inconel 718, Mild Steel with Alloy, 316 S.S., Stellite \#6, Chromium Oxide (coating), Tungsten Carbide (coating), Chromium Oxide Lubricated. The friction coefficient of these materials ranged from $0.195-0.41$. The pin and disk wear of the material showed that 
wear was measurable although in most cases it was insignificant. Results of the pin and disk wear [5] are shown in Figure 2.2 and Table 2.1.

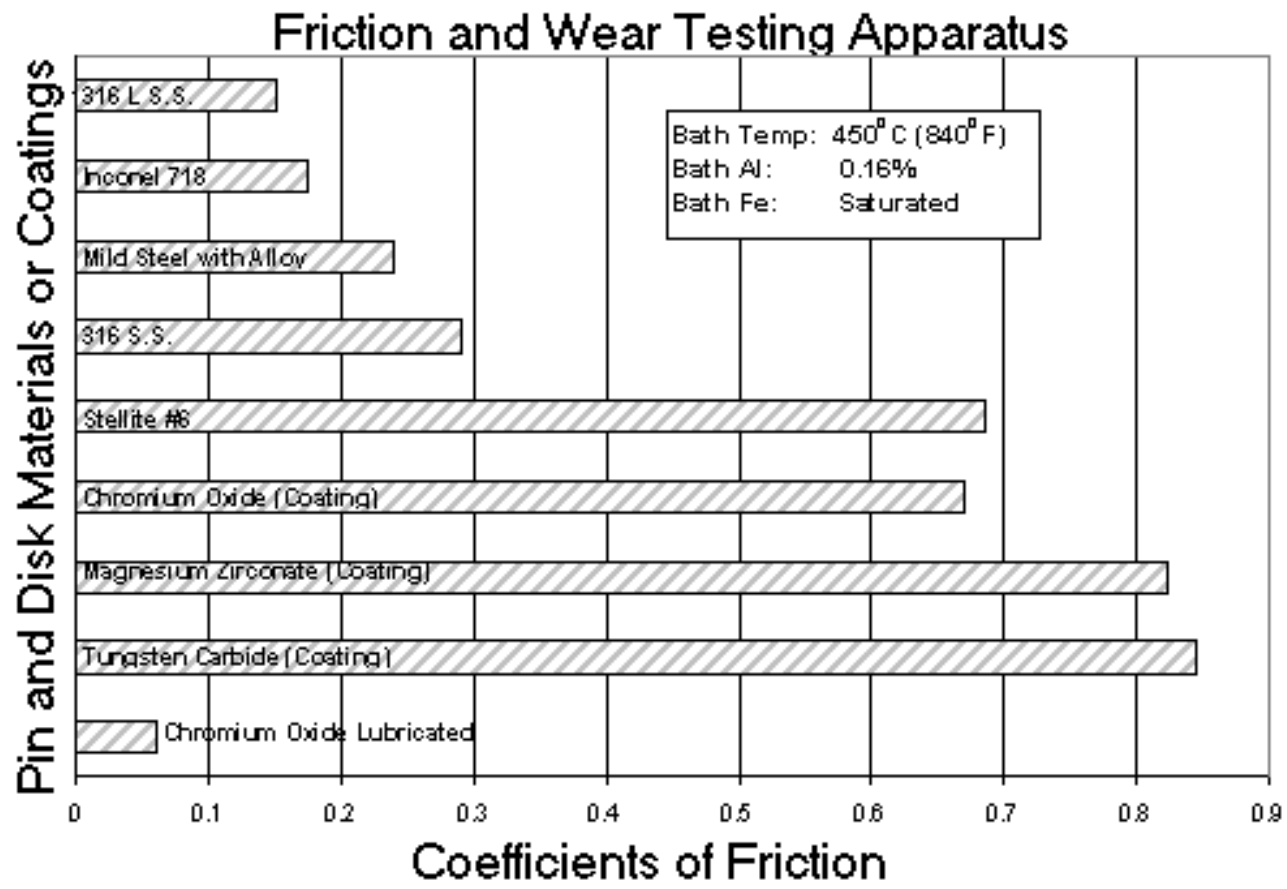

Figure 2.2: Graph of Teck Cominco's friction coefficient data of pin and disc materials with and without coatings [5]. 
Table 2.1: Teck Cominco's study of friction and wear results for different material combinations.

Test Conditions: Bath Composition: $0.20 \% \mathrm{Al}, 0.0016 \% \mathrm{Fe}$

Melt Pot Temperature: $470^{\circ} \mathrm{C}$

\begin{tabular}{|l|l|l|l|l|}
\hline Plate Material & Pin Material & $\begin{array}{l}\text { Coef. of Friction } \\
(\boldsymbol{\mu})\end{array}$ & $\begin{array}{l}\text { Plate Wear } \\
(\mathbf{i n})[\mathbf{m m}]\end{array}$ & $\begin{array}{l}\text { Pin Wear } \\
(\mathbf{i n})[\mathbf{m m}]\end{array}$ \\
\hline Stellite \#6 & Stellite \#6 & 0.29 & -- & $0.0009[0.023]$ \\
\hline Stel. \#6 with Graphite & Stellite \#6 & 0.36 & -- & $0.0005[0.013]$ \\
\hline Stel. \#6 with Graphite* & Stellite \#4 & 0.23 & -- & -- \\
\hline Tribaloy T-800 & Stellite \#4 & 0.39 & -- & $0.0003[0.008]$ \\
\hline Triabaloy T-800 & Stellite \#4 & 0.37 & -- & $0.0005[0.013]$ \\
\hline AmZirOx 86 & AmZirOx 86 & 0.40 & $0.001[0.025]$ & $* *$ \\
\hline AmZirOx 86 & Stellite \#4 & 0.37 & Light scoring & -- \\
\hline SIALON & Stellite \#4 & 0.59 & -- & $0.0004[0.010]$ \\
\hline SIALON*** & Stellite \#4 & 0.41 & -- & $0.0005[0.013]$ \\
\hline
\end{tabular}

* Plate surface coated with graphite lubricant spray prior to test.

** Pin wear not measured, pins fractured on removal from test rig.

*** Sialon plate polished to ensure flat surface.

A static immersion test was used to evaluate the molten zinc alloy attack. It measures material loss due to the corrosiveness of zinc. Samples were weighed before and after submersion into the zinc pot, to determine loss/unit area. Table 2.2 shows the loss/unit area measured in $\left(\mathrm{g} / \mathrm{dm}^{2}\right)$.

Table 2.2: Teck Cominco's static immersion (dissolution) tests.

Test Conditions: Zinc alloy: $\mathrm{Zn}+0.2 \% \mathrm{Al}+0.022 \% \mathrm{Fe}$

Temperature: $470^{\circ} \mathrm{C}$

Time: 96 Hours

\begin{tabular}{|l|l|}
\hline Material & Loss / Unit Area $\mathbf{( g / \mathbf { d m } ^ { 2 }} \mathbf{~}$ \\
\hline AmZirOx86 & $*$ \\
\hline SIALON & $*$ \\
\hline Tribaloy T-800 & 0.7 \\
\hline Stellite \#6 & 1.9 \\
\hline Inconel 718 & 2.5 \\
\hline 316L S.S. & 2.8 \\
\hline Mild Steel & 32.8 \\
\hline
\end{tabular}


Ceramic Materials were not wetted or attacked by the zinc and are resistant to molten zinc alloy attack.. Of the metallic materials, Tribaloy was the most resistant followed by Stellite, Inconel and 316L Stainless Steel.

The conclusions drawn from Teck Cominco's submerged hardware research were that metallic materials reacted with the bath to form intermetallics. This was shown to be dependent on the zinc composition and pot temperature, and also affects friction and wear of the material. They found that aluminum in the bath had a strong effect on friction and wear, while lead and antimony had no effect.

Following the pin-on-disk testing apparatus, Teck Cominco (Teck Cominco, 1999 [6]) designed and built a test rig to simulate actual operating conditions of galvanizing lines. The Teck Cominco full journal-bearing tester is capable of testing full-size stabilizer rollers or half-size sink roll bearings. In their setup a motor and shaft supports a hollow drive shaft inclined at a 30 degree from horizontal incline. The test journal in the form of a stub shaft is secured to the end of the drive shaft with a tapered fit. A hydraulic system provides the side loading for the bearing. A tension compression load cell is utilized to measure the bearing load. The system can be loaded in both the up and down direction, with the down direction being best to simulate the sinker roll loading. An electrically heated zinc-pot sits below the test bearing. It is raised in testing position by a hydraulic stacker.

The wear tests were performed under typical operating conditions of the galvanizing lines. "The bushings used for the testing the liquid zinc were modified by giving them larger clearance on their unloaded side so that experimental work was facilitated. Four tests were run with the low-load air cylinder to examine hydrodynamic 
operation and one test with the hydraulic cylinder, fully testing the capabilities of the apparatus. Significant zinc attack was seen on all materials after testing. In one case dross was allowed to be introduced to the bearing clearance by allowing the bath level to drop to the clearance height allowing dross entry. This was found to give particularly severe wear. In general this apparatus appears to be well suited for simulation of pot hardware bearing operations seen on sheet galvanizing lines." Results of attack for both stainless steel and Stellite materials are found in Tables 2.3 and 2.4.

Table 2.3: Results of EDS analysis of the various alloy layers on the 316L bushing

\begin{tabular}{|l|l|l|l|l|l|l|l|}
\cline { 2 - 8 } \multicolumn{1}{c|}{} & \multicolumn{6}{c|}{ Elements Analyzed (Normalized wt\%) } \\
\hline Probe Location & Zn & Fe & Al & Cr & Ni & Mo & Si \\
\hline Surface crystal particle (A) & 92.4 & 5.2 & 1.8 & 0.3 & 0.4 & --- & -- \\
\hline Upper amorphous layer (B) & 87.2 & 6 & 3.6 & 0.6 & 0.6 & 1.4 & 0.5 \\
\hline Lower amorphous layer (C) & 73.8 & 13.4 & 9.1 & 1 & 0.9 & 1.2 & 0.6 \\
\hline Interface line (D) & 59.8 & 20.4 & 15 & 1.5 & 1.3 & 1.3 & 0.8 \\
\hline Stainless steel substrate & --- & 71.5 & --- & 14.7 & 12.2 & 1.3 & 0.4 \\
\hline
\end{tabular}

Table 2.4: Results of EDS analysis of the alloy layer on the Stellite \#6 sleeve

\begin{tabular}{|l|l|l|l|l|l|l|l|}
\cline { 2 - 9 } \multicolumn{1}{c|}{} & \multicolumn{9}{c|}{ Elements Analyzed (Normalized wt\%) } \\
\hline Probe Location & Zn & Co & Fe & Cr & W & Al & Mo \\
\hline Surface crystal particle (A) & 94.5 & 3.1 & 2.1 & 0.4 & --- & --- & --- \\
\hline Alloy layer (B) & 79.2 & 8.9 & 2.9 & 2.2 & 4.4 & 2.5 & --- \\
\hline Stellite dendrite structure & --- & 76.6 & 2.6 & 19.6 & 0.8 & --- & 0.4 \\
\hline Stellite inter-dendritic structure & --- & 18.2 & 1 & 79.3 & 1 & --- & 0.5 \\
\hline
\end{tabular}

\subsection{WVU's Lubricity Research and Testing Apparatus}

During a methanol fueled gas turbine test at West Virginia University in 1998, the fuel controller bearings seized up, indicating the need for an additive to improve the fuel lubricity properties. In auto racing on methanol a variety of fuel additives are on the market. To minimize the operational cost increase associated with adding a lubricant to the methanol, a test was performed at West Virginia University, to determine the 
minimum acceptable concentration of the lubricity augmenters required. For this purpose a new friction test apparatus was designed to measure the friction coefficient of the bearing materials used in the gas-turbine fuel controller [1]. The objective was to find the most cost effective fuel additive for methanol to provide lubricity equal or better than jet fuel. The apparatus was designed to measure friction coefficient, because conventional lubricity tests measuring wear showed erratic data due to the methanol.

The methanol/additive test apparatus at WVU, shown in Figure 2.3, was designed to operate at typical bearing pressures by means of a dead weight attached to the spindle. The spindle transferred this load to a disk containing three balls, which rotated on a fixed washer. The load had to be lower than for the BOCKLE Test Standard, to prevent seizing the balls to the washer. To guarantee that the disk rotates smoothly about its axis, a ball bearing was installed on the centering pin in the center of the fixed washer. A vertical mill was used to accurately control the disk position and RPM. 


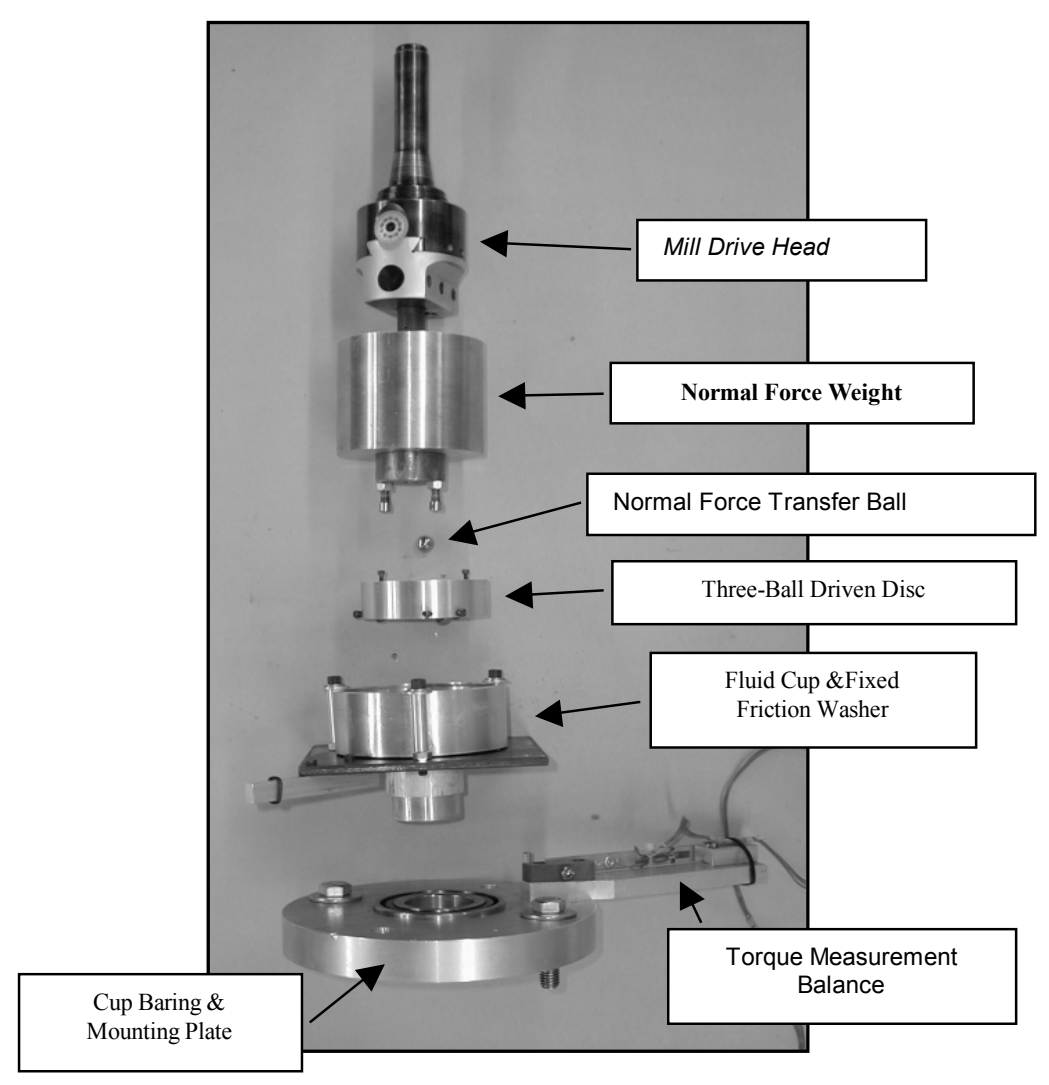

Figure 2.3: WVU lubricity test apparatus used to measure friction coefficient

Torque is transferred from the drive shaft to the dead weight by a pin and from there by two pins, to the rotating $1 / 2$ inch ball holder. A cup filled with methanol and fuel additive, contains the machined washer, on which the three balls slide. Torque measurements were taken with a beam type load cell.

The WVU lubricity test apparatus was relatively easy to use and provided the needed repeatable data. Each run was conducted for 10 minutes at $3.5 \%$ of a lubricated bearing design load. This test apparatus proved to provide consistent data. It was a significant improvement over previous work done at WVU in the past. The data scatter was so great that only statistical analysis could provide a useful average. Table 2.5 shows Standard handbook friction data [10] in addition to results obtained with WVU's apparatus without testing fuel additives. 
Table 2.5: Friction coefficient data from WVU's test apparatus prior and after testing fuel additives.

\begin{tabular}{|l|l|}
\hline \multicolumn{1}{|c|}{ System } & \multicolumn{1}{c|}{ Friction Coefficient } \\
\hline Metal on Metal (Dry) [10] & $0.15-0.20$ \\
\hline Metal on Metal (Wet) [10] & 0.3 \\
\hline Occasionally Greased [10] & $0.07-0.08$ \\
\hline Continuously Greased [10] & 0.05 \\
\hline Mild Steel on Brass [11] & 0.44 \\
\hline LPMEOH ${ }^{\text {TM }}$ Methanol (Mild Steel on Brass)(WVU) & $\mathbf{0 . 3 0 9}$ \\
\hline Jet A (Mild Steel on Brass)(WVU) & $\mathbf{0 . 1 6 7}$ \\
\hline
\end{tabular}

\subsection{Bearing Material Research}

The primary contributor to galvanizing line outage is wear of the zinc pot bottom roller bearings. A case study done by (Zoz, et al., [7]), shows the advantage of replacing common bearing-materials with advanced materials and coatings. Stellite \#6 is a common bearing material, which is corrosion resistant and thus does not contribute to dros buildup, although Stellite \#6 has poor lubricating physical properties. Various materials for testing were used, made of Stellite-4 powder with two different alloying elements A+B under each 3 different parameter settings 1-3, shown in Figure 2.4. A process control agent had to be added in the case of using alloying element B. By Hot Isolated Pressing (HIP), El-Madg et, al [12] used powder consolidation to press the required test samples. Ten new material Stellite samples were consolidated into test specimen. To evaluate the wear-behavior of these samples, Zoz, et, al [7] designed a cylinder and bush test apparatus (CIBA). 


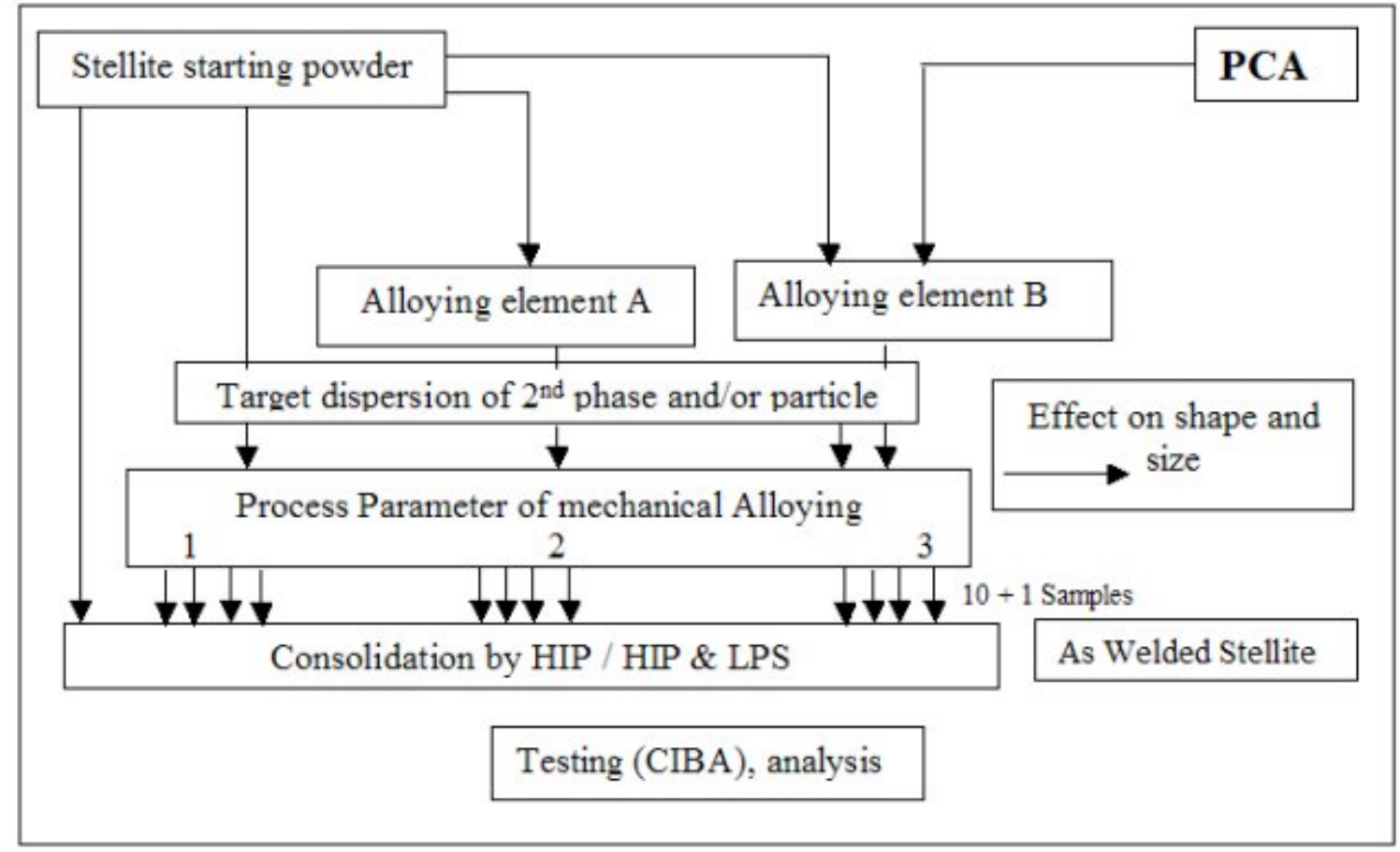

Figure 2.4: Flow-chart of powder production by HIP for the consolidation of 10 different samples.

Zoz, et, al described the cylinder in bush apparatus as follows: "The inner part of the bearing system (bush fixed on the rolls) is simulated by the bulk sample itself (cylinder), carrying the new materials as well as the reference material. The outer part of the bearing (bush) is simulated by real Stellite counter-bearing parts." The bush is lowered into a zinc bath, loaded and rotated against the cylinder, by a drilling machine, to simulate wear in hot dip galvanizing lines.

The CIBA experiments have shown better wear resistibility in the bearing test samples, than in galvanizing lines. Any dependency between hardness and abrasion resistance cannot be observed. The test samples did not show any cracks, inclusions, hollows or binding failures in the diffusion-zone between inner cylinder and consolidated material. 
Tungsten carbide (WC) composite coating is another popular material. The coatings can be laser cladded on Stainless Steel or on ORNL 4 base material. WC Laser Cladded coatings seem to be the most wear resistant of the materials. Surface and Coatings Technology have produced an article describing the effects of Tungsten-Carbide laser coatings submerged in zinc. Laser surface cladding (Seong, et, al [8]) is capable of producing a wide range of surface alloys and composites of desired properties. "Application of the laser beam cladding surface engineering [8] allows to obtain porosity and cracking free surface clads containing uniformly distributed hard particles in the softer and tough matrix." Powder blowing, wire feed, and pre-placed powder coating are some of the ways that material is fed into the substrate surface under the laser beam.

The proper structure of WC Laser Cladding depends on the right selection of the laser processing parameters to achieve porosity and crack free WC-metal composite coatings. Studies have also been done, looking at the effects of WC laser coating reaction with molten zinc. "Understanding the coating degradation processes [8] is very important for the development of better coatings for CGL pot rolls. WC-Co coating usually does not exceed 100 days. The dross build up of the zinc of the rollers can cause degradation of the coating."

In experiments, (Seong, et, al [8]) rollers have been immersed in molten zinc to examine the effects of zinc attack on the coating. The specimens were analyzed with a scanning electron microscope and energy disperse spectrum. Dozens of dross specimens were collected for comparisons of reaction products. The experiments showed that aluminum in molten zinc reacted with the coating layer along cracks and diffused into the coating with similar diffusion depths. 
Various companies have measured wear and friction coefficient of submerged pot roll bearings in molten zinc to design better test rigs and apparatus. Although successful, a standard test machine has not been established. Tests have proven that the temperature of the molten zinc has a strong effect on bearing materials. Zinc composition can break down the structure of the material and coatings of the bearings. It has been shown that the material with the best wearing properties may not have the best friction coefficient.

Extensive research has been done on the bearing materials itself. Static immersion tests were done to show how materials and coatings react with the zinc. New compositions of the zinc bath have been researched for the best reaction with the materials. Bearing materials like Stellite \#6 and Tungsten Carbide coatings have been reviewed as strong pot roll bearing materials. Research like this gives good basis to further investigate the materials and coatings of the submerged pot roll bearings. New test machines can be designed to more accurately determine the friction coefficient and wear of the materials. With this knowledge materials can be designed to help increase the lifetime of the bearings. 


\section{Chapter 3 - Steel Mill Operating Conditions}

\subsection{Steel Mill Zinc Pot Bearing Operating Conditions}

Past studies have shown that bearing life depends on zinc pot temperature, contact velocity, and contact pressure. It is necessary that any testing on zinc bearing materials operate at conditions that resemble real life galvanizing lines. Bearing life fluctuates even under identical operating conditions. Therefore, multiple test data are needed to get statistical meaningful results, which allow ranking new materials in order of cost effectiveness. A schematic of galvanizing lines roller and bearing submerged in molten zinc, is shown in Figure 3.1.

Galvanizing lines travel at certain sheet velocities. The sheet velocity, which is the speed at which the steel sheet travels over the rollers, controls the RPM of the roller and thus bearings. The size of the bearings allows the calculation of the contact area. Sheet tension determines the force on the bearings. Dividing the bearing force by the projected bearing area provides the bearing contact pressure $\mathrm{P}_{\mathrm{B}}$.

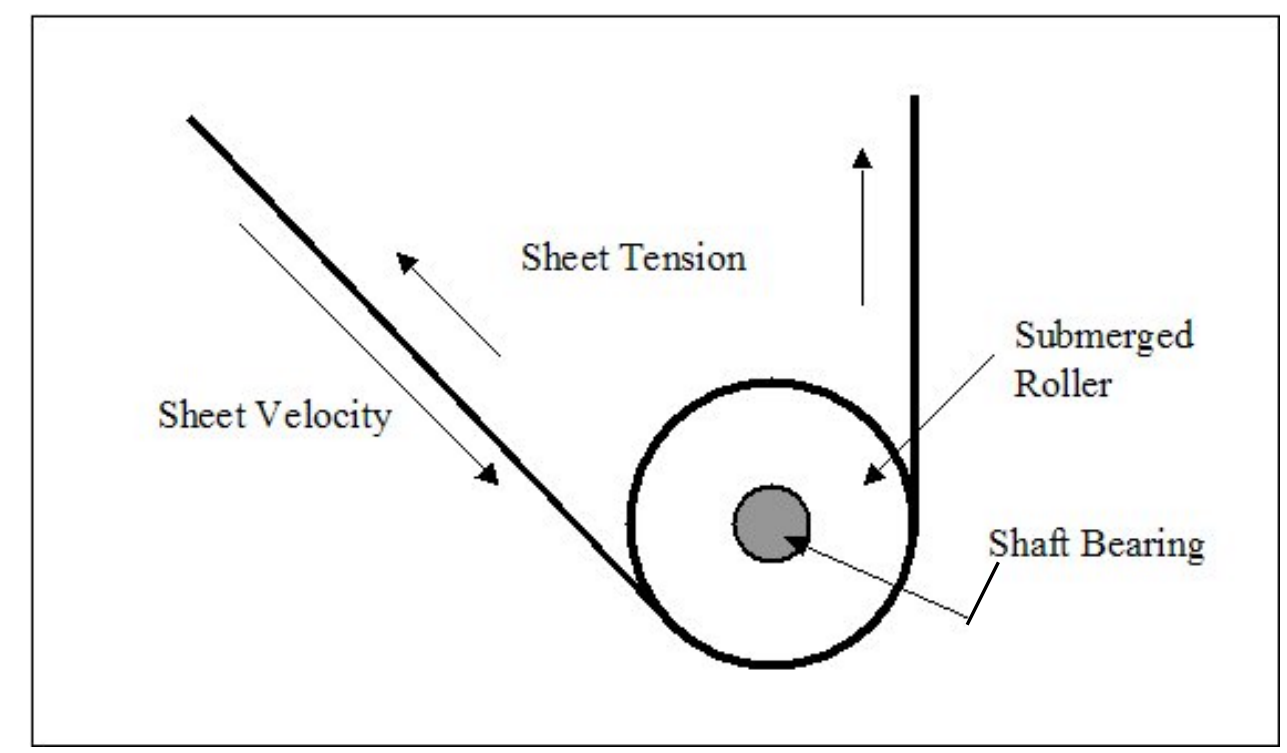

Figure 3.1: Schematic of galvanizing lines roller and bearing submerged in molten zinc. 
Weirton Steel provided three galvanizing lines operating data ranges. From these were derived the contact velocities and contact pressures of the bearing during operation. Table 3.1 shows Weirton Steels galvanizing lines operating data range. These data proved converted to contact pressures $P_{B}$ and contact velocities $V_{B}$ determine the test conditions for the laboratory research ball and seat tests.

Table 3.1: Weirton Steel operational galvanizing lines data ranges

\begin{tabular}{|c|c|c|c|}
\hline & Line \#3 & Line \#4 & Line \#5 \\
\hline Pot Liner & Ceramic Brick & Ceramic Brick & Ceramic Brick \\
\hline Zinc Pot Chemistry & $0.08-0.22 \% \mathrm{Al}$ & $0.15-0.22 \% \mathrm{Al}$ & $0.08-0.22 \% \mathrm{Al}$ \\
\hline Temperature & $880-1100^{\circ} \mathrm{F}$ & $900-940^{\circ} \mathrm{F}$ & $880-900^{\circ} \mathrm{F}$ \\
\hline Sheet Width & $24-49$ inch & $24-42$ inch & $24-49$ inch \\
\hline Sheet Thickness & $.028-.165$ inch & $\begin{array}{l}.0094-.028 \\
\text { inch }\end{array}$ & $.012-.045$ inch \\
\hline Sheet Tension (Ts) & $3200-5000 \mathrm{lbf}$ & $1000-2000 \mathrm{lbf}$ & $3200-4800 \mathrm{lbf}$ \\
\hline Sheet Velocity & $50-300 \mathrm{ft} / \mathrm{min}$ & $100-410 \mathrm{ft} / \mathrm{min}$ & $110-550 \mathrm{ft} / \mathrm{min}$ \\
\hline \multicolumn{4}{|c|}{ Bottom Roller Characteristics } \\
\hline Bearing Life & $7-14$ days & $7-14$ days & 7 - 30 days \\
\hline Bearing Materials & 316L S.S. & 316L S.S. & 316L S.S \\
\hline Outside Diameter $\left(D_{R}\right)$ & 24 in & 20 in & 20 in \\
\hline Shaft Diameter $\left(D_{B}\right)$ & $5.25 \mathrm{in}$ & 3.875 in & 3.875 in \\
\hline Bearing Length & 4 in & 4 in & 4 in Inserts \\
\hline Bearing Area $\left(A_{B}\right)$ & $21 \mathrm{in}^{2}$ & $15.5 \mathrm{in}^{2}$ & $9.65 \mathrm{in}^{2}$ \\
\hline
\end{tabular}

With this information the bearing contact pressures and velocities were calculated as follows. Assuming the bath entry angle of the sheet to be all the same at $56^{\circ}$ from vertical, then each bearing carries a load:

$$
F_{B}=F_{\text {Sheet }}\left[\cos \left(0.5^{*} 56^{\circ}\right)\right]=0.88 * F_{\text {Sheet }}
$$


The bearing contact pressure can be calculated from the ratio of bearing force over contact area of the bearing.

$$
P_{B}(p s i)=\frac{F_{B}}{A_{B}}=0.88 *\left(\frac{F_{\text {Sheet }}}{A_{B}}\right)
$$

The contact velocity of the bearing was determined by the ratio of roller and bearing diameters and velocities. This calculation results in the equation:

$$
V_{B}=V_{\text {Sheet }} *\left[\frac{D_{B}}{D_{\text {Roller }}}\right]
$$

Table 3.2 shows the velocity of the bearing and the bearing pressure in the zinc pot galvanizing lines. This data range was used to define the material tester to be designed.

Table 3.2: Steel mill bearing pressures and velocities in actual galvanizing lines

\begin{tabular}{|l|l|l|l|}
\hline & Line \#3 & Line \#4 & Line \#5 \\
\hline Thickness (in) & $0.028-0.165$ & $0.0094-0.028$ & $0.120-0.045$ \\
\hline Line Speed (ft/min) & $50-300$ & $100-410$ & $110-550$ \\
\hline Line Tension (LB) & $3200-5000$ & $1000-2000$ & $3200-4800$ \\
\hline Bearing contact $\mathbf{V}_{\mathbf{B}}$ (inch/s) & $2.19-13.1$ & $3.88-15.9$ & $4.26-21.3$ \\
\hline Bearing contact $\mathbf{P}_{\mathbf{B}}(\mathbf{p s i})$ & $235-352$ & $57-114$ & $293-440$ \\
\hline
\end{tabular}

\subsection{Laboratory Simulated Operating Conditions}

The 1-inch ball and circular seat design shown in figure 3.2 has a specified 45degree average contact angle and 5/8-inch diameter hole, from this one can derive the mean contact diameter to be 0.707 -inch and seat width of 0.187 -inch and initial horizontal projected area $\mathrm{A}_{\mathrm{Hor}}=0.171$ square inch. 


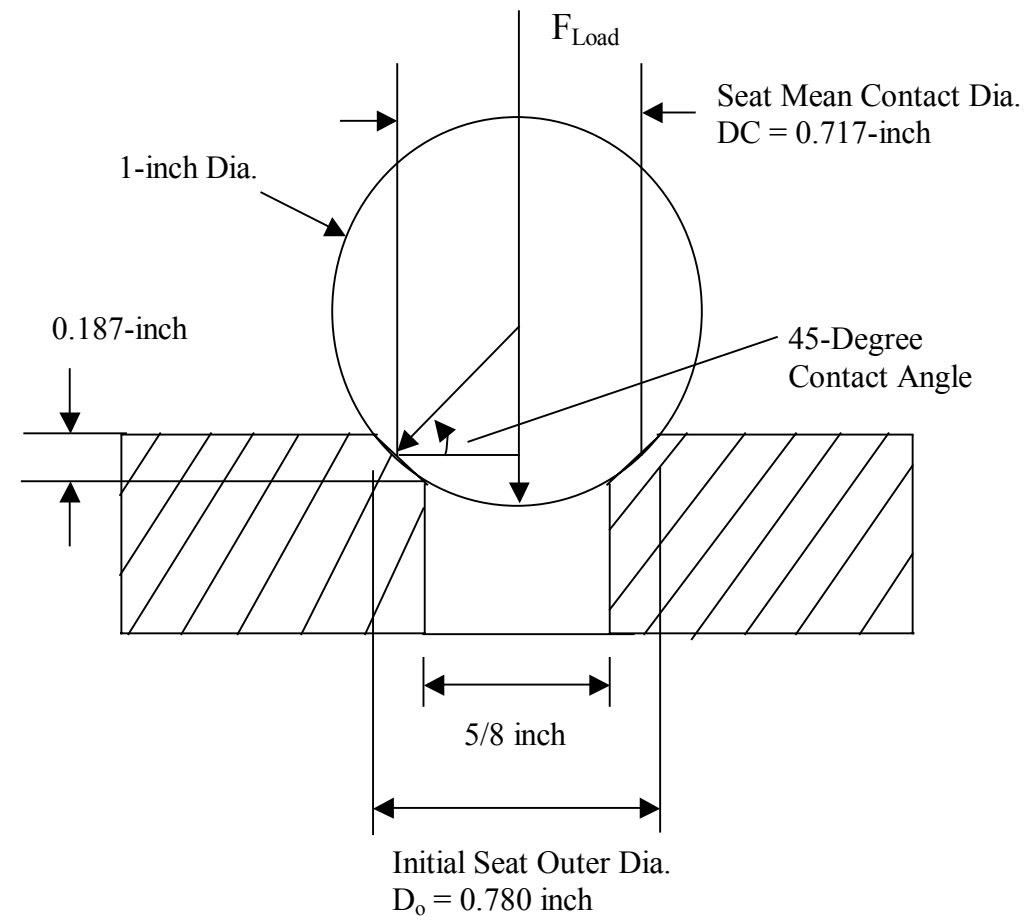

Figure 3.2: Ball and seat free body diagram

To duplicate steel mill operating bearing pressure $\mathrm{P}_{\mathrm{B}}(\mathrm{psi})$, in the laboratory tester sample contact pressure $\mathrm{P}_{\mathrm{C}}(\mathrm{psi})$, it is necessary to load the ball holding spindle by $\mathrm{F}_{\text {Load }}$. The test ball load range can be calculated by the equation:

$$
P_{B}=P_{C}=\frac{F_{\text {Load }}}{A_{\text {Hor }}=0.171}=\frac{F_{\perp}}{A_{\text {Seat }}}
$$

With the known seat diameter, and contact velocity $V_{C}($ inch/s $)=V_{B}$, the RPM of the 1inch ball is generated during testing by:

$$
\text { Ball RPM }=60 * V_{C} /(0.707 * \pi)=V_{C}(\text { inch } / s) * 27=V_{C}(f t / s) * 324
$$

The data were reduced to give a range of contact pressures $\mathrm{P}_{\mathrm{C}}(\mathrm{psi})$ and contact velocities $\mathrm{V}_{\mathrm{C}}$ (inch/s) during testing. This range simulates the actual pressures and velocities of the hot dip galvanizing lines. Table 3.2 shows the range of loads applied to the seat by the ball and the necessary RPM of the spindle. 
Table 3.3: Test ball on seat contact load and RPM range for testing

\begin{tabular}{|l|l|l|l|}
\hline & Line \#3 & Line \#4 & Line \#5 \\
\hline Thickness (in) & $0.028-0.165$ & $0.0094-0.028$ & $0.120-0.045$ \\
\hline Line Speed (ft/min) & $50-300$ & $100-410$ & $110-550$ \\
\hline Line Tension (lb) & $3200-5000$ & $1000-2000$ & $3200-4800$ \\
\hline Bearing contact $\mathrm{V}_{\mathrm{C}}(\mathrm{inch} / \mathrm{s})$ & $2.19-13.1$ & $3.88-15.9$ & $4.26-21.3$ \\
\hline Bearing contact $\mathrm{P}_{\mathrm{B}}(\mathrm{psi})$ & $235-352$ & $56.8-114$ & $292-438$ \\
\hline Tester Ball RPM & $\mathbf{5 9 . 3}-\mathbf{3 6 5}$ & $\mathbf{3 4 . 3}-\mathbf{4 2 9}$ & $\mathbf{1 1 7}-\mathbf{5 7 5}$ \\
\hline Tester Ball Load $(\mathbf{l b})$ & $\mathbf{4 0 . 2}-\mathbf{6 0 . 2}$ & $\mathbf{9 . 7 1}-\mathbf{1 9 . 4}$ & $\mathbf{5 0}-\mathbf{7 4 . 9}$ \\
\hline
\end{tabular}

With the known bearing contact velocity and pressures in the steel mill lines equal those in the tester, plots can be generated to correlate the two while testing. Figure 3.3 and figure 3.4 show the testing pressures and velocities corresponding to the actual galvanizing lines.

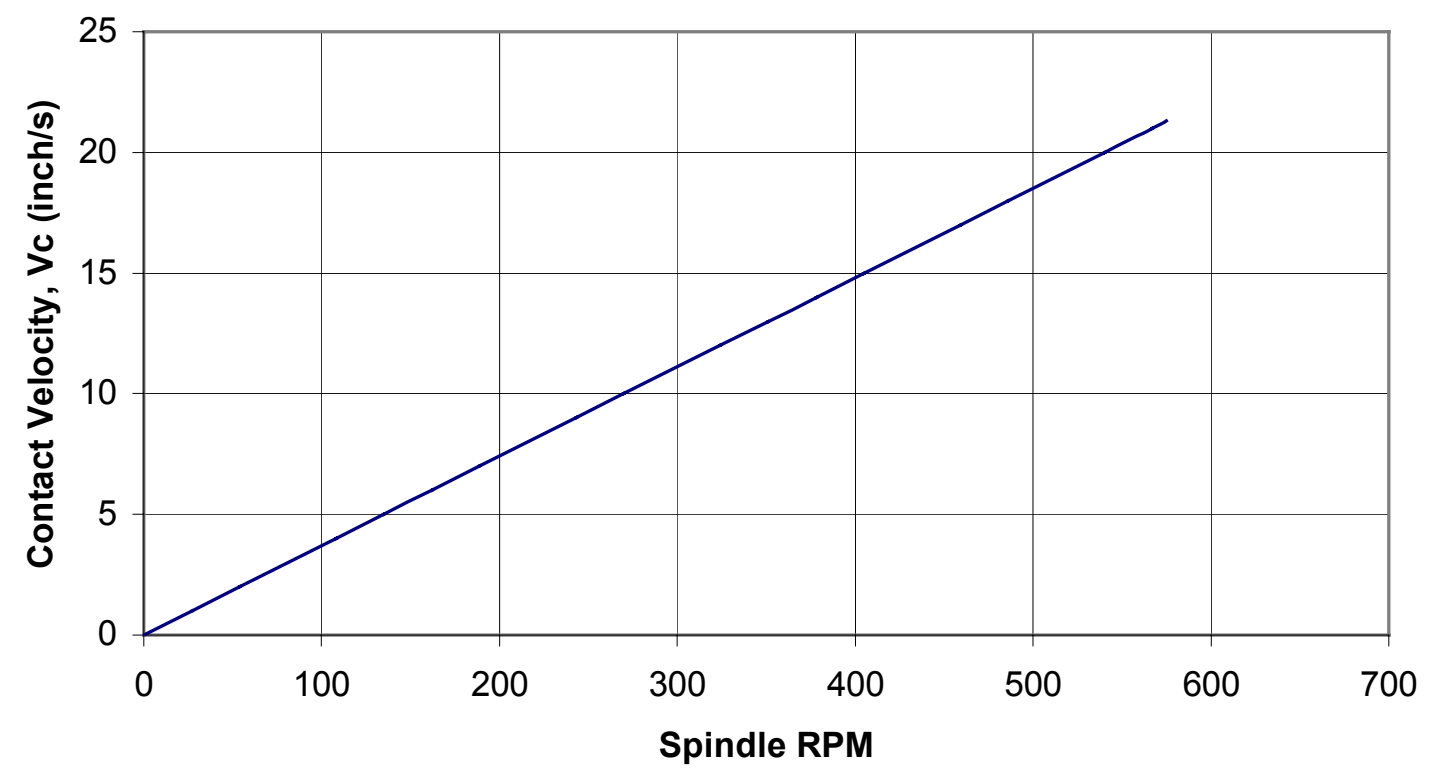

Figure 3.3: Contact velocity versus spindle RPM 


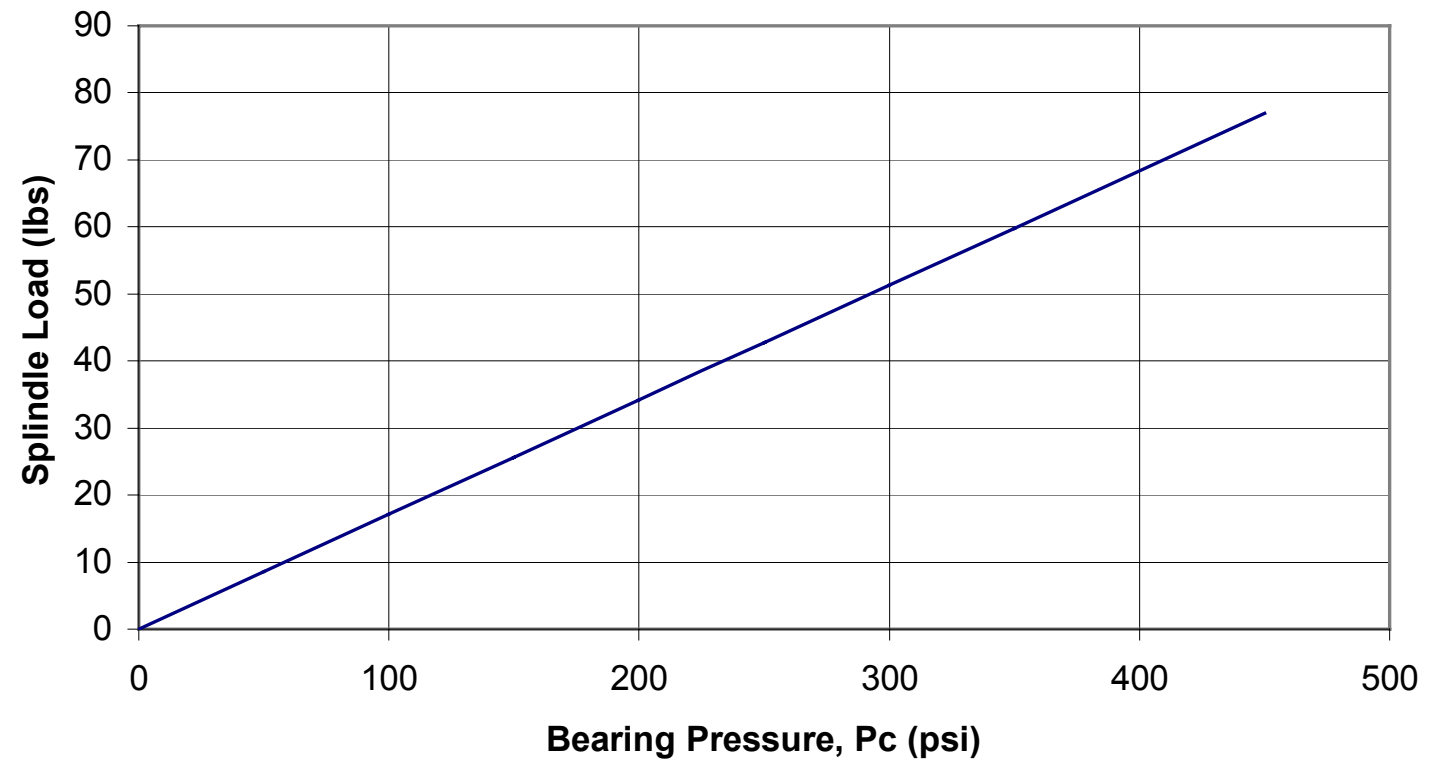

Figure 3.4: Contact pressure versus spindle load 


\section{Chapter 4 -Bearing Material Wear Tester Design}

\subsection{Design Objectives}

Galvanizing line zinc pot bearings are all of the journal type; all known attempts to use roller or ball bearings have failed in the past. The lifetime of these bearings is relatively short and depends greatly on line tension, speed, vibrations, pot chemistry, concentration of dros and most of all on the materials used for both the bearing and the shaft. Only a decade ago most submerged bottom roller bearing and shafts were made out of 316 stainless steel. Currently, at least one and often both are made of Stellite \#6, which extends bearing life significantly. Many high tension and high velocity lines are using better and more costly bearing materials. Some of these bearing surfaces are laser clad with tungsten carbide and then machined smooth. Others use Vesuvius ceramic inserts on a Stellite \#6 or laser shaft or Metaullics MSA 2012. Future materials may include ORNL alloy \#4. Most of the potential bearing materials are difficult and expensive to machine. The experience gained during the development of a methanol bearing material wear tester designed at WVU for gas turbine operation, also contributed to defining the following design objectives for a suitable zinc-pot bearing material tester.

a) Design the rotating and stationary material samples to be tested inside a hot zinc bath such that they are of low cost and easy to fabricate.

b) Reducing the size of the material samples to be tested not only helps to keep their cost down but also reduces the size and cost of all components of the tester to be designed. 
c) Operator safety is greatly enhanced by keeping the equipment small. Of special danger are items falling into the hot-zinc pot resulting in splashing. Therefore zinc pot should have a lid with a lip on it so as to contain all splashes.

d) The test sample zinc-pot chemistry is an important parameter, which should be closely controlled. In this test series all DOE research project teams use the same source by melting some zinc from a 2000-pound ingot supplied by Wheeling Nisshan from one of their galvanizing lines. See Table F.1 in Appendix F for its chemical composition.

e) To minimize pot chemistry changes with time during testing, do not conduct each test inside the electrically heated zinc pot itself, but inside a separate crucible or cup submerged in the heated zinc-pot. Each test sample pair should stay with its own crucible or cup, and saved for future repeat testing if necessary.

f) The test sample zinc-pot temperature is very important. To minimize the number of variables in the tests, all teams are going to test wear at the same zincpot temperature of $460^{\circ} \mathrm{C}=860^{\circ} \mathrm{F}$.

g) Minimize vibrations, which means designing for operation at low rpm and mounting all components rigidly and on a concrete base. Further design facility to be self-aligning and eliminate rotating weights for loading the samples.

h) Design tester for operation in the same range of bearing contact pressures and contact velocities as used industry.

i) Design tester to maintain constant load independent of material wear and measure load accurately. 
j) Design tester such that the torque required to rotate the material sample can be measured accurately as a function of time as this is needed for friction coefficient. k) Water cool material sample drive spindle so as to protect the bearings in the driver, while minimizing heat loss from zinc pot, to prevent undesirable temperature gradients in the zinc pot.

1) Design with an adequately strong drive motor to maintain constant RPM throughout the test period even when friction torque fluctuates significantly.

m) Test in a well-ventilated facility to reduce the risk of breathing hot zinc fumes. Safety should be top priority when dealing with molten metals.

\subsection{Zinc-Pot Bearing Material Wear Tester Design Aspects}

Design objectives a) and b) were satisfied by selecting the test materials to be made out of a 1-inch diameter hemisphere or ball rotating on a stationary seat at an average contact angle of 45 degree and with a 5/8-inch diameter hole. The seat was made $3 / 4$-inch thick and $1 \frac{1}{2}$-inch by $1 \frac{1}{2}$-inch square, which facilitating clamping it inside a 316 stainless cup. The rotating 1-inch diameter hemisphere or ball is press fitted in a 0.960 inch inside diameter by $1 \frac{1}{8} / 8$-inch outside diameter 316 stainless steel tube which is part of a spindle mounted inside a vertical mill. The mill satisfied objective 1) and was placed inside a large stainless steel tray and bolted to a concrete base and thus satisfy objective g). The stainless steel tray proved to be very convenient to store the many 316 stainless steel cups with the stationary sample inside, even when filled with hot liquid zinc. Using individual cups for each sample satisfied objective e). To accurately measure the friction torque on the stationary ball-seat, the cup containing the seat was suspended with a clamp 
below a flat circular horizontal disc. This disc is supported on 1/4-inch ball bearings running in a V-groove with a 12-inch radius machined in an aluminum ring. This suspension has several advantages: The disc floats on the ball bearing to provide automatic alignment with the rotating 1-inch ball as mentioned in g). Further it has negligible friction in rotation so that torque can be accurately measured with a strain-gage beam as mentioned in $\mathrm{j}$ ). The combination of the disc and $\mathrm{V}$-groove ring form a lid-like assembly over the zinc pot to protect the operator from splashing as required in c). Instead of loading the rotating spindle with weights, which may induce vibrations, the load was applied from below. The V-groove containing ring was mounted with linear bearings on three vertical 3/4-inch shafts to allow friction free up and down movements. The ring is supported on an inflated inner tube, which in turn rests on a weight scale with strain gages. This arrangement satisfies e) and g). As the ball is pushed down on the seat, the resulting load is digitally displayed on the scale. A strain gage Wheatstone bridge provides a milli-Volt output of the applied load to the computer driven data acquisition system, likewise for the torque measuring beam.

Press fitting a 5-inch diameter aluminum disc to the spindle provided spindle water-cooling, by having this disc ride on a spring-loaded and water-cooled stationary disc of equal diameter. The water-cooling protects the vertical mill bearings and is at 8inch distance from the liquid zinc in the cup. Using a thin 1/16-inch wall spindle satisfies objective $\mathrm{k}$ ) which is to minimize heat loss from the cup.

It is very important to simulate steel mill operating conditions, for the bearing contact pressure $\mathrm{P}_{\mathrm{c}}$ and contact velocity $\mathrm{V}_{\mathrm{c}}$. The design of the testing apparatus facilitates controlling the desired operating conditions. A test range from 10 to 575 RPM at a 
vertical load range from 10 to 75 pounds covers the bearing operating conditions used at Weirton Steel in their galvanizing lines \#3, \#4, and \#5. A dial type controller is used to set the operating temperature of the melting pot. Type $\mathrm{K}$ thermocouples are mounted in the cup and in the melting pot. The materials are ready to test once the temperature in the cup equals the temperature of the melting pot. An infrared sensor measures the RPM of the spindle. A ventilation fan is installed to carry to zinc fumes away from the testing laboratory. Leather gloves, safety glasses, face shields and leather long sleeve shirts and pants must be worn at all times while testing.

\subsection{Sample Holding and Preparation}

The test sample design is an important aspect of the testing process. An inexpensive, easily producible test specimen was chosen. Since machining of the bearing materials is often impossible, the specimen geometry was designed to be castable. Most materials of interest can be cast in the from of the desired specimen, and polished in preparation for testing. Other materials can be applied by laser coating or welding to base materials like stainless steel or ORNL-4.

To ensure the samples rotates true, with a smooth contact surface on both the ball

and seat, they are first polished with a diamond lapping compound on the vertical mill. Diamond lapping should be continued until all voids and burrs have been removed.

A hemispherical test ball and a polished matching seat simplify centering and have been found to make suitable test specimen. The seat specimen are small and made in the form of a square block, $1 \frac{1}{2}$-inches by $1 \frac{1 / 2}{2}$ - inches by $3 / 4$-inch thick, with a $5 / 8$-inch 
diameter hole in the center. A hemispherical ball shape, with $1 / 2$-inch radius, contacts the seat at a 45-degree average angle, simulating the contact angle in Vesuvius bearings.

At that angle the mean contact diameter of the seat becomes 0.707 -inch, with a 0.78 -inch outside diameter. The horizontally projected contact area of the seat is 0.171 square-inch which limits the required spindle load to $751 \mathrm{~b}$ and RPM to 575 .

To submerge the cup into the electrically heated zinc pot, a clamshell type clamp was designed to suspend the cup. This clamp is made to fit in the solid aluminum ball bearing disk. Two handles in the form of opposing 12-inch long threaded rods are attached to the clamp to conveniently remove the clamp with cup from the melting pot. Weights attached to the ends of the threaded rod, gives the cup inertia in rotation, as needed to minimize cup oscillations due to fluctuating friction torque.

The zinc in the cup rotates with the spindle, and causes a shear force on the cup wall. Calculations were preformed to determine if this liquid zinc shear force interferes with the accuracy of the measured torque produced by the friction in the test specimen. The viscous shear was calculated to be $1.141 * 10^{-9}$ inch*lb. This is negligible and its calculations are shown in Appendix A. 


\section{Chapter 5 - Construction of Bearing Material Wear Tester}

\subsection{Vertical Mill, Melting Pot, and Testing Facility}

The hot zinc pot test facility had to be secure and ventilated to provide a safe place for testing. A photography dark room was converted for that purpose. The room could be locked, to prevent unauthorized personnel from coming in contact with the molten zinc bath. A concrete block bench was built in the room to support a vertical mill. The mill was placed on a stainless steel tray to safely store cups with test samples, even if they tip over. The room has a stainless steel sink which is convenient for component cooling. An exhaust fan was installed in the ceiling to remove zinc fumes from the room. This arrangement provided a safe room to conduct all tests.

A vertical milling/drilling machine was chosen to provide constant RPM at changing torque levels while testing. The mill bed is adjustable in both the $\mathrm{x}$ and $\mathrm{y}$ directions, to provide alignment of the two test specimen. The mill accepts any R-8 collets, for spindle diameters up to 3/4-inch. A radial arm lever is used to push the spindle with ball on the seat at the desired initial loading. The RPM range from this mill could be adjusted by varying the drive belts. The variable RPM range, from 100-750 RPM, is adequate to simulate bearing velocities shown in Table 3.2.. The only required modifications to the mill, was to insert a 12 -inch spacer to increase the distance between the mill head and the bed. Without the spacer, the spindle could not be removed from the cup.

A 2000 watt zinc melting pot was used to melt the zinc to the desired temperature. The pot dimensions are 10-inch outside diameter by 10-inch tall, with a 6-inch inside diameter by 6-inch inside height. This small size melting pot allowed it to be mounted 
directly on the vertical mill bed. This allows using the adjustable X-Y axis mill bed to align the ball and seat. An insulated pad was installed under the melting pot, to minimize heat loss.

\subsection{Bearing Track Assembly}

The bearing track assembly, shown in Figure 5.1, surrounds the zinc pot and is designed with multiple functions. Its aluminum base plate is water-cooled and bolts to the mill bed. Three equally spaced vertical 3/4-inch precision ground linear bearing shafts are attached to the plate. They enable a spindle load-carrying ring to be adjusted up and down and prevent splashing of hot zinc by minimizing the clearance between zinc pot and its cover. Two sets of strain gage equipped beams are stacked on top of each other to measure the spindle load. The top strain gage beams are part of weighing scale, which displays the initial spindle load in pounds. Those on the lower beam are used during testing to display and record the time varying load in $\mathrm{mV}$. Two 1/4-inch thick flat aluminum rings separated by an inflated inner tube are used to transfer the spindle load to the weighing scale. A short water-cooled aluminum ring with a 1/4-inch ball bearing track machined in it, rests on top of this assembly, and is guided up and down the $3 / 4$-inch vertical shafts by three linear bearings. Its ball bearing track allows the zinc-pot cover, a flat aluminum plate, to rotate friction free on the $1 / 4$-inch ball -bearings. The inner tube, which is sandwiched between the two plates dampens vibrations and to keeps the spindle load constant even if the test specimen wear down.

The zinc-pot cover has a 3.5-inch hole cut in its center. This hole is used for the cup holder clamp, which suspends a cup with the ball-seat type test specimen. 


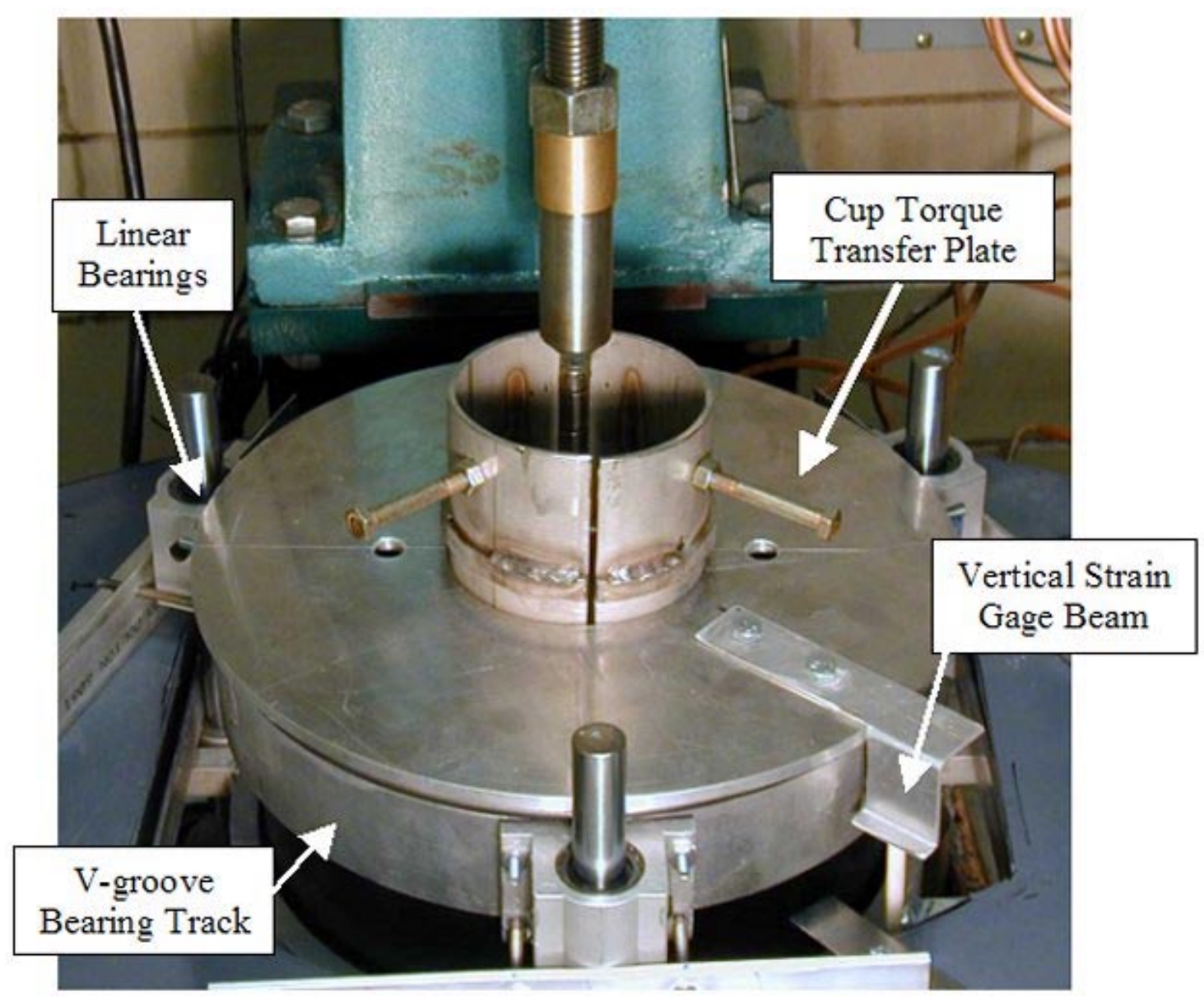

Figure 5.1: Linear bearings, bearing track and cup torque transfer plate

In addition to supporting the cup holder, the zinc pot cover plate, floating on the 1/4-inch ball bearings, allows the ball/seat test specimens to center themselves. The other function of the cup torque transfer plate/bearing ring, is to protect the operator from zinc splashes. The mill bed adjustment is used to center the zinc pot cover plate in between the three linear bearings. Figure 5.2 shows a cross-section drawing of the bearing track assembly. 


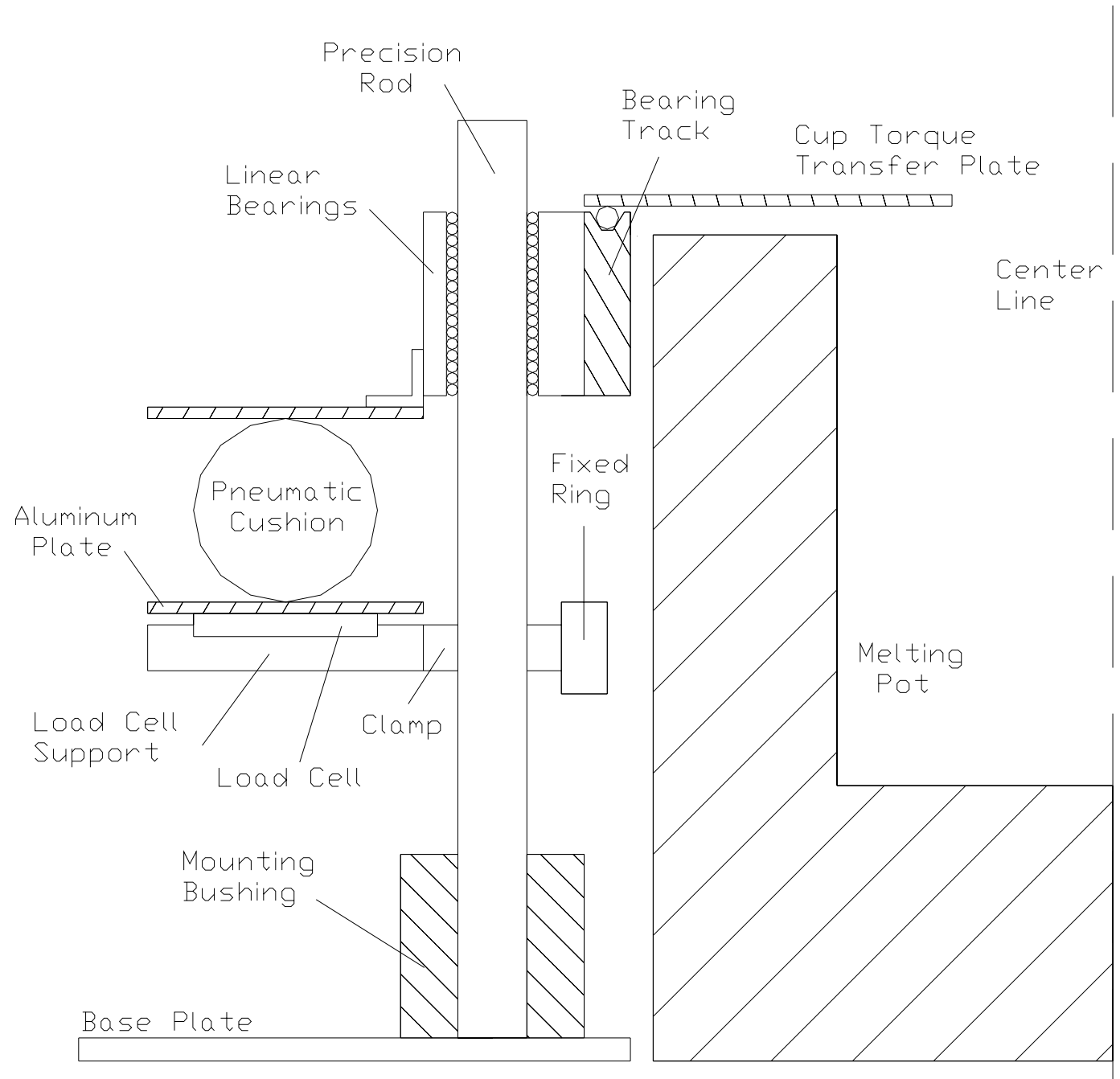

Figure 5.2: Cross section of the bearing track assembly

The bearing track assembly carries all loads that are applied to the specimen. It is necessary to build the system as structurally sound as possible. Close tolerances in the design are a must to reduce unwanted vibrations and to ensure the free movement of the linear bearings and ball bearing track. Figure 5.3 shows a picture of the actual bearing track assembly used for testing. 


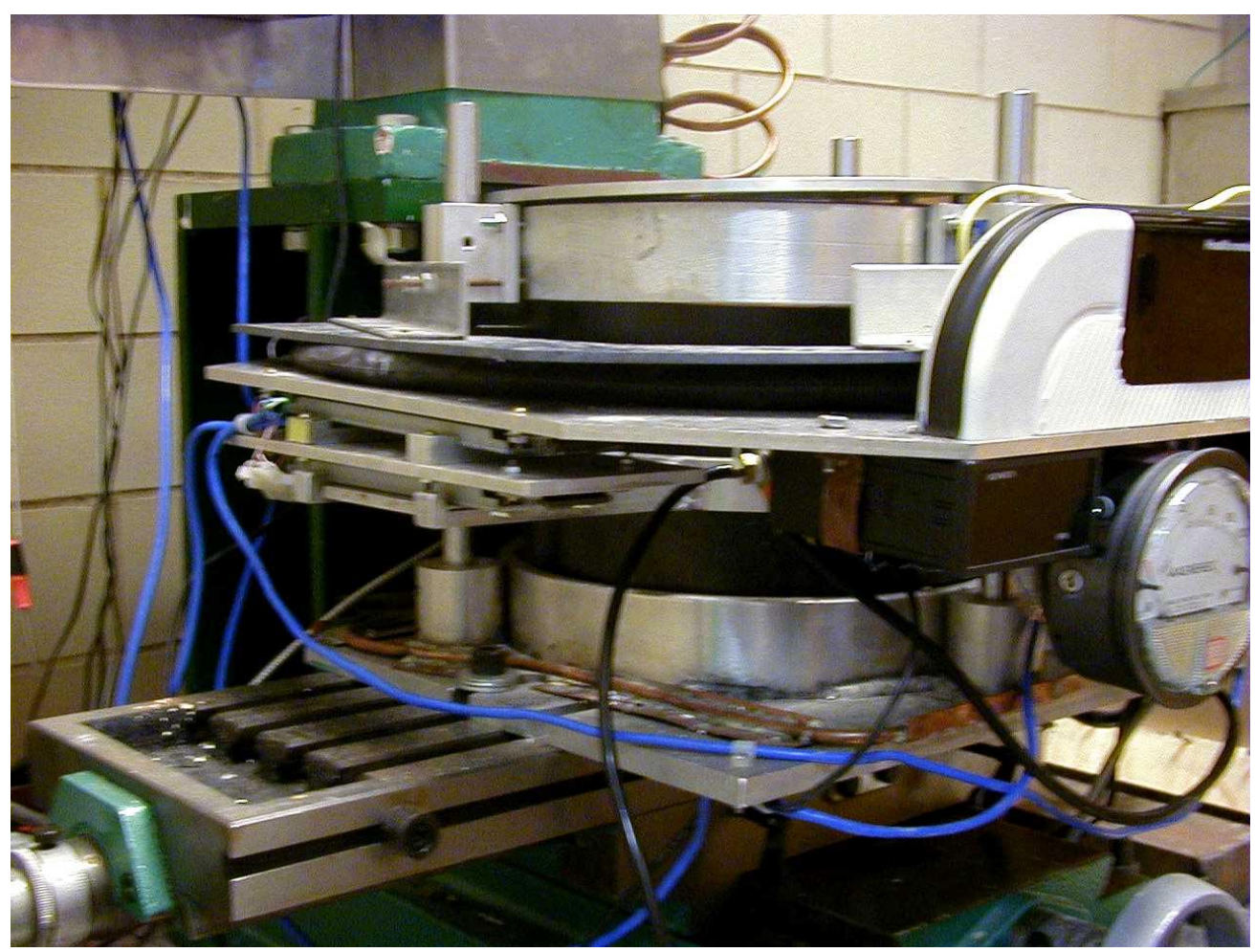

Figure 5.3: Bearing track assembly

\subsection{Spindle}

The spindle was designed to hold the ball specimen which rotates on the seat. The spindle had to be easily adjustable and interchangeable. The spindle also has to run true with absolutely no "wobble" in it. A 0.96-inch inside diameter thin walled piece of 316 stainless steel tubing was used to secure the ball test specimen with a press fit. Figure 5.4 shows the initial testing spindle, prior to update. 

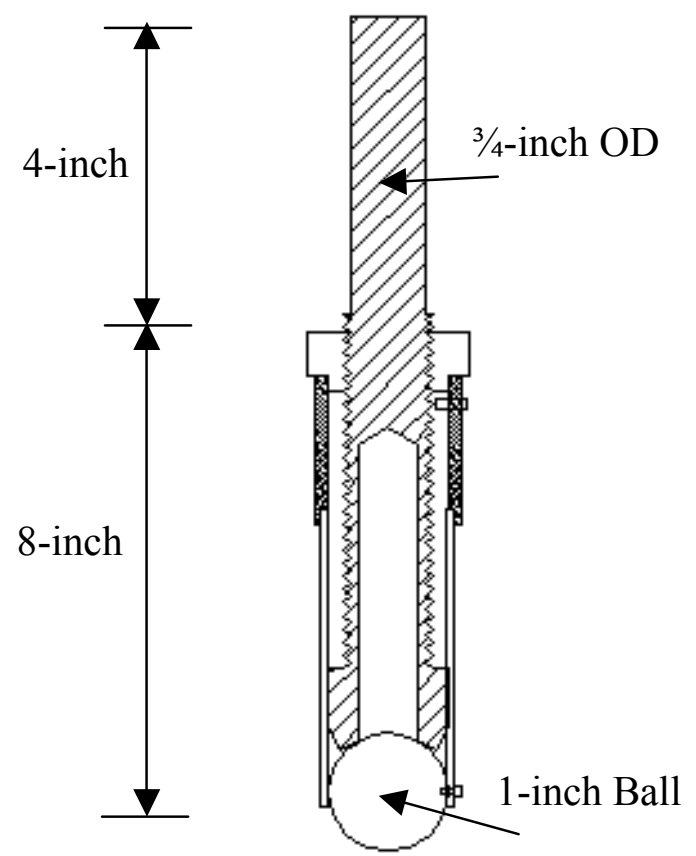

Figure 5.4: Initial spindle setup for the testing apparatus, prior to update.

Another spindle made virtually out of all tubing allowed the heat to escape at a faster rate, but maintained the simplicity of the previous design, see Figure 5.5. The ball is pressed into the end of a thin walled stainless steel tube, against three equally space rivets, and prevented from rotating by a pop rivet. This tube is connected to a 1 -inch OD tube by press fit. Inside the 11/16-inch OD drive shaft is pressed. The depth of pressing is limited by some $1 / 8$-inch pop rivets. An additional pop-rivet is used to lock the ball to the tube. At that junction is also press fitted a 5 -inch diameter by $1 / 2$-inch thick aluminum disc, used to cool the spindle by rubbing it on a spring-loaded stationary water-cooled disc attached to the mill. The thin wall minimized heat loss, and being hollow simplifies ball removal. 


\section{Spindle}

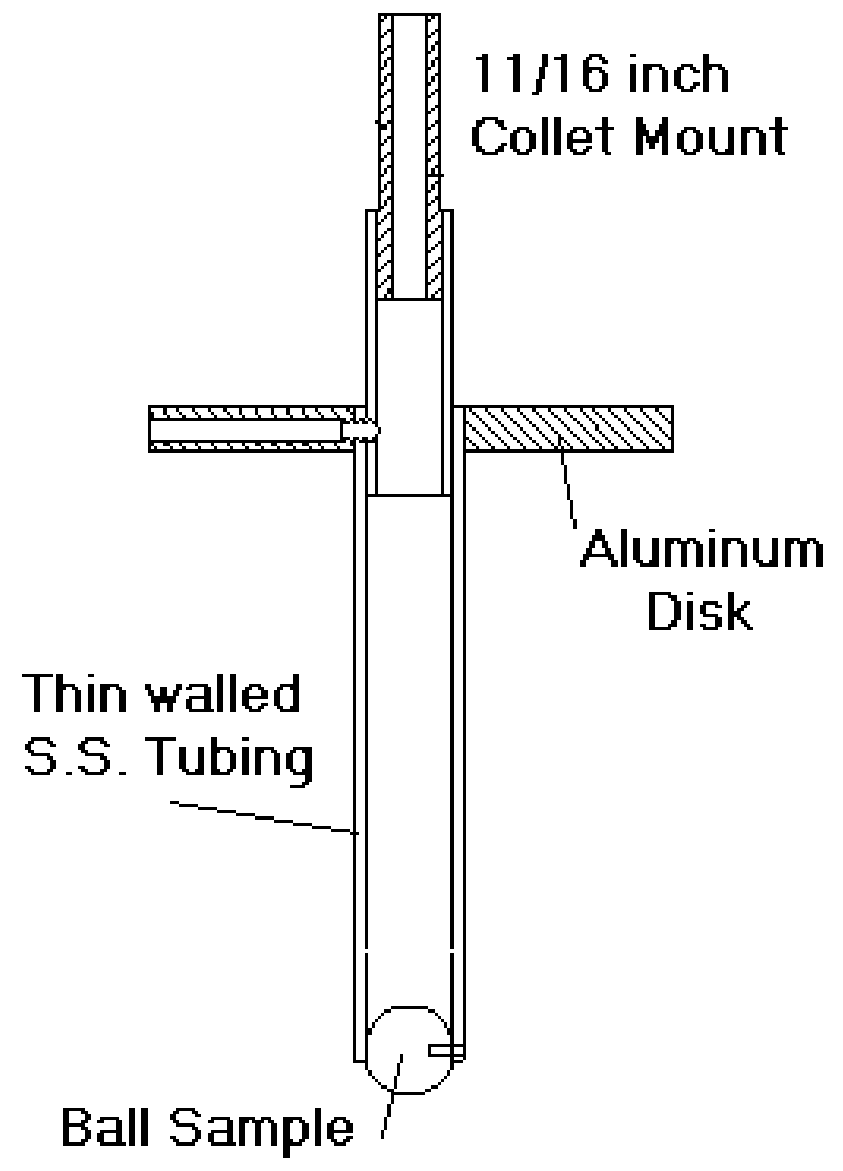

Figure 5.5: Cross section drawing of spindle.

The press fit was selected to improve alignment, but the result was far from perfect. A new well-aligned version is under design. Once the test is completed the test ball can be pressed out quickly and easily. The next test specimen can be mounted in the same spindle for testing. The ease of interchanging the specimen allows for more tests to be completed in a day. 


\subsection{Cooling System}

Since the $860{ }^{\circ} \mathrm{F}$ hot molten zinc-pot transfers heat by conduction, convection and radiation throughout the apparatus, a cooling system was needed. This ensured the apparatus and instrumentation remain cool during testing. Appendix $G$ shows heat transfer calculations for the test apparatus. Since water is available in the test laboratory, a water-cooled system was the obvious choice. A groove was machined into the ring containing the $1 / 4$-inch ball bearing track, and into the cylindrical plate on which the melting pot rests.. Copper tubing was press fitted into the grooves and hooked up to the water supply, see Figure 5.6.

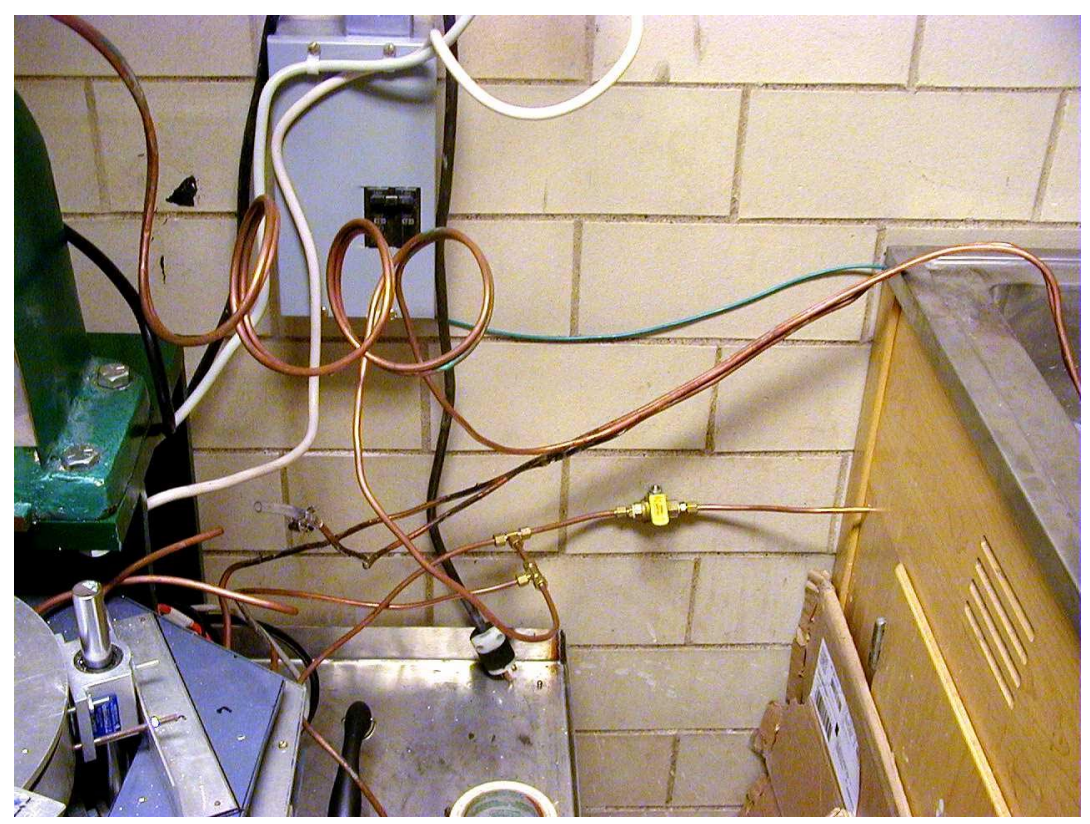

Figure 5.6: Copper water lines mounted to the V-groove ring, base plate, spindle.

To cool the spindle a spring-loaded 5-inch diameter water-cooled aluminum disc was attached to the vertical mill at the collet side. When the spindle with its aluminum disc is inserted in the collet, the spring loaded water-cooled disc rests on top of the spindle disc to keep the upper portion of the spindle cool. 


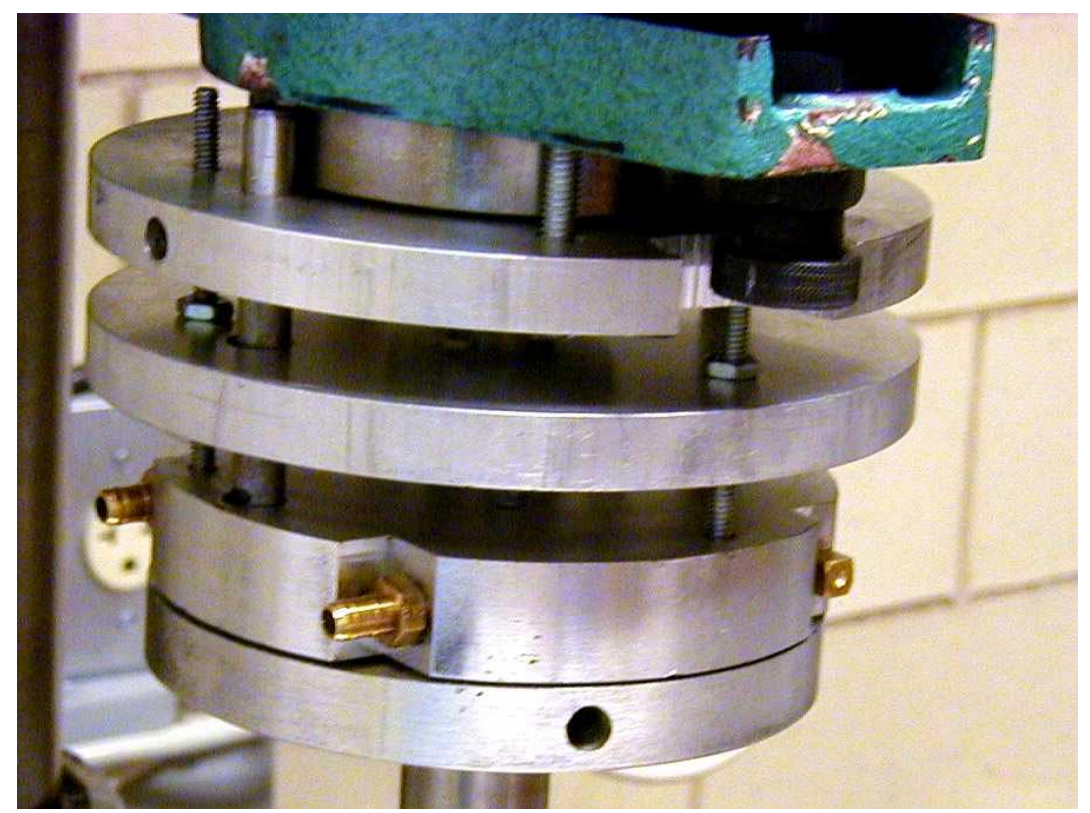

Figure 5.7: Water cooled spindle

\subsection{Material Type and Test Specimens}

In galvanizing lines, the performance of bearings, corrosion of molten metal bath hard wear, and dross build up on bath hardware are three key factors that cause the bearings to fail. New materials and coatings have been designed to give the bearing a longer life. In the first stage of this project, three new materials and one new coating will be tested. A combination of the new materials and coatings has been listed in a test matrix. When the wear of the material has been examined, the best combination can be concluded. Stellite 6, MSA 2012, ORNL 4 (with WC-Laser Cladding), and 316 Stainless Steel (with WC-Laser Cladding) are the materials and coatings that will be looked at in the first stage of testing.

Stellite 6 is the most generally useful cobalt alloy, having excellent resistance to many forms of mechanical and chemical degration over a wide temperature range. Particular attributes are its outstanding self-mated antigalling properties, which result in its wide use as a valve seat material, high temperature hardness, and a high resistance to 
cavitation erosion. Oak Ridge National Laboratory provided the cast samples of Stellite 6 used in the testing.

MSA 2012 is another choice of bearing material. This alloy supplied by Metaullics, has been performing well in galvanizing lines without any pretreatment. When samples become available, they will also be tested.

The ORNL-developed alloy \#4 series of $\mathrm{Fe}-\mathrm{Cr}$-Al promises over an order of magnitude better performance than Type 316L. Such improvement in performance occurred consistently with a preoxidation treatment. The ORNL \#4 material will be coated with WC-Laser cladding .

WC-Laser Cladding is a process that Zoz, et al. metallurgicaly bonds the Tungsten-Carbide with Cobalt to the specified material. The laser process typically produces an overlay with no more that 5\% Dilution. This allows for better chemistry and physical properties than are achievable with conventional welding processes. Praxair surface technologies assisted with all the WC-Laser cladding that was accomplished.

A material test matrix was selected at a group conference as shown in Table 5.1. This test matrix will be used initially to verify the test procedure. Stainless Steel 316 was used as a trial testing material. This material is easily obtainable and machinable, thus a good choice for initial testing. 
Table 5.1: Initial test series material combination matrix

\begin{tabular}{|l|l|l|l|l|l|}
\hline & $\begin{array}{l}\text { Seat: } \\
\text { 316SS }\end{array}$ & $\begin{array}{l}\text { Seat: } \\
\text { 316SS with } \\
\text { Laser Cladding }\end{array}$ & $\begin{array}{l}\text { Seat: } \\
\text { Stellite \#6 }\end{array}$ & $\begin{array}{l}\text { Seat: } \\
\text { ORNL-4 with } \\
\text { Laser Cladding }\end{array}$ & $\begin{array}{l}\text { Seat: } \\
\text { MSA } \\
\mathbf{2 0 1 2}\end{array}$ \\
\hline $\begin{array}{l}\text { Ball: } \\
\text { 316 SS }\end{array}$ & $\begin{array}{l}\text { Trial } \\
\text { Test }\end{array}$ & $\begin{array}{l}\text { Trial } \\
\text { Test }\end{array}$ & $\begin{array}{l}\text { Trial } \\
\text { Test }\end{array}$ & $\begin{array}{l}\text { Trial } \\
\text { Test }\end{array}$ & $\begin{array}{l}\text { Trial } \\
\text { Test }\end{array}$ \\
\hline $\begin{array}{l}\text { Ball: } \\
\text { Tungsten }\end{array}$ & $\begin{array}{l}\text { Trial } \\
\text { Test }\end{array}$ & $\begin{array}{l}\text { Trial } \\
\text { Test }\end{array}$ & $\begin{array}{l}\text { Trial } \\
\text { Test }\end{array}$ & $\begin{array}{l}\text { Trial } \\
\text { Test }\end{array}$ & $\begin{array}{l}\text { Trial } \\
\text { Test }\end{array}$ \\
\hline $\begin{array}{l}\text { Ball: } \\
\text { 316SS with } \\
\text { Laser Cladding }\end{array}$ & & & Test & & Test \\
\hline $\begin{array}{l}\text { Ball: } \\
\text { Stellite \#6 }\end{array}$ & & Test & Test & Test & Test \\
\hline $\begin{array}{l}\text { Ball: } \\
\text { ORNL-4 with } \\
\text { Laser Cladding }\end{array}$ & & & Test & & Test \\
\hline $\begin{array}{l}\text { Ball: } \\
\text { MSA 2012 }\end{array}$ & & Test & Test & Test & Test \\
\hline
\end{tabular}

Once the material matrix was chosen, the specimen had to be prepared for testing.

The specimen would take the form of a 1-inch diameter hemispherical ball and a square seat specimen, with a 1 -inch diameter ball seat milled in the center. Since machining most of the materials is very costly and time consuming, a mold was designed to cast the materials. A graphite mold was the first attempt to cast the samples. Two carbon blocks were purchased and specimen shapes were milled into the bottom mold. Pouring channels were milled into the top block, so the molten metal can easily flow into the specimen channels.

The mold proved to be unsuitable for pouring the test samples. The channels were too small to allow the metal to flow through, and the pouring trough was not deep enough to provide the hydraulic head pressure necessary for filling the casting. Filling the mold took too much time, which resulted in the solidification of the metal before it reached its final destination. Detailed drawing of the graphite-carbon mold can be found in appendix B. 
Next a cope and drag sand casting technique was designed at WVU to improve the casting. A circular and rectangular pattern was formed, with samples specimen attached with tapered side, which allow the mold to slide out of the sand easily. A deep pouring channel allowed for the necessary head pressure desired. A rectangular pattern was tested at WVU by pouring aluminum samples. At ORNL, this mold was redesigned using parts of the WVU mold and resulted in a successful Stellite \# 6 casting. Figures 5.9 and 5.10 show the two sand casting molds used to cast the material samples.

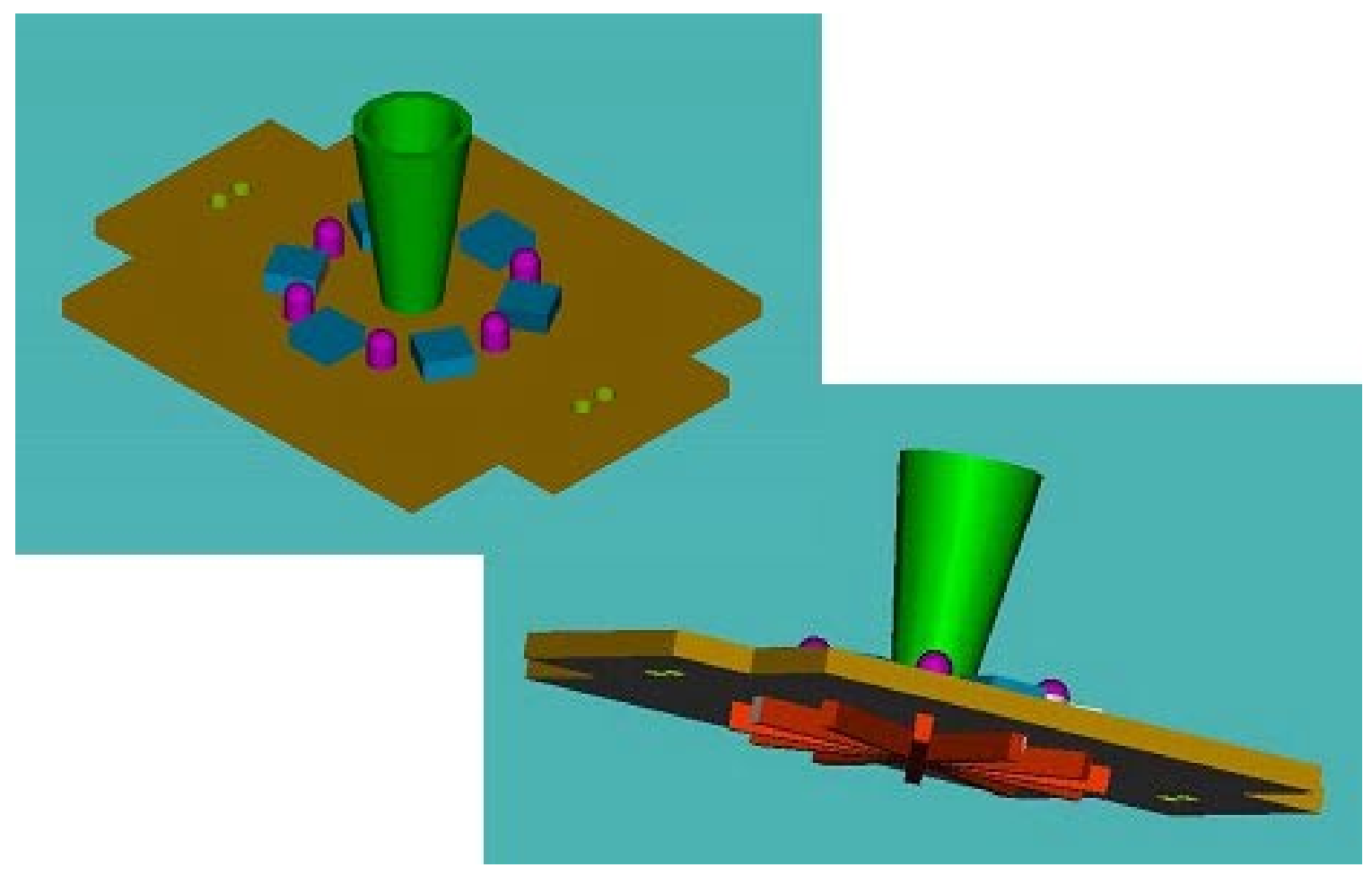

Figure 5.9: Upward sand casting mold designed at ORNL 


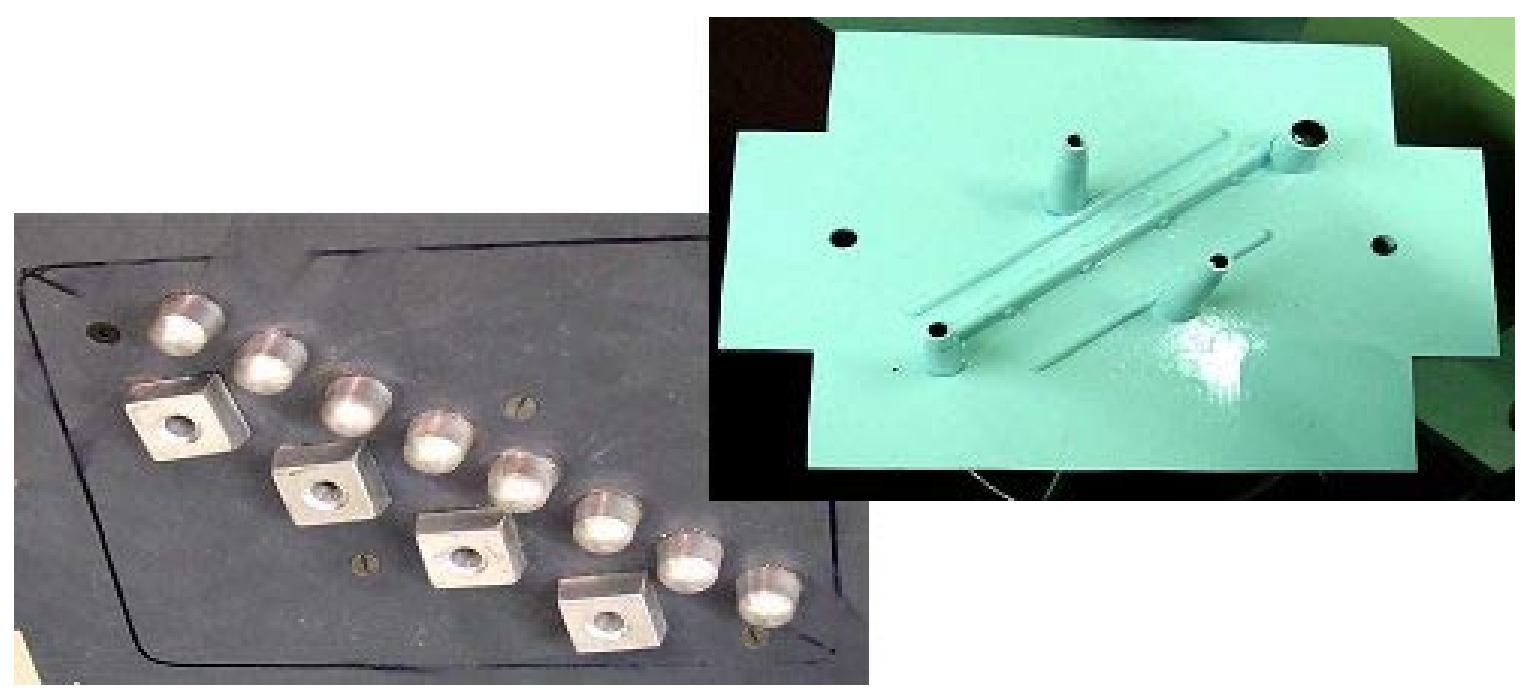

Figure 5.10: Downward sand casting mold designed at WVU

Other test specimen were prepared by machining the stainless steel 316 seats and commercial 1 -inch diameter balls and shipping them to Praxair for laser cladding. After cladding or casting, the samples had to be polished to achieve the smooth finish required for testing. The samples were polished with diamond lapping compound. Figure 5.11 shows a polished Stellite \#6 seat sample ready for testing.

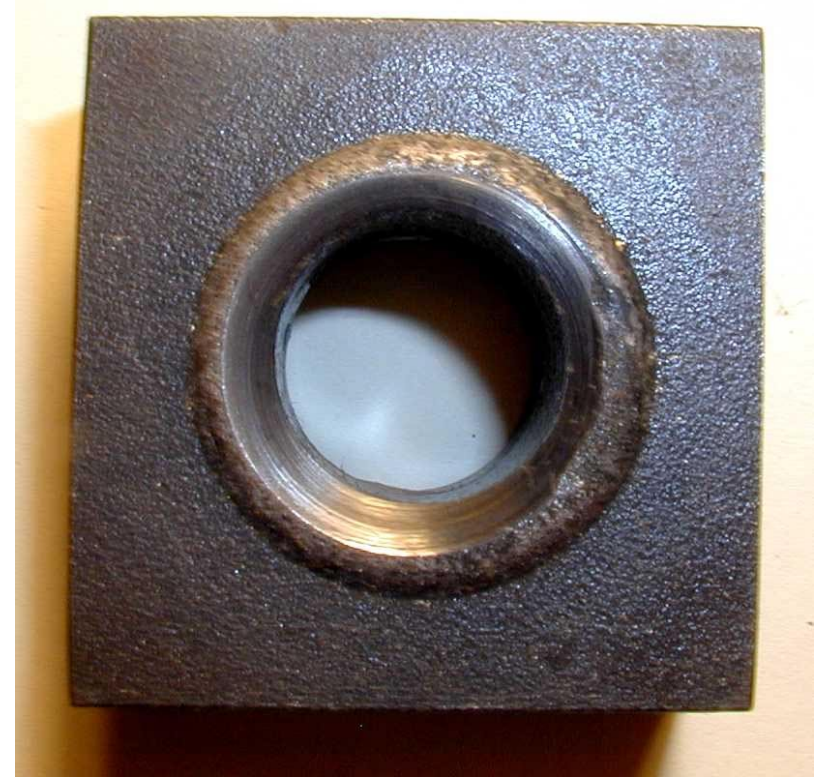

Figure 5.11: Polished stellite \#6 seat sample 
The ball and seat samples were polished to the desired outside diameter of the seat. The specimen had to be fixed to the cup so that the friction torque is transferred to the cup. A strut channel clamp was machined to allow adequate flow around the specimen, while locking it in place, shown in figure 5.12 and 5.13. A piece of strut channel was milled so the specimen could be pressed in. A hole was drilled through both the channel and the cup then bolted together with a stainless steel bolt. A detailed drawing of the strut channel is found in appendix B.

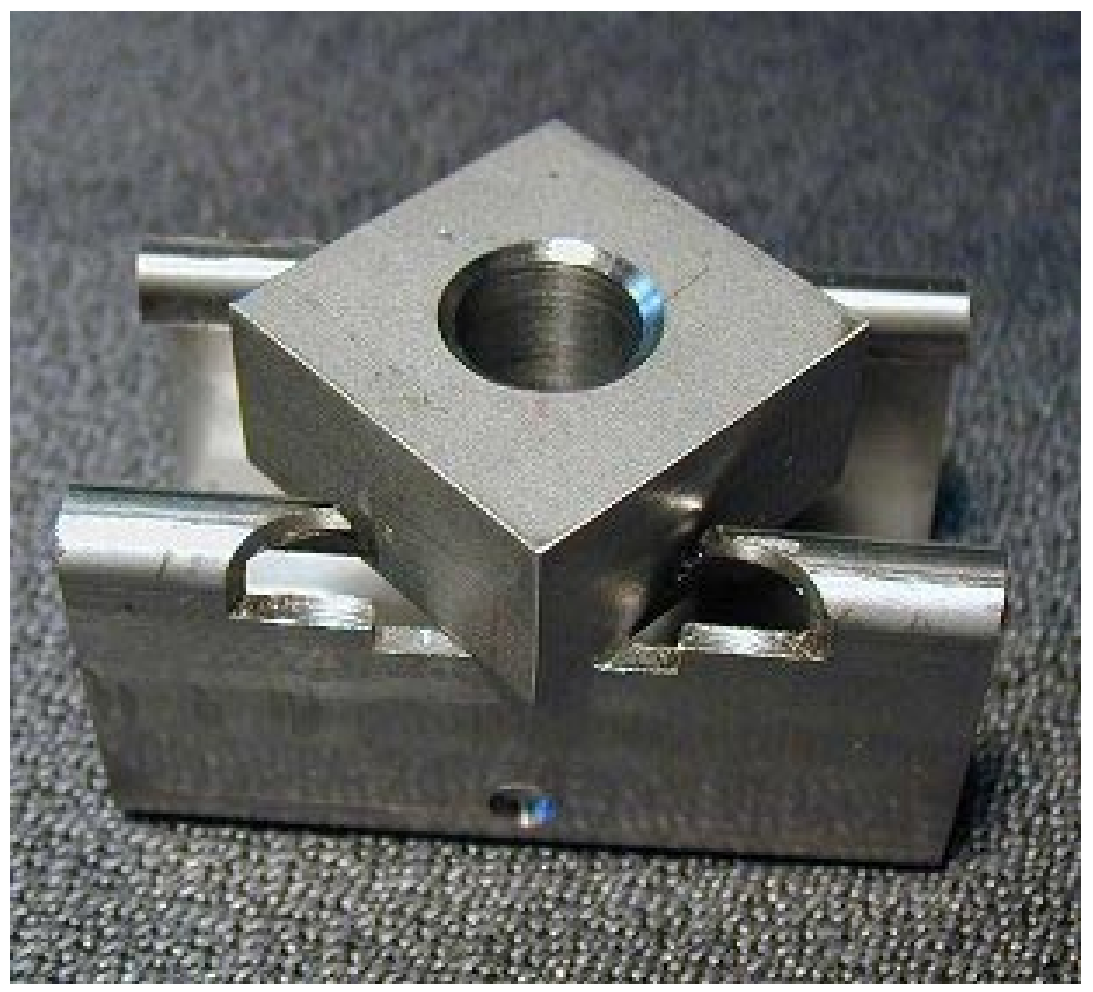

Figure 5.12: Specimen pressed into the strut channel clamp 


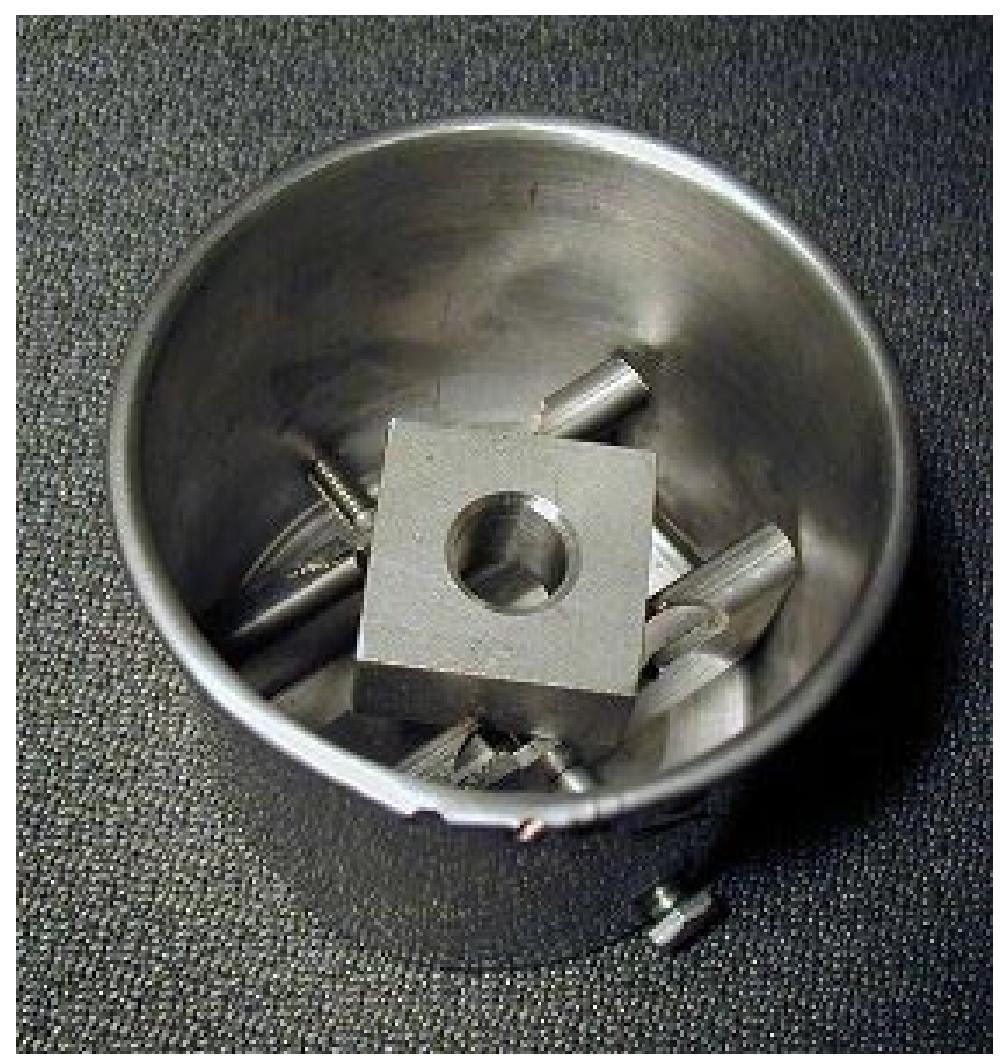

Figure 5.13: Strut channel locked into the cup

\subsection{Assembly of Test Apparatus}

Once the components of the system were designed and built, they were assembled together to form a testing apparatus, see Figure 5.14. The polished ball is pressed into the stainless steel tubing of the designed spindle. The mill turns the ball against the seat, and the rotating aluminum disk against the stationary water-cooled disk.

The zinc pot is placed in the center of the bearing track assembly. Once the $1 / 4$ inch balls are set in the V-groove bearing track, the cover plate is installed. The cup is assembled together with the seat sample pressed in the strut channel clamp in. The cup and clamp are mounted in the cover plate, which rotates freely on the ball bearing track.

The seat is aligned with the ball sample by the adjustable vertical mill bed. Once the samples are centered and the zinc is melted to the correct testing temperature, a load 
can be applied by lowering the ball into the seat. Testing of the specimen is now ready to start and data can be taken. A scaled drawing of the testing apparatus can be found in appendix B.

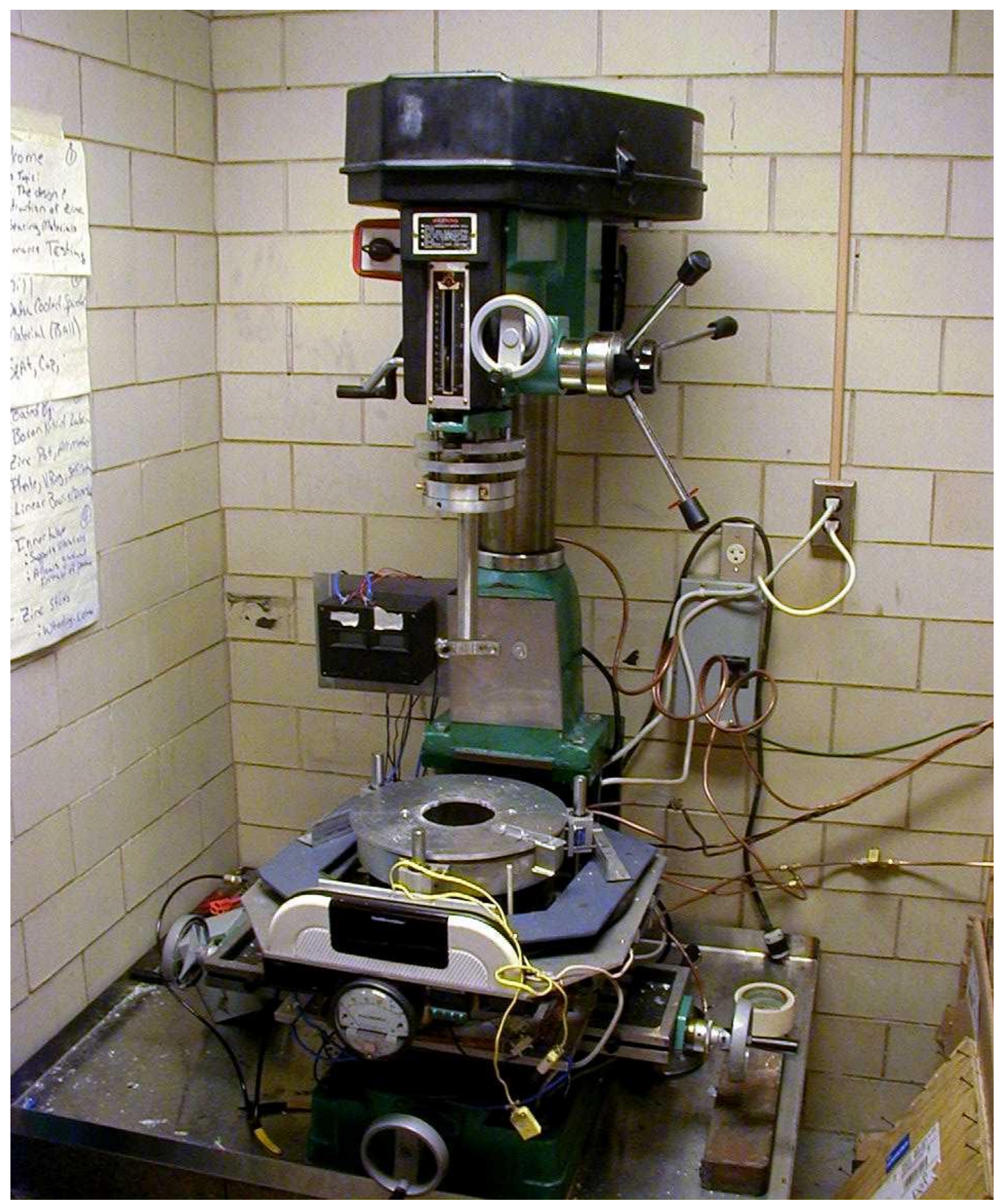

Figure 5.14: Assembled test apparatus 


\section{Chapter 6 - Instrumentation}

\subsection{Measurements}

Accurately measuring the correct temperature, pressure, torque and RPM during the test is a critical part of the data recording process. The analog output signal of the measuring instruments is calibrated against known loads. Calibration curves for the instrumentation can be found in Appendix $\mathrm{H}$

The torque on the aluminum cover plate caused by the ball and seat friction exerted a force on a vertical beam with a strain gage attached. The strain gage output was calibrated with a known force at a radial distance $\ell_{\text {Gage }}=6.75$ inches. The measured torque from the following equation is recorded:

$$
T=F_{\text {Gage }} * \ell_{\text {Gage }}
$$

This is the frictional torque from the ball and seat. Because the ball contacts the seat at 45 degree angle, the perpendicular force on the seat is greater than $\mathrm{F}_{\text {load }}$ and equal $\mathrm{F}_{\text {load }} * \sqrt{2}$. The friction coefficient is the ratio between the tangential friction force $\mathrm{T} / \ell_{\text {Ball }}$ and the perpendicular force above:

$$
T=F_{\text {load }} * \sqrt{2} * \ell_{\text {Ball }} * \mu_{F}
$$

Where $\ell_{\text {Ball }}=\frac{0.707}{2}$ inch, therefore a simple ratio between these two forces provides the friction coefficient.

$$
\mu_{F}=\frac{F_{\text {Gage }} * \ell_{\text {Gage }}}{F_{\text {Load }} * \sqrt{2} * \ell_{\text {Ball }}}=\frac{13.5 * F_{\text {Gage }}}{F_{\text {Load }}}
$$


The output signal was directed into a digital readout, where the reading could be monitored with a milli-voltmeter.

Two load cells stacked on top of each other, measured the ball load on the seat. One set of load cells provides the initial scale reading, while the other load cell sends an output signal to the computer as a function of time. Two ungrounded, type K, stainless steel sheathed thermocouples measure the temperature of the zinc in the cup and the melting pot. Both thermocouples are needed to assure stabilization of the temperature in the cup. The thermocouples produce a signal read by a thermometer, which produce an analog output signal that is sent to the computer. An infrared RPM sensor counts the spindle RPM, which produces the output voltage read by the computer. A mechanical pressure gage is used to monitor the pressure of the inner tube. The instrumentation used for the testing apparatus is shown in Figure 6.1.

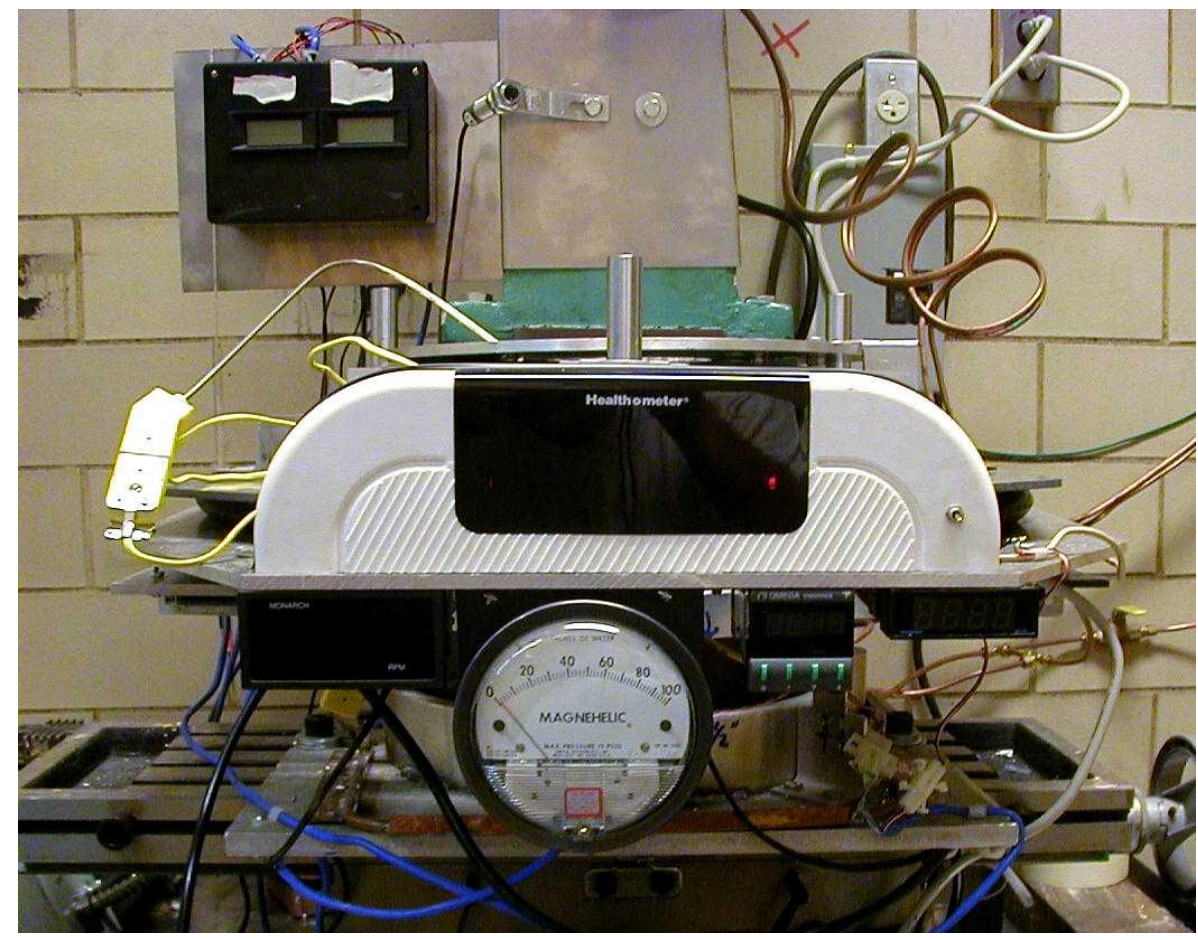

Figure 6.1: Instrumentation setup for the test apparatus 


\subsection{Circuit Board Setup}

A circuit board was designed to neatly organize the signal coming from the instruments, and transfer them into the computer by the way of a ribbon cable, see Figure 6.2. The instrumentation was wired into connectors on the board, which transferred the signal into easily read channels. The Wheatstone Bridge was completed in the circuit board and potentiometers were incorporated to zero the strain gage.

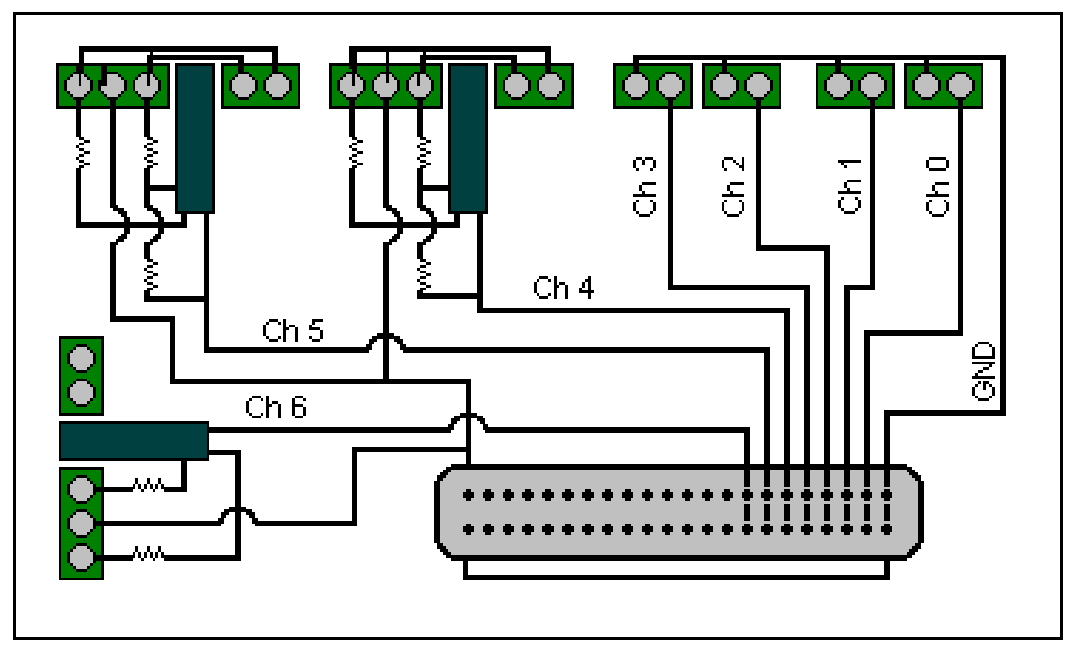

Figure 6.2: Instrumental setup circuit board

Power supplies were built to produce power to the gages and meters used. Three 10-volt supplies were used to produce the voltage across the strain gage and load cells, while a 6-volt supply powered the load scale.

The circuit board was mounted in an easily assessable plastic box. The power supply was mounted externally to the box to avoid its heat generation. A ribbon cable attached to the circuit board sends the signals to the computer. The wiring diagram for the circuit board can be found in Appendix E. 


\subsection{Computer Setup}

An Analog Devices RTI-800 was used as an interface board to collect the analog output voltage. James Snider II, wrote a computer program in Quick Basic ${ }^{\circledR}$, to store the data obtained in a file. The program will store the voltage, then the data can be transformed in Microsoft Excel ${ }^{\circledR}$. 


\section{Chapter 7 - Preliminary Tests and Test Results}

\subsection{Preliminary Trial Tests}

Initial tests were completed to ensure that the test apparatus was functional and all problems were resolved. Water tests were performed on a commercial stainless steel ball on a machined stainless steel matching seat. The molten zinc was simply replaced by water and the tests were completed. Three preliminary tests were completed at 126 RPM, under three different contact pressures of: $31.0 \mathrm{psi}, 49.1 \mathrm{psi}$, and $71.3 \mathrm{psi}$. These initial conditions were in the range of velocities and pressures obtained by Weirton Steel line operating ranges.

Each test ran for 15 minutes. The data obtained from these tests are shown in Table 7.1. The ball/seat load and torque strain gage force remained constant throughout the duration of the tests. After the procedure was found to be satisfactory, hot zinc pot testing was performed. Plots from the preliminary water test is found in Appendix C.

Table 7.1: Data obtained during preliminary water testing of stainless steel ball on stainless steel seat.

\begin{tabular}{|l|l|l|l|l|l|}
\hline & Avg Load (lbs) & $\begin{array}{l}\text { Avg. Contact } \\
\text { Pressure (psi) }\end{array}$ & Avg. RPM & $\begin{array}{l}\text { Avg. Contact } \\
\text { Velocity (in/sec) }\end{array}$ & $\begin{array}{l}\text { Friction } \\
\text { Coefficient }\end{array}$ \\
\hline Test 1A & 5.3 & 31.0 & 126 & 4.67 & 0.201 \\
\hline Test 1B & 8.4 & 49.1 & 126 & 4.67 & 0.202 \\
\hline Test 1C & 12.2 & 71.3 & 126 & 4.67 & 0.177 \\
\hline
\end{tabular}




\subsection{Test Results}

Once preliminary testing was completed, hot zinc pot test could be performed. Tests $2 \mathrm{~A}-2 \mathrm{~F}$ were completed at a molten zinc temperature of approximately $860^{\circ} \mathrm{F}$. A WC-LC ball on a Stellite \#6 seat, were the chosen materials for testing. Table 7.2 shows the ball/seat load and RPM, at which each test operated.

Table 7.2: Hot zinc pot load, RPM, and temperature ranges for testing.

\begin{tabular}{|l|l|l|l|}
\hline & $\begin{array}{l}\text { Ball/Seat } \\
\text { Load }(\mathbf{l b s})\end{array}$ & $\begin{array}{l}\text { Spindle } \\
\text { RPM }\end{array}$ & $\begin{array}{l}\text { Temperature } \\
\left.\mathbf{(}^{\mathbf{}} \mathbf{F}\right)\end{array}$ \\
\hline Test 2A & 3.7 & 126 & 870 \\
\hline Test 2B & 7.3 & 126 & 861 \\
\hline Test 2C & 10.5 & 126 & 870 \\
\hline Test 2D & 3.8 & 367 & 863 \\
\hline Test 2E & 7.1 & 367 & 860 \\
\hline Test 2F & 9.2 & 367 & 858 \\
\hline
\end{tabular}

The load cells and torque strain gage were calibrated to reduce the data and determine the friction coefficient of the ball and seat material. The operating conditions of the hot zinc pot test were in the range of velocities, pressures and temperatures in Weirton Steel's galvanizing lines. The torque and load remained constant throughout the duration of the test. The friction coefficient of the materials remained constant in all six tests. The observations of the hot zinc pot tests are shown in Table 7.3.

Table 7.3: Hot zinc pot test data obtained from testing a WC-LC ball on a Stellite \#6 seat.

\begin{tabular}{|l|l|l|l|l|l|l|}
\hline & $\begin{array}{l}\text { Avg. } \\
\text { Ball/Seat } \\
\text { Load } \\
(\mathbf{p s i})\end{array}$ & $\begin{array}{l}\text { Avg. } \\
\text { Contact } \\
\text { Pressure } \\
(\mathbf{p s i})\end{array}$ & $\begin{array}{l}\text { Avg. } \\
\text { RPM }\end{array}$ & $\begin{array}{l}\text { Avg. } \\
\text { Contact } \\
\text { Velocity } \\
(\mathbf{i n} / \mathbf{s e c})\end{array}$ & $\begin{array}{l}\text { Temperature } \\
\left({ }^{\mathbf{}} \mathbf{F}\right)\end{array}$ & $\begin{array}{l}\text { Friction } \\
\text { Coefficient } \\
\left(\boldsymbol{\mu}_{\mathbf{F}}\right)\end{array}$ \\
\hline Test 2A & 3.7 & 21.6 & 126 & 4.67 & 870 & 0.327 \\
\hline Test 2B & 7.3 & 42.7 & 126 & 4.67 & 861 & 0.363 \\
\hline Test 2C & 10.5 & 61.4 & 126 & 4.67 & 870 & 0.358 \\
\hline Test 2D & 3.8 & 22.2 & 367 & 13.6 & 863 & 0.313 \\
\hline Test 2E & 7.1 & 41.5 & 367 & 13.6 & 860 & 0.338 \\
\hline Test 2F & 9.2 & 53.8 & 367 & 13.6 & 858 & 0.369 \\
\hline
\end{tabular}


Plots can be found in Appendix D, that shows the analog output readings, ball/seat load, toque strain gage load, and friction coefficient as a function of time. 


\section{Chapter 8 - Conclusions and Recommendations}

A safe testing apparatus was designed and built to measure wear and friction of new zinc pot bearing materials. The objectives were met and testing was completed. The testing apparatus was able to test the bearing material sample at operating conditions similar in industry. The rotating ball sample and matching seat sample were easy to fabricate and low cost. By reducing the size of the testing samples, the size and components of the material wear tester were reduced. A range of contact pressures and velocities were established for all zinc pot testing.

A constant load can be maintained between the bearing material samples, even if wear occurs. The test machine is nearly free of all vibrations, which allow for a steady frictional torque to be produced by the samples. Test data show minimal fluctuation in the load or torque in the system. The zinc melting pot allows testing to be performed at the desired temperature of $860^{\circ} \mathrm{F}$. These data can be measured and recorded as a function of time. The friction coefficient of the bearing material can be determined, with no need for statistical analysis.

The small size of the testing apparatus, allowed for safe testing. An exhaust fan mounted in the testing facility carried all zinc fumes away. In conclusion, all design objectives were met, and a functional zinc pot bearing material wear test apparatus has been constructed and evaluated.

New zinc pot bearing materials should be tested to improve the life of zinc pot bearings in industry. Data shows that the friction coefficient stabilizes after only a few

minutes. Improved shielding of the computer components may be needed to assure consistent data, as necessary for long term testing. Evaluating the wear of the materials is 
crucial in the search for improved zinc pot bearing materials. A correlation between the friction coefficient and wear rate of the materials will be the final objective in this research. Longer tests may need to be performed on each set of samples, to achieve consistent wear rate of the materials. The materials/coatings show little wear in the 15minute friction coefficient test. Once this is completed a correlation between friction coefficient and wear data as a function of contact pressures and velocities might be found. 


\section{References}

[1] R.E. Bond, J.L. Loth, R.W. Guiler, and N.N. Clark, "Lubricity Problems and Solutions for a Methanol Fueled Gas Turbine," Rheology and Fluid Mechanics of Nonlinear Materials, FED-Vol 252.

[2] American Society for Testing and Materials, Standard Test Method for Measurement of Lubricity of Aviation Turbine Fuels by Ball on Cylinder Lubricity Evaluator, D500190a(1995)a American Society for Testing and Materials, West Conshohocken, PA., 1999.

[3] Lubrizol Corporation, Lubrizol Scuffing BOCLE, http://www.lubrizol.com/referencelibrary/news, Lubrizol Corporation, 2000.

[4] Rabinowicz, Ernest, Friction and Wear of Materials, John Wiley \& Sons, Inc., New York, 1995, pgs 239-250.

[5] Teck Cominco LTD, "Continuous Galvanizing Line (CGL) Submerged Hardware Research," Oct 1996.

[6] Teck Cominco LTD, “Study of Hydrodynamic Bearing Operation with Cominco's Full Journal Bearing Test Rig," Nov 1999.

[7] H. Zoz, H.U. Benz, K. Huttebraucker, L. Furken, H. Ren, R. Reichardt, "Stellite bearings for liquid Zn-/Al-system with advanced chemical and physical properties by MA," Metall 54, Jahigang, Nov 2000.

[8] B.G. Seong, S.Y. Hwang, M.C. Kim, K.Y. Kim, "Reaction of WC-Co coating with molten zinc in a zinc pot of a continuous galvanizing line," Surface and Coatings Technology, 138 (2001) 101-110.

[9] F.M. White, Viscous Fluid Flow $2^{\text {nd }}$ edition, McGraw-Hill, 1991

[10] Oberg, Eric and Jones, F. D., Machinery's Handbook, $16^{\text {th }}$ Edition, The Industrial Press, New York, NY, 1962, pg 509.

[11] Avallone, E. and Baumeister III, T. Mark's Standard Handbook for Mechanical Engineers, Ninth Edition, McGraw-Hill, Inc., New York, NY, 1987, pg 3-26.

[12] El-Madg, M.A. Shaker, R. Hechor, A.E. Nasser, Mechanical Behavior of Stellite 6 Produced by Powder. Metallurgicaly Process, $6^{\text {th }}$ Int. Conf. on Mechanical Design and Production (mpd-6). Cairo, Egypt. 1996. 


\section{Appendix A Viscous Drag on Cup}

The spindle of radius $r_{1}$, containing the ball, is submerged a distance $h$ inch deep into the liquid zinc inside a stationary cup of radius $r_{2}$. When the spindle rotates at $\omega$ $\mathrm{rad} / \mathrm{s}$, its wall shear stress sets the liquid inside the cup spinning. This fluid rotation exerts a wall shear stress $\tau_{\text {wall }}$ on the cup. This multiplied by the cup wetted area $A_{\text {wall }}=2 \pi \mathrm{r}_{2} \mathrm{~h}$ gives the wall shear force on the cup. The resulting torque $\Delta \mathrm{TQ}$ is in addition to the desired bearing friction torque. The objective here is to calculate the order of magnitude of the added torque

$$
\Delta T Q=\tau_{\text {wall }} * A_{\text {wall }} * r_{2}
$$

The viscous flow velocity field inside the cup is assumed to be only in the tangential direction, and given by $V_{\theta}$, which is the sum of an irrotational velocity component $\mathrm{C} / \mathrm{r}$ and a solid body rotational component $\omega^{*} \mathrm{r}$.

$$
V_{\theta}=\frac{C}{r}+\omega^{*} r
$$

The boundary condition at the stationary cup wall, where $r=r_{2}$, forces $V_{\theta}$ there $=$ zero.

$$
V_{\theta}=0=\frac{C}{r_{2}}+\omega^{*} r_{2} \quad \text { or } \quad C=-\omega^{*} r_{2}^{2}
$$

Insert in Eq. A.1 gives at any radius r:

$$
V_{\theta}=\frac{-\omega^{*} r_{2}^{2}}{r}+\omega^{*} r \quad \text { or } \quad \frac{V_{\theta}}{r}=\omega\left[-\left(\frac{r_{2}}{r}\right)^{2}+1\right]
$$


The Navier-Stokes equation that describes the flow field is:

$$
\tau_{r, \theta}=\mu\left[r \frac{\partial}{\partial r}\left(\frac{V_{\theta}}{r}\right)+\frac{1}{r} \frac{\partial V_{r}}{\partial \theta}\right]
$$

Inserting Eq. A.4 and neglecting the radial velocity component $\mathrm{V}_{\mathrm{r}}$ gives:

$$
\begin{gathered}
\tau_{r, \theta}=\mu\left[r \frac{\partial}{\partial r}\left(\omega\left[-\left(\frac{r_{2}}{r}\right)^{2}+1\right]\right)\right] \\
\tau_{r, \theta}=\mu * r * \omega\left(\frac{2 r_{2}^{2}}{r^{3}}\right)=2 \mu * \omega\left(\frac{r_{2}}{r}\right)^{2}
\end{gathered}
$$

Note at the cup wall where $r=r_{2}$, the shear stress simplifies to

$$
\tau_{\text {wall }}=2 \mu * \omega
$$

Or the shear force on the cup wall is

$$
\Delta T Q=F_{\text {wall }} r_{2}=\tau_{\text {wall }} A_{\text {wall }} r_{2}=4 \mu^{*} \omega^{*} \pi r_{2} h
$$

When the viscosity of zinc equals that of water at $\mu=2 * 10^{-5} \mathrm{lb}_{\mathrm{f}} \cdot \mathrm{s} / \mathrm{ft}^{2}$ and $\omega=100 \mathrm{rad} / \mathrm{s}$, cup radius $r_{2}=1.5$ inch and $h=1$ inch, then added torque on cup due to viscous shear is

$$
\Delta T Q=4 * 2 * 10^{-5} * 100 \frac{\pi 1.5^{2}\left(f t^{2}\right)}{144} 1(\text { inch })=4 * 10^{-4}\left(\text { inch.lb }_{f}\right)
$$




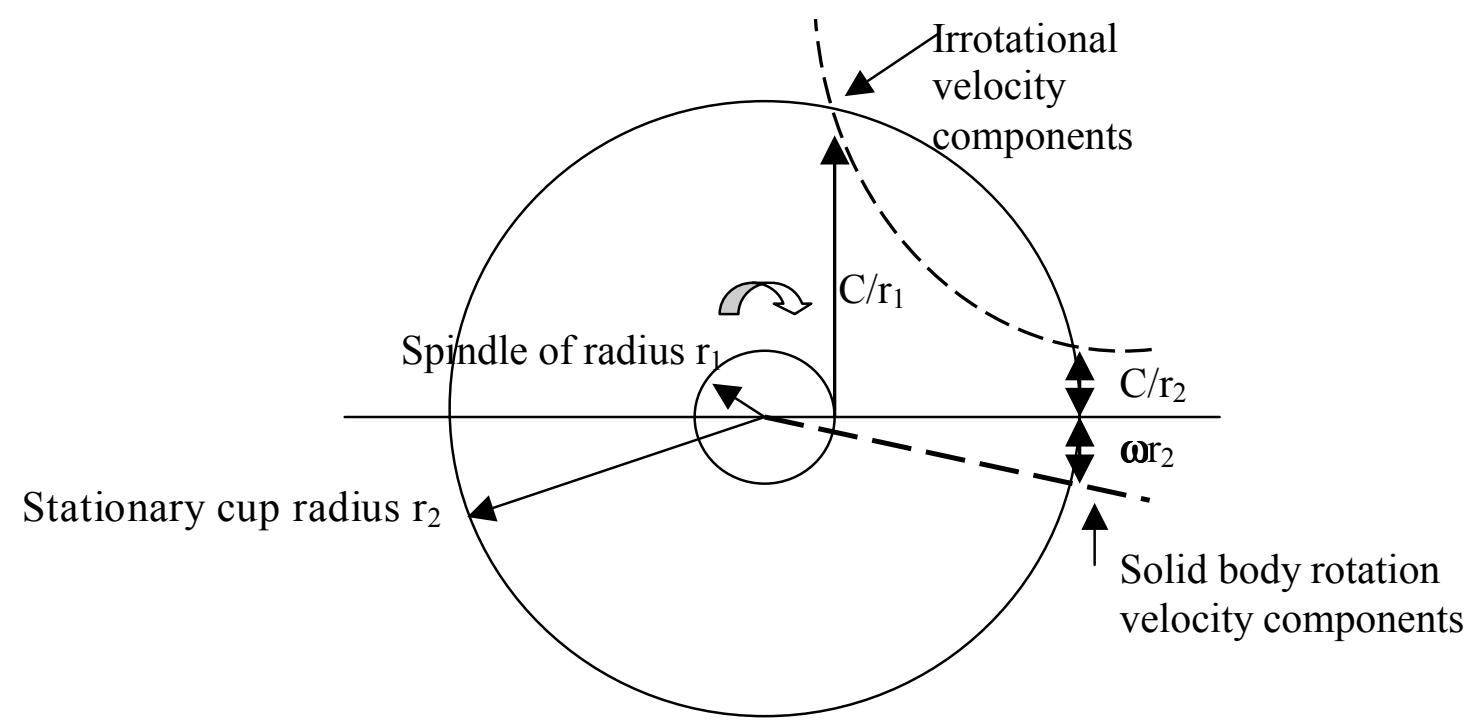

Figure A.1 Schematic of viscous effects on the cup 


\section{Appendix B Drawings of Test Apparatus}

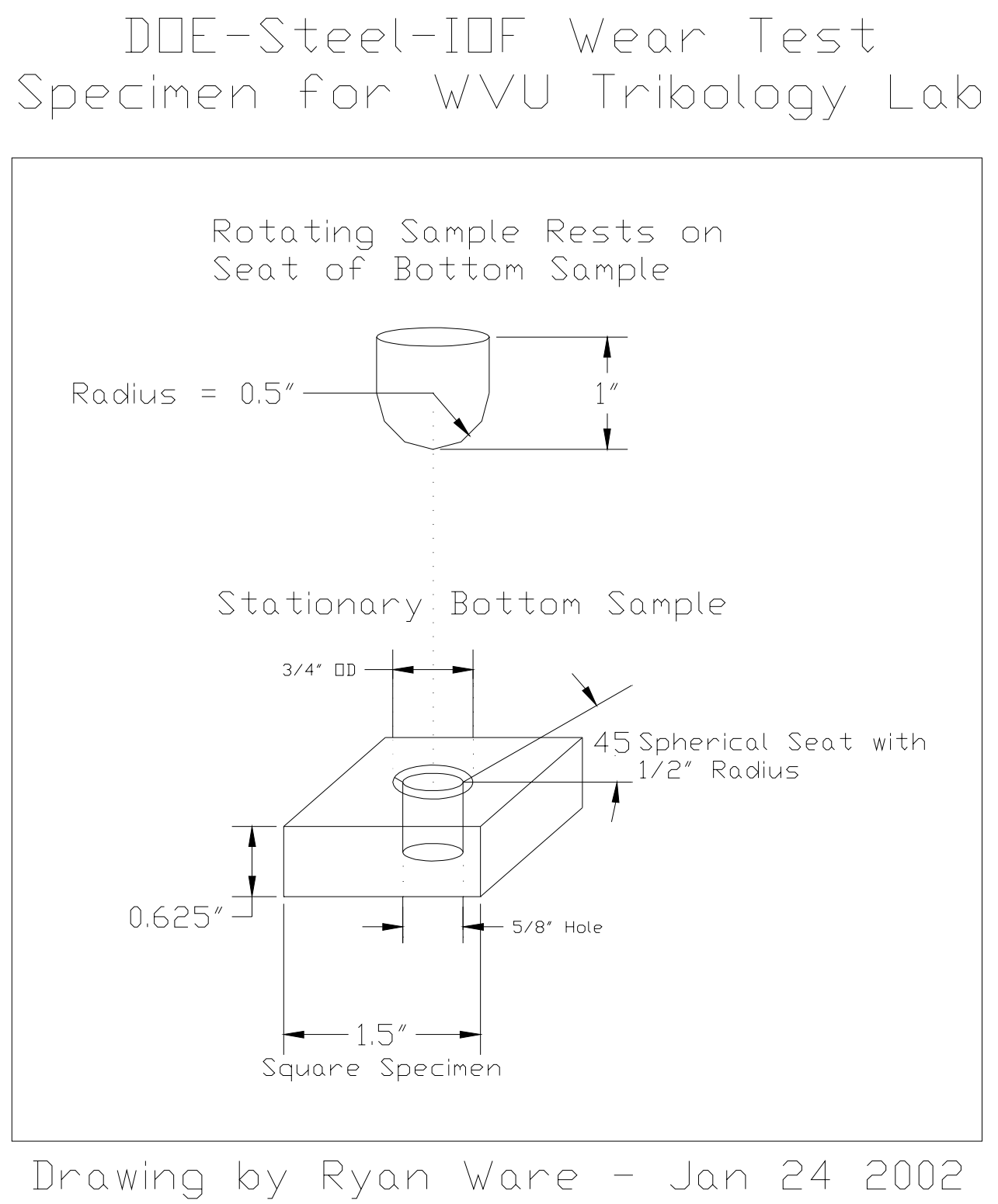

Figure B.1: Ball and seat AutoCAD drawings 


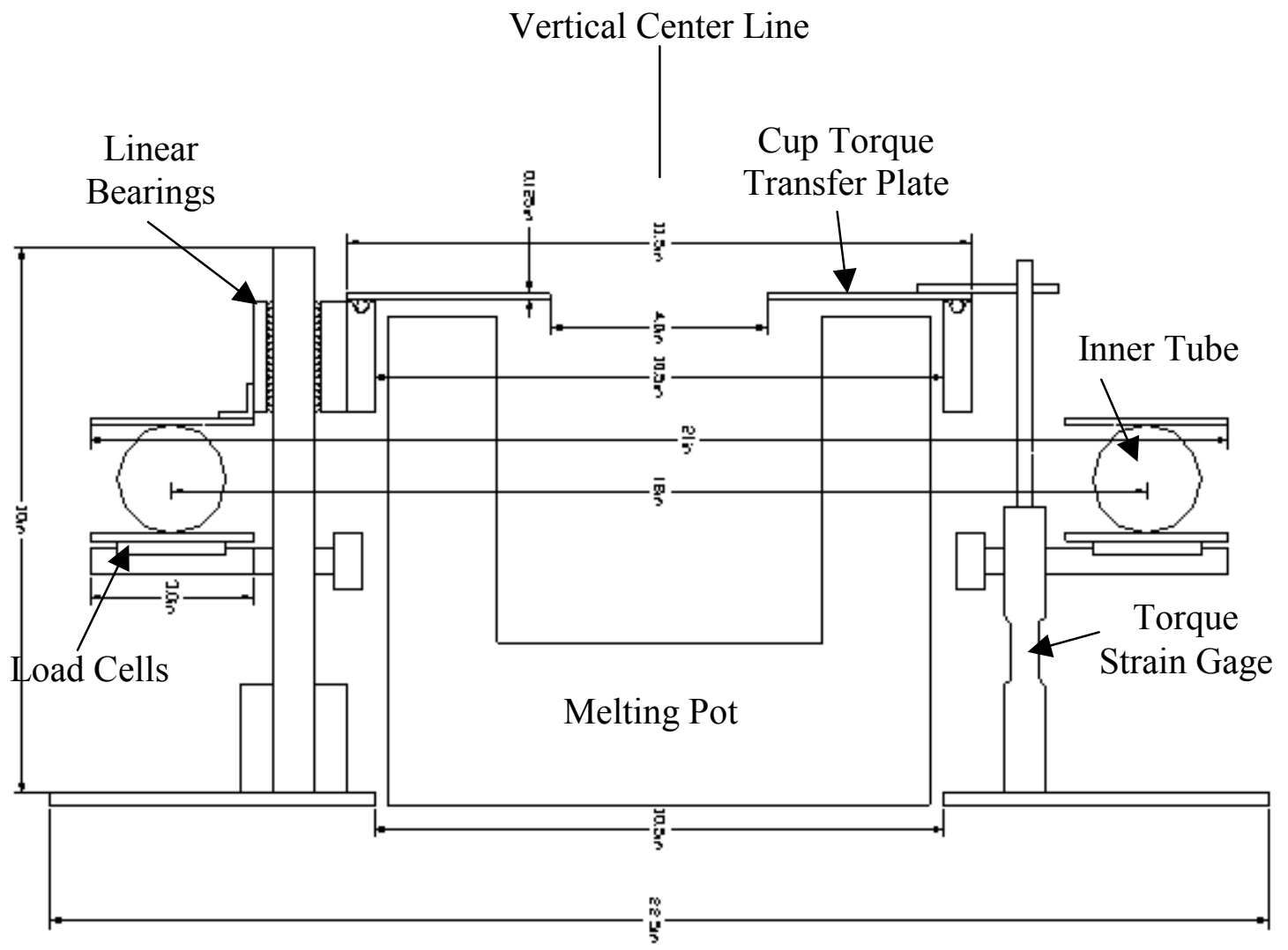

Figure B.2: Bearing track assembly dimensions 


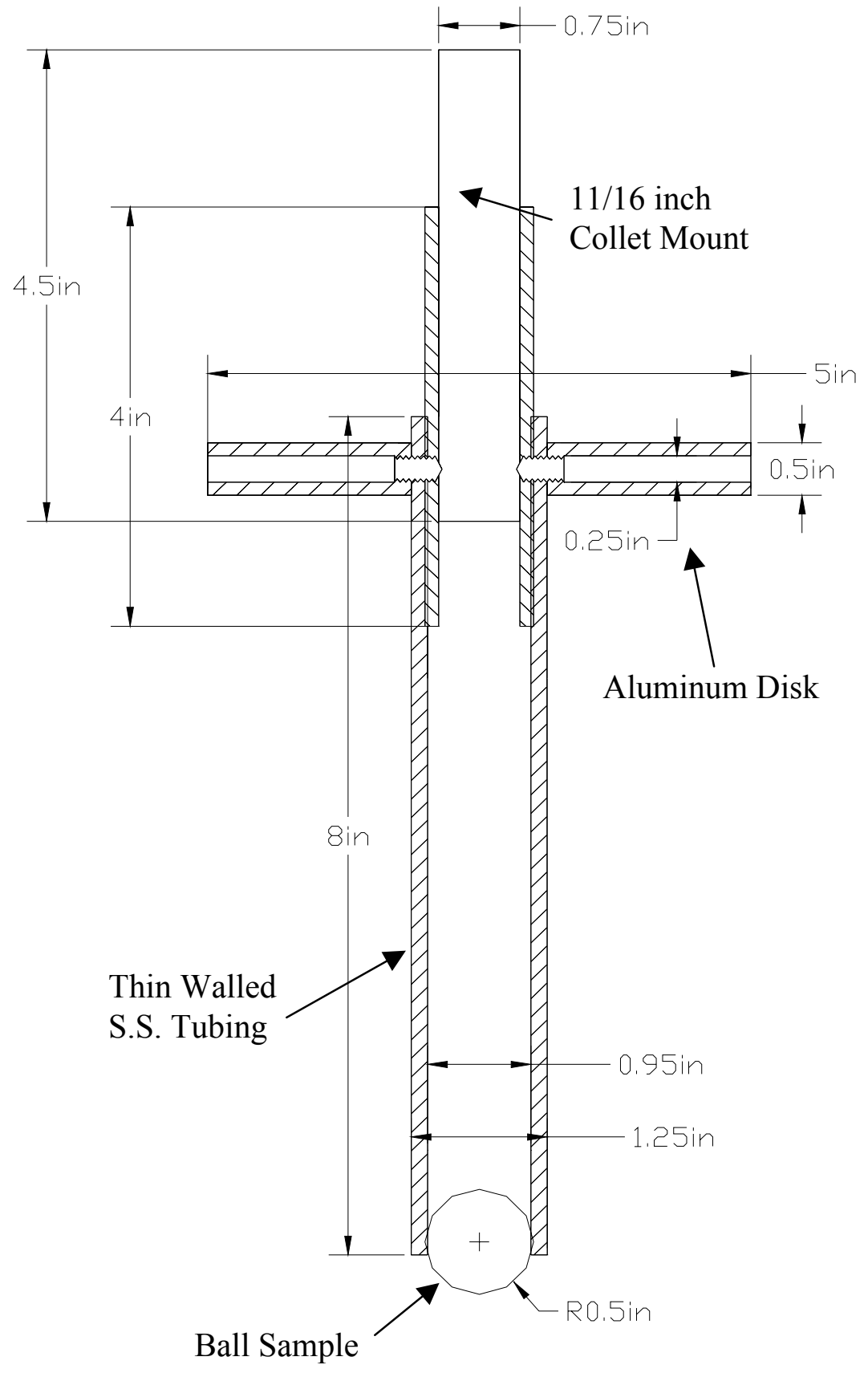

Figure B.3: Rotating spindle dimensions 


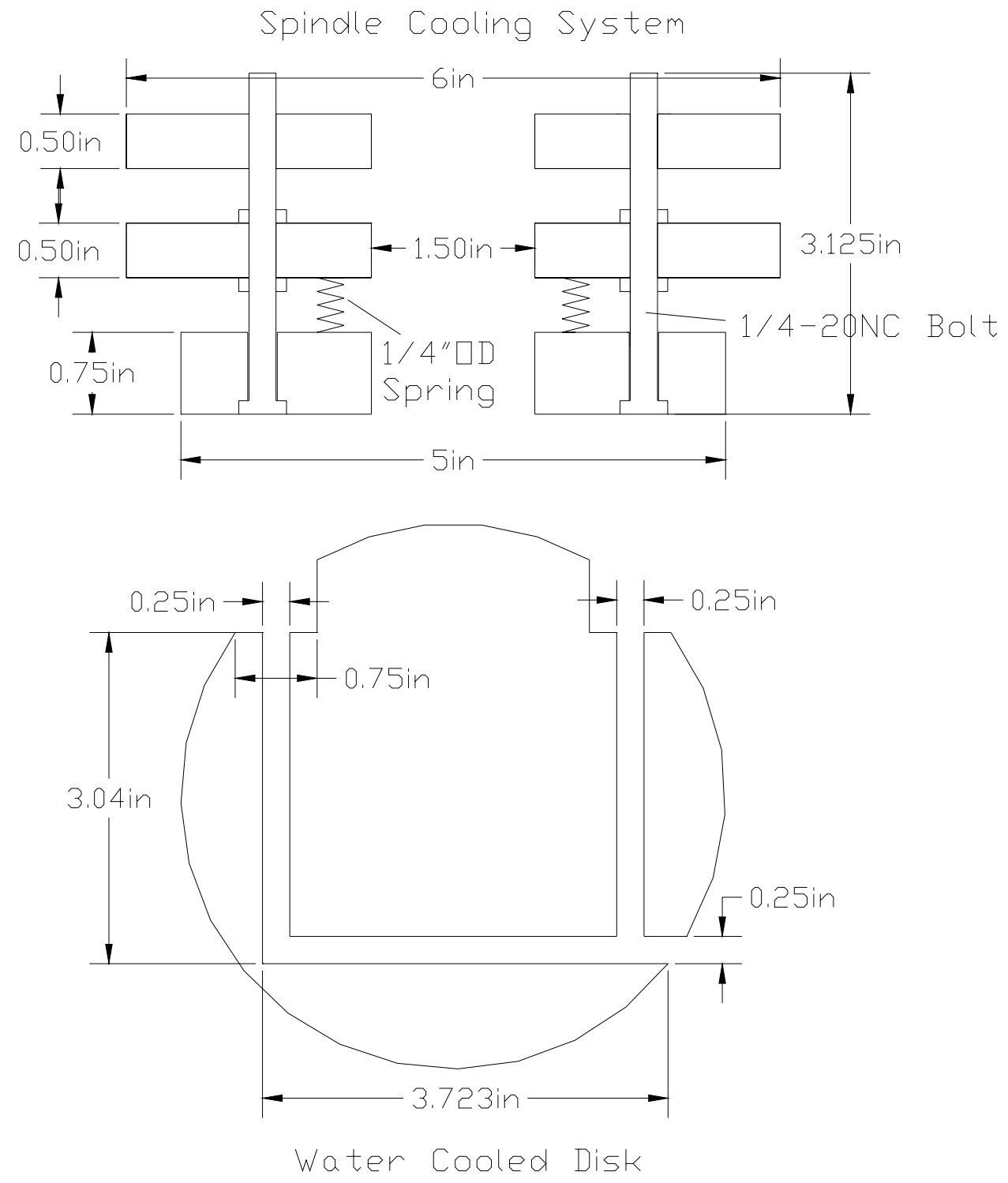

Figure B.4: Water cooled spindle system 


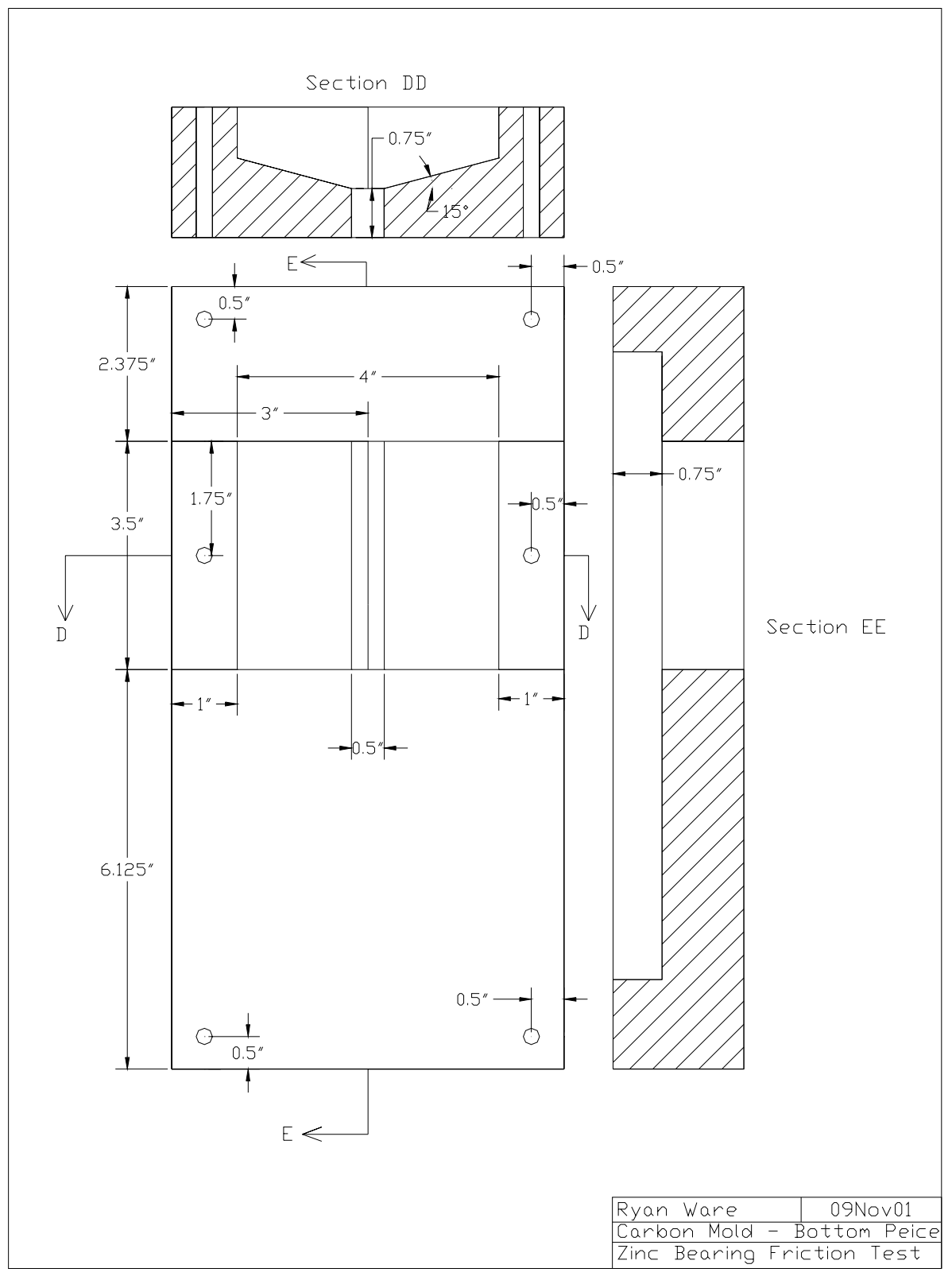

Figure B.5: Carbon mold bottom piece, top view 


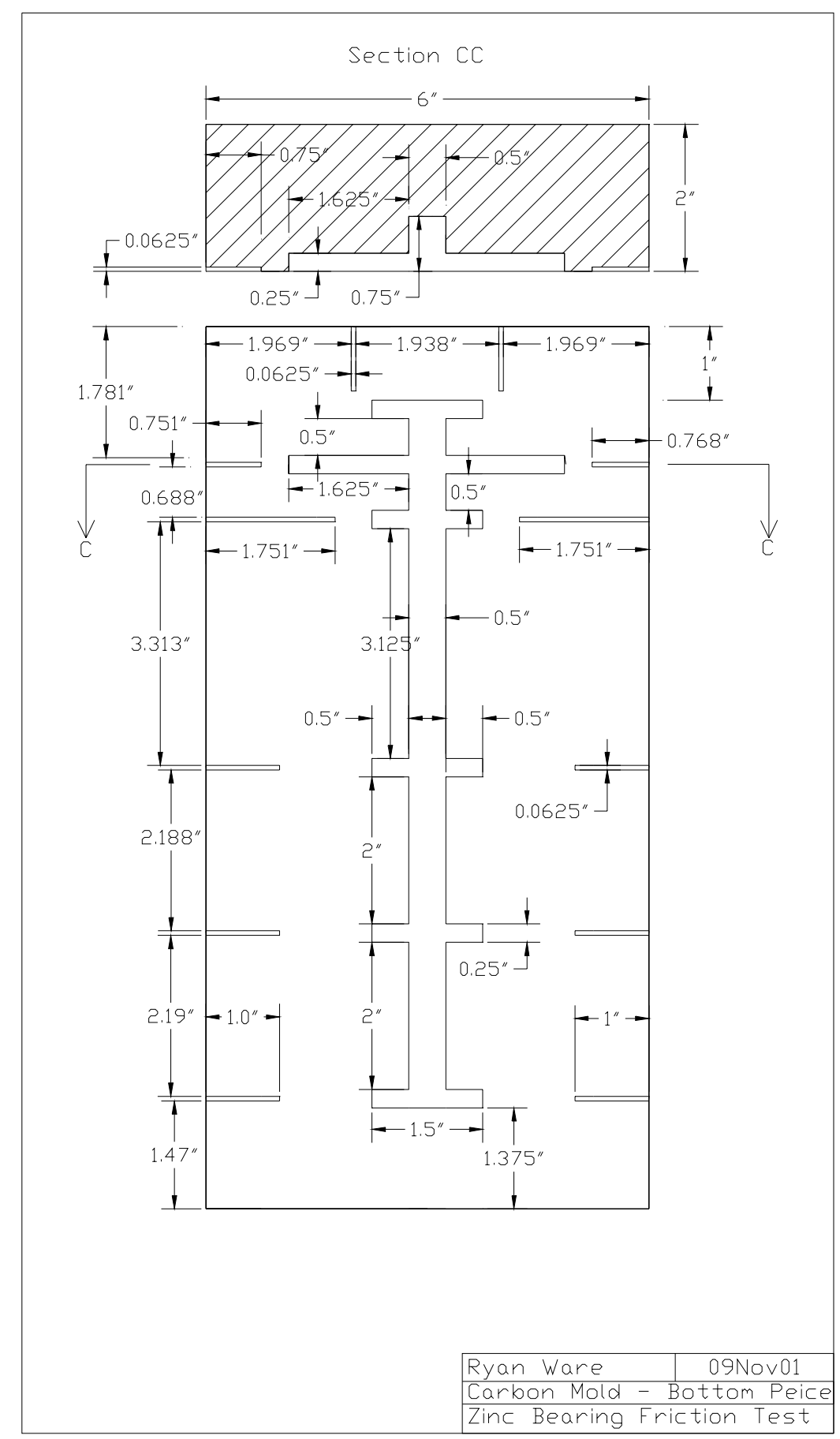

Figure B.6: Carbon mold bottom piece, bottom view 


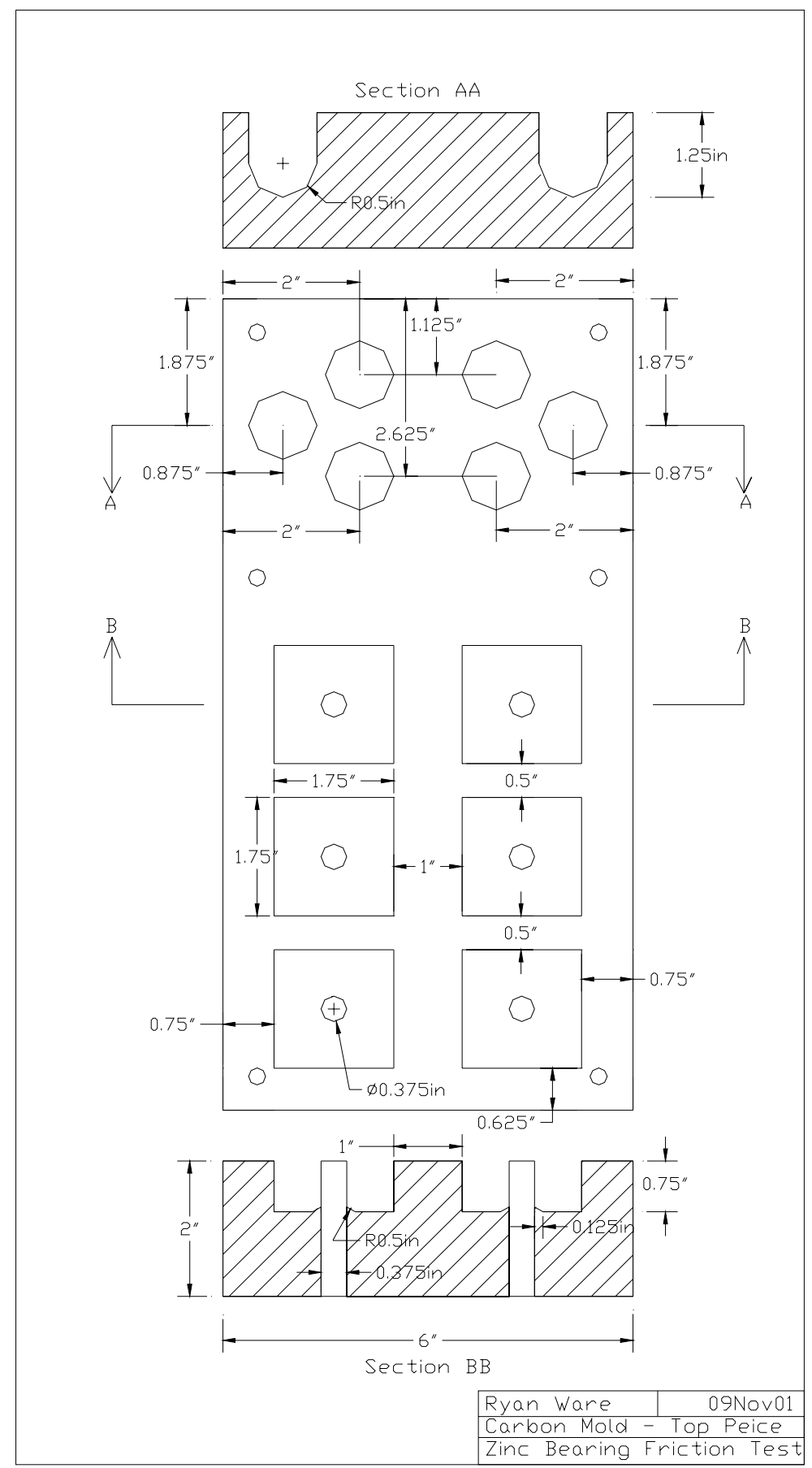

Figure B.7: Carbon mold top view 


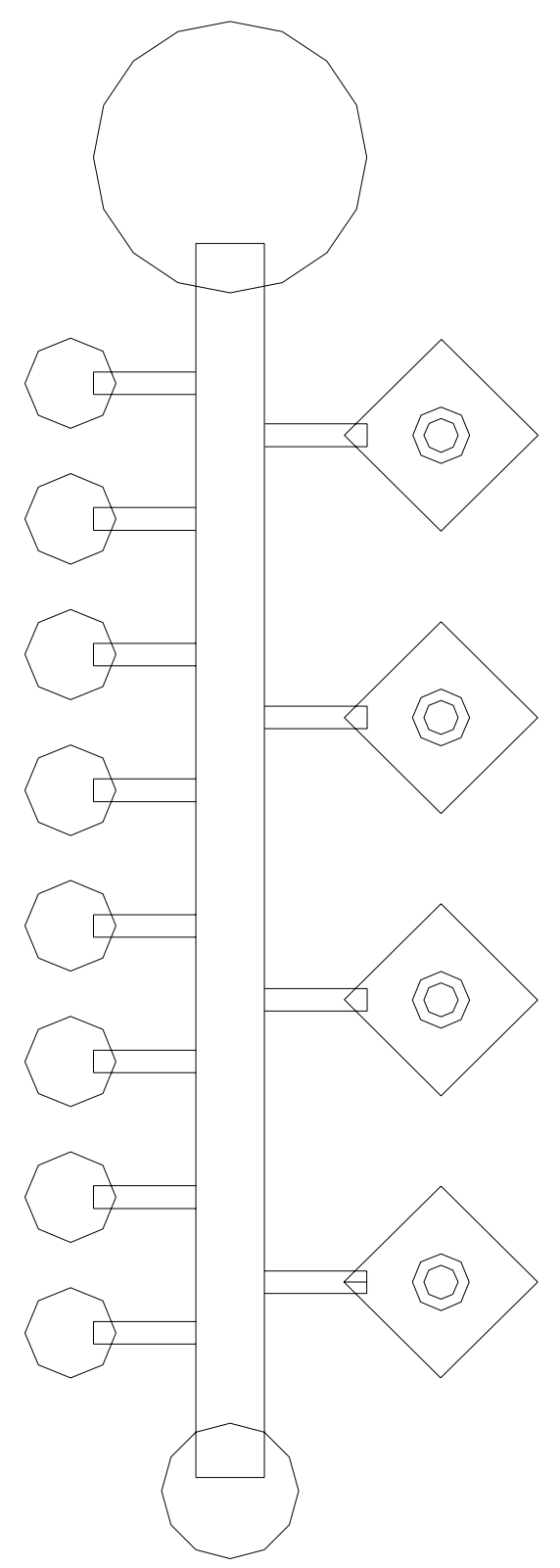

Figure B.8: Layout of cope and drag sand casting technique 

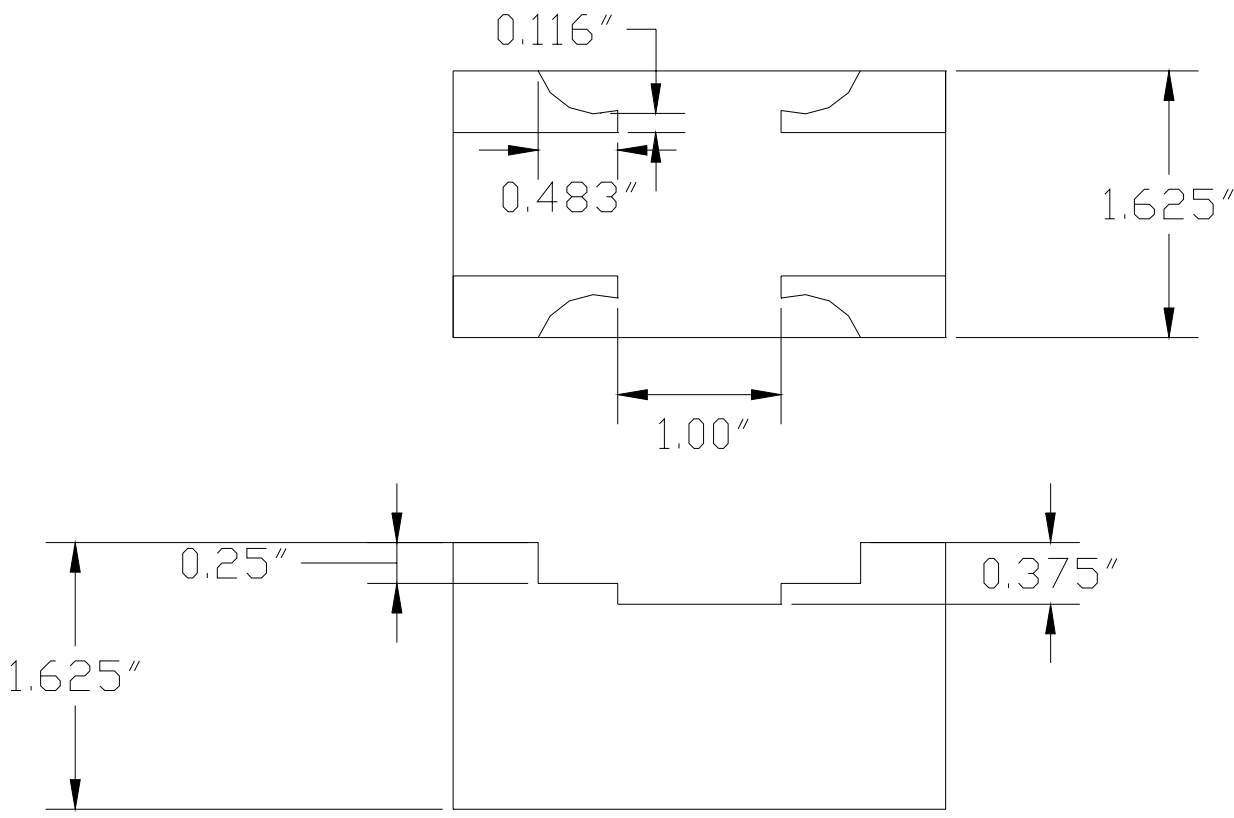

Figure B.9: Channel clamp for cup and specimen

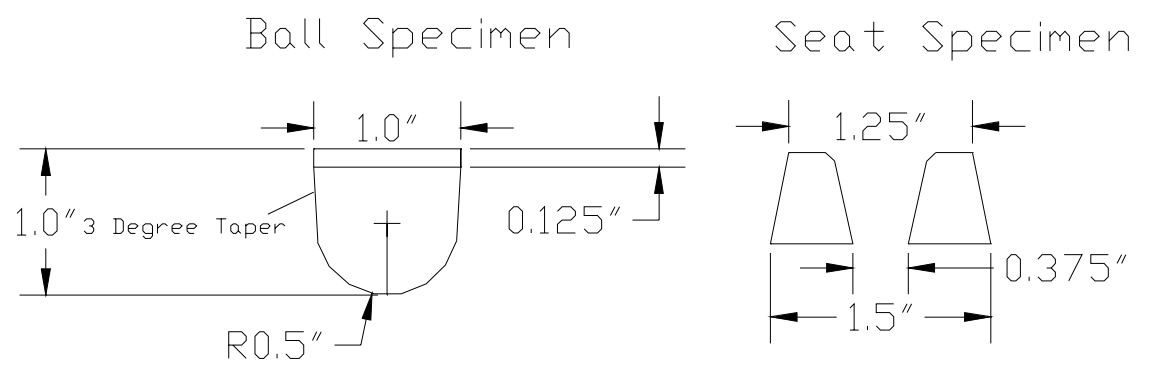

Figure B.10: Tapered ball and seat specimen for sand casting 


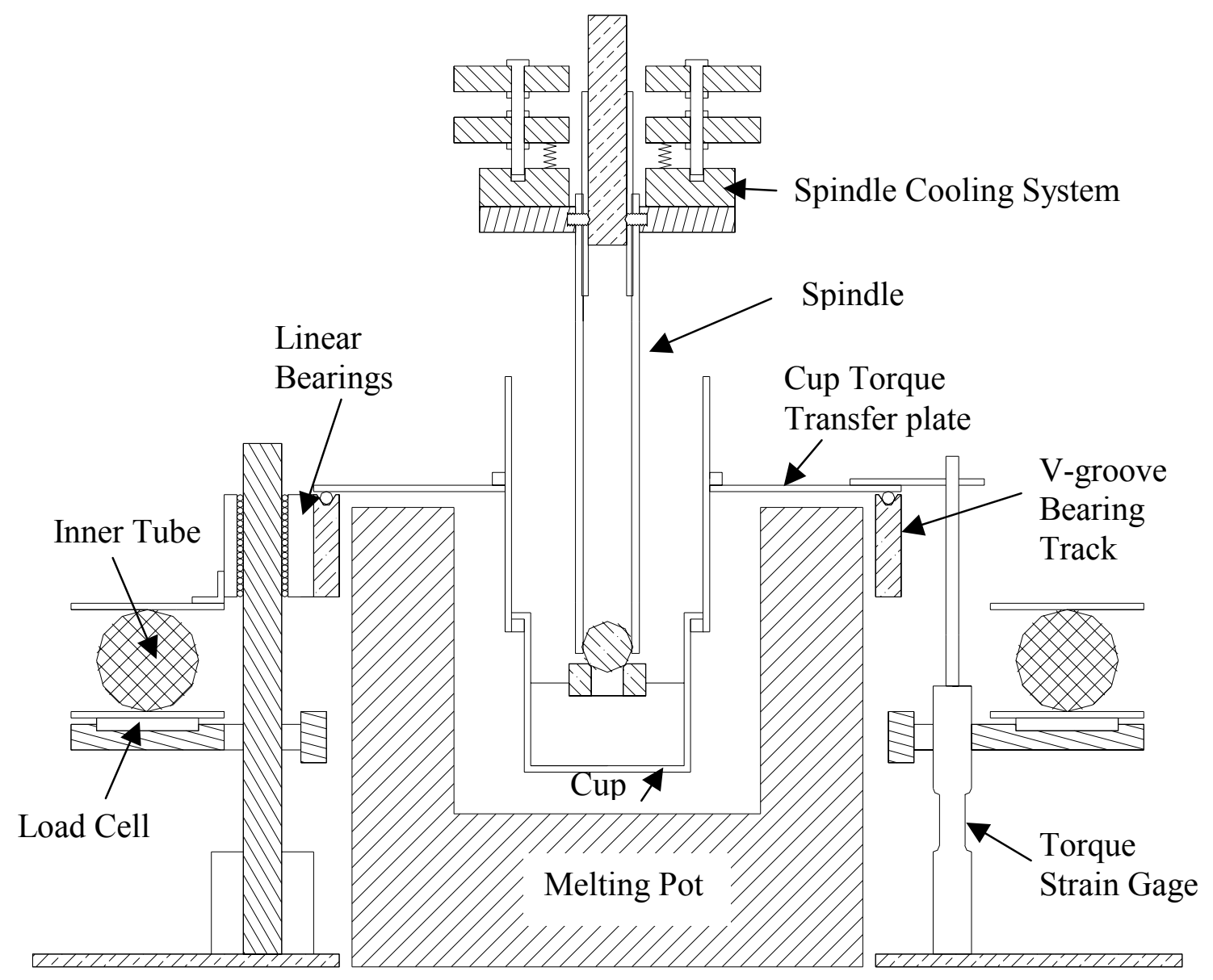

Figure B.11: Friction coefficient testing apparatus 
Appendix C: Preliminary Water Test Data 


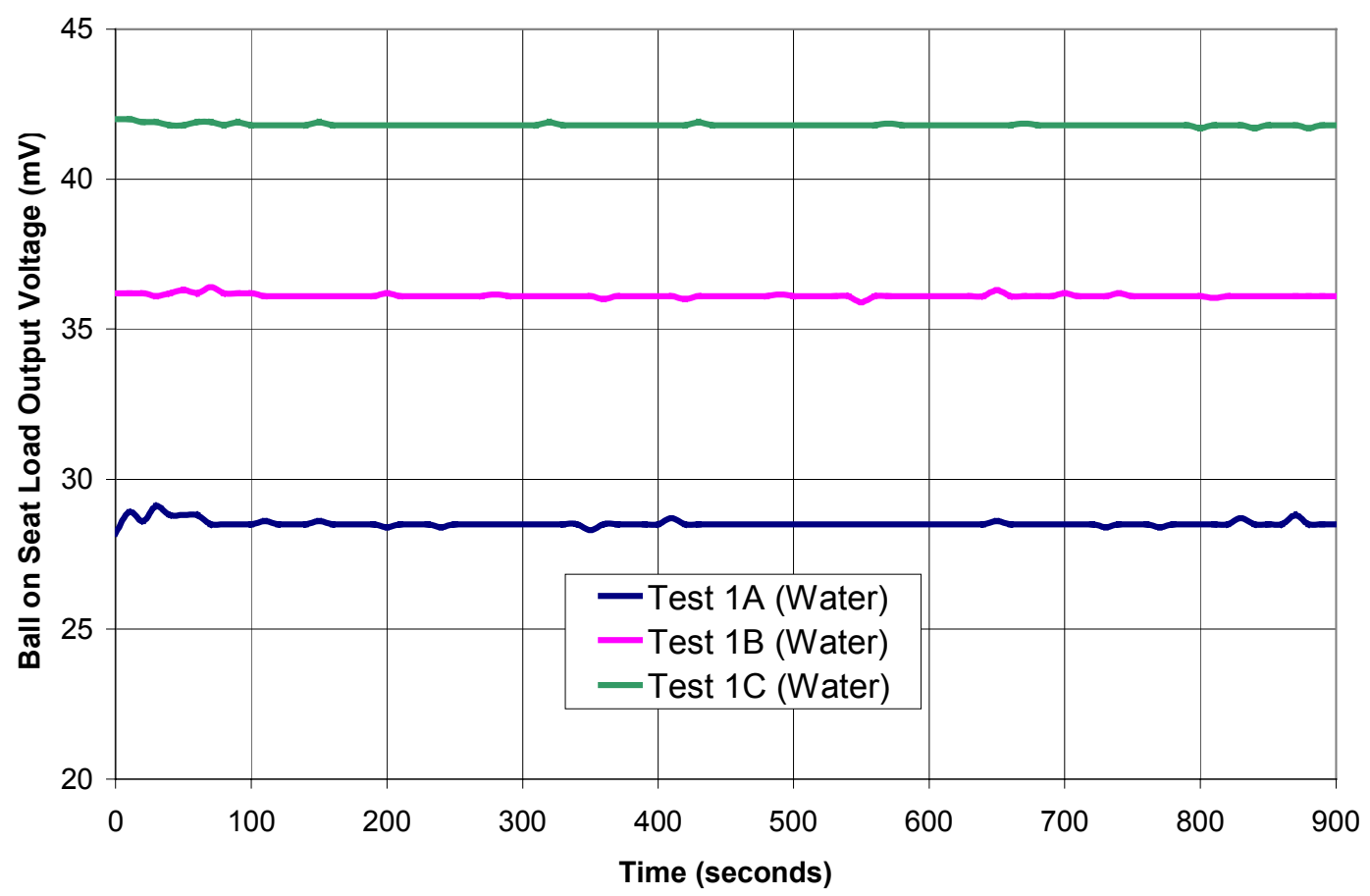

Figure C.1: Ball/seat load output voltage as a function of time in preliminary water test.

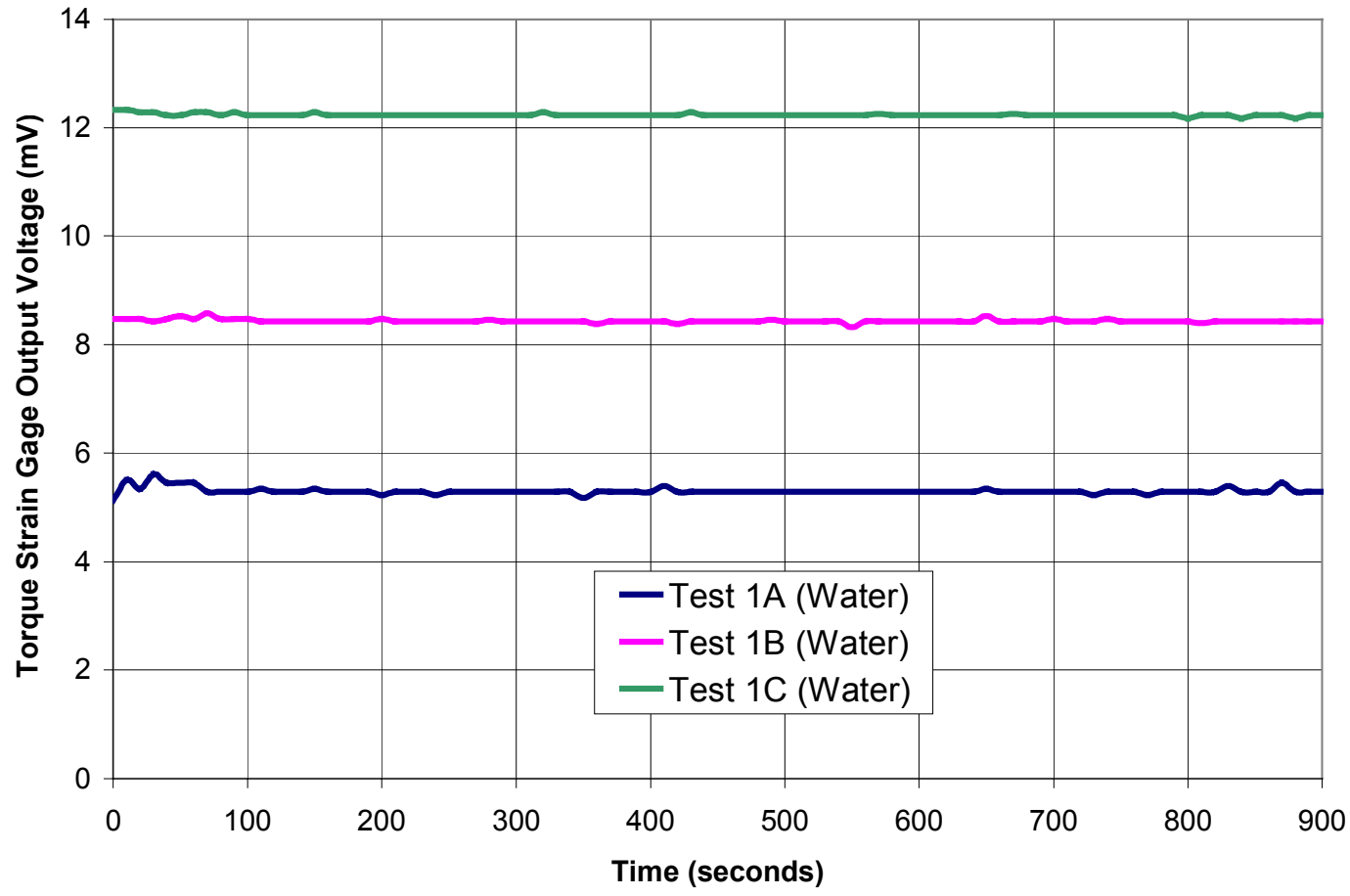

Figure C.2: Torque strain gage output voltage as a function of time in preliminary water test. 


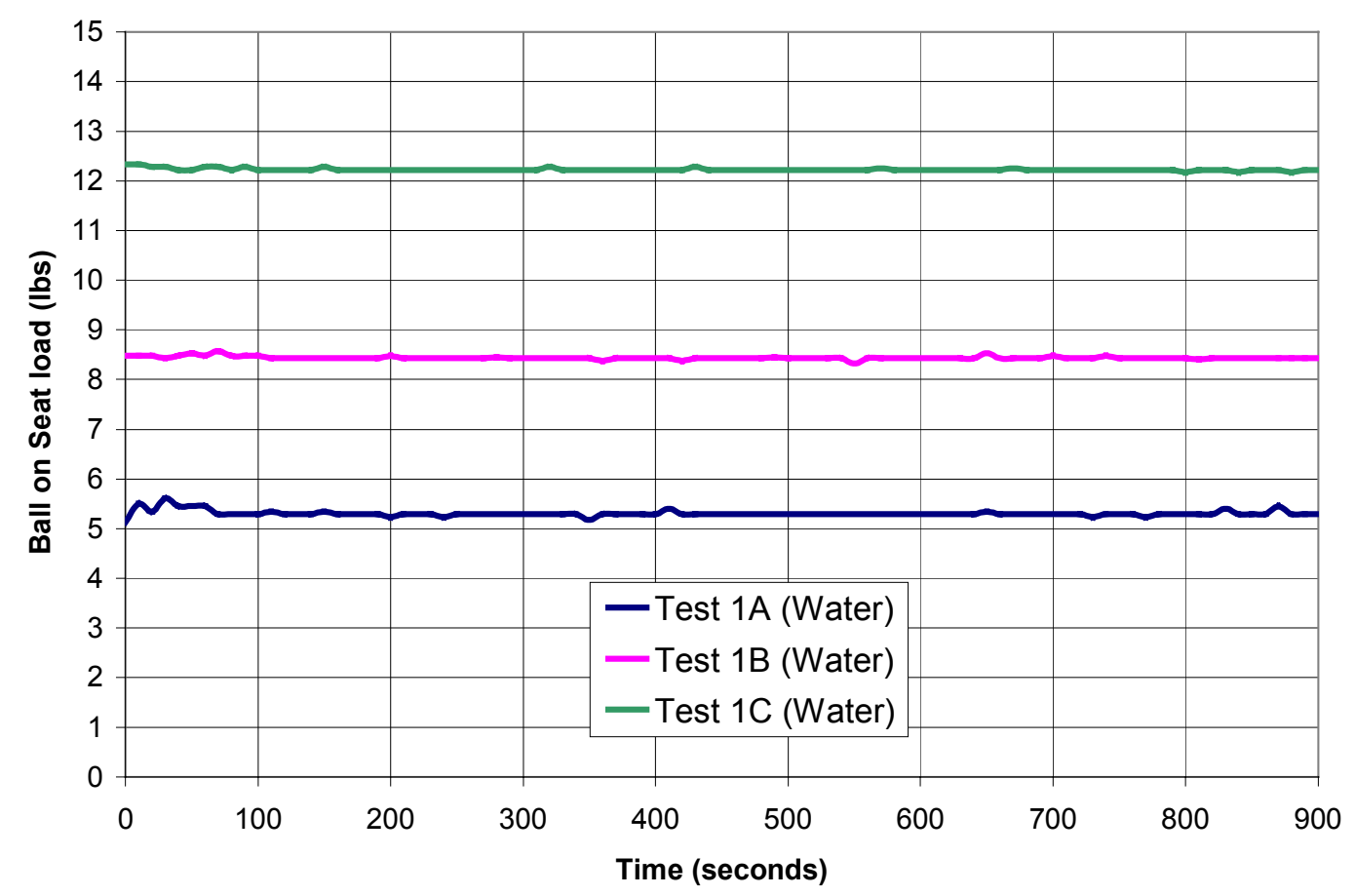

Figure C.3: Ball/seat load as a function of time in preliminary water test.

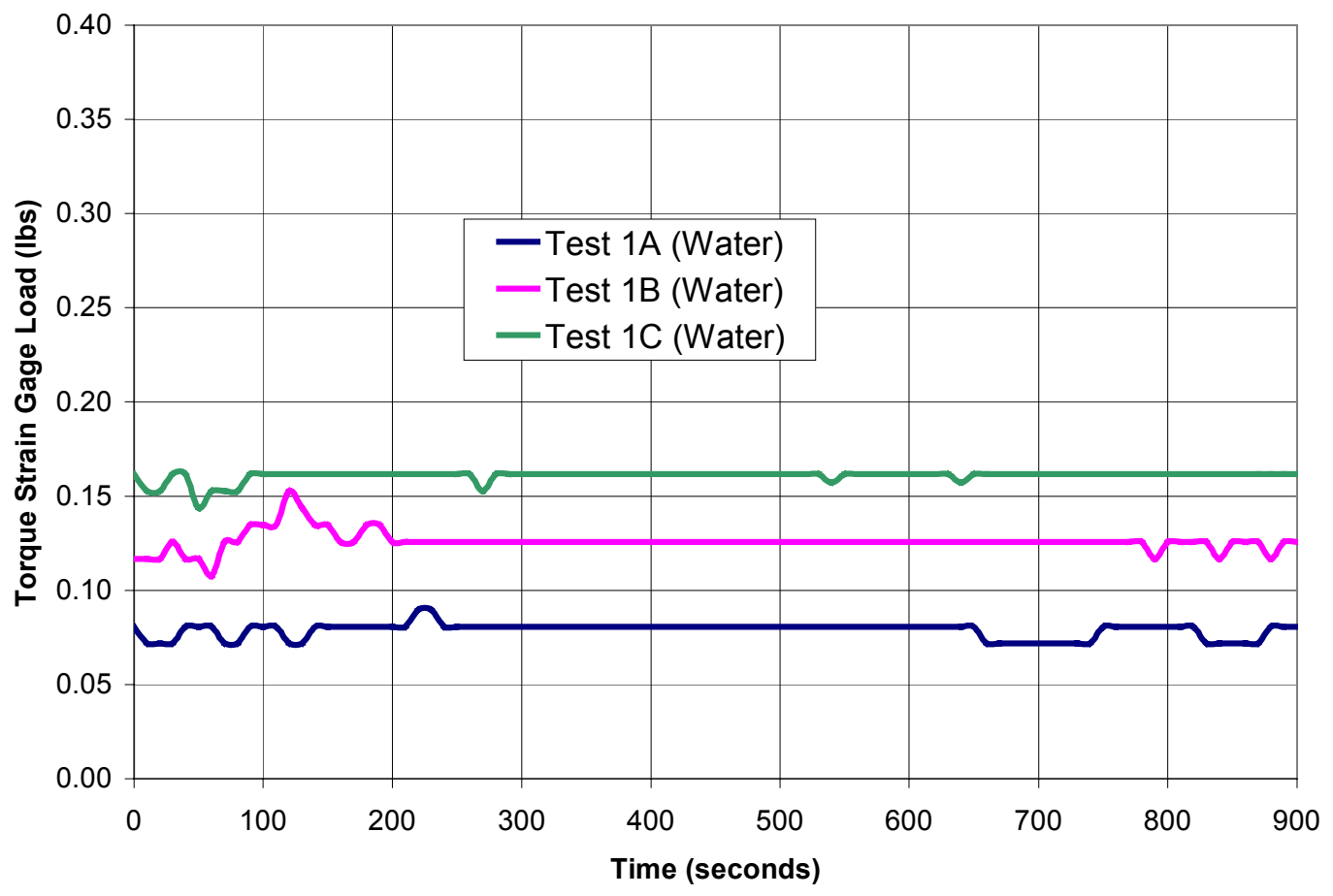

Figure C.4: Torque strain gage load as a function of time in preliminary water test. 


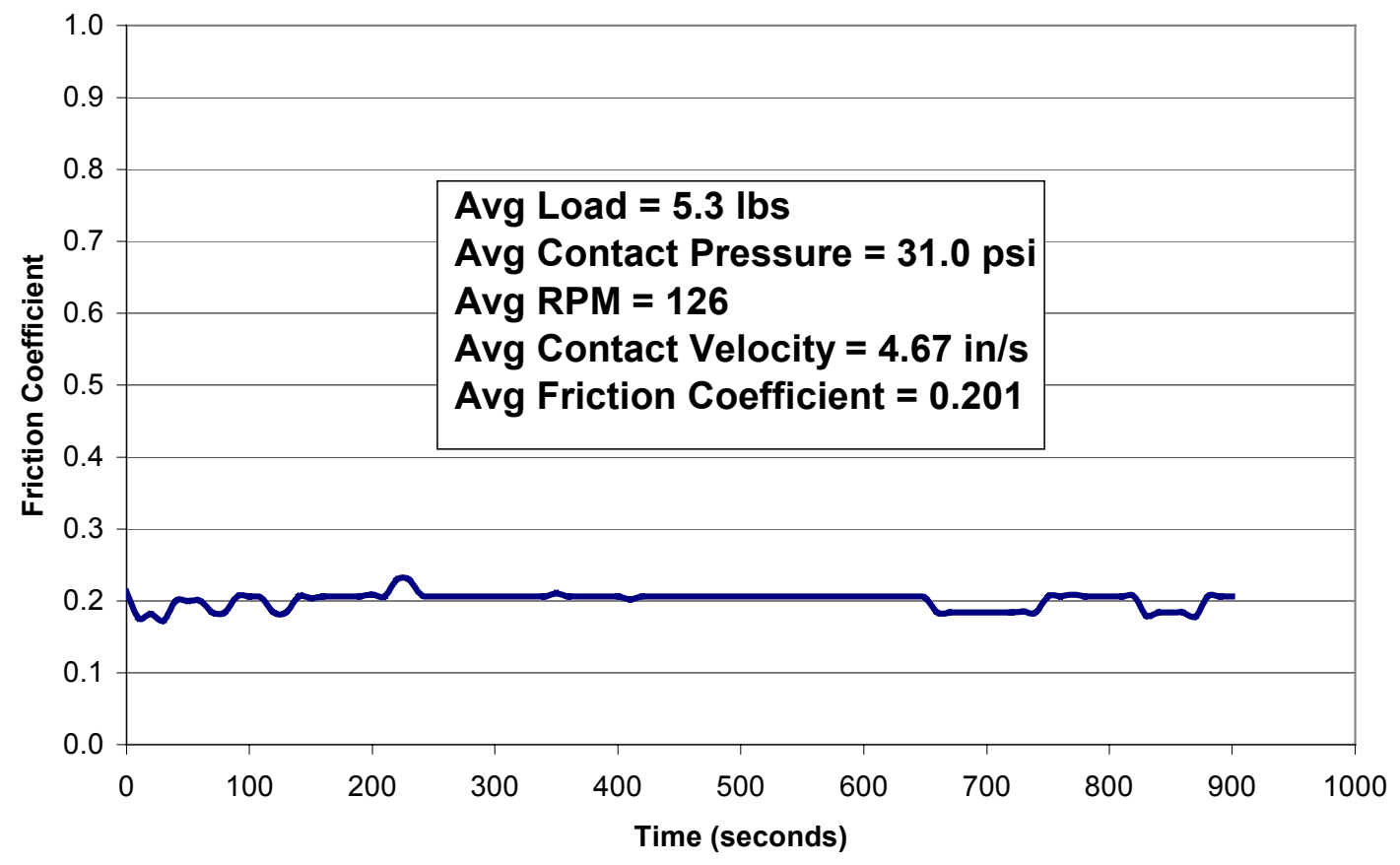

Figure C.5: Zinc pot bearing material friction coefficient as a function of time, for test $1 \mathrm{~A}$ in preliminary water test.

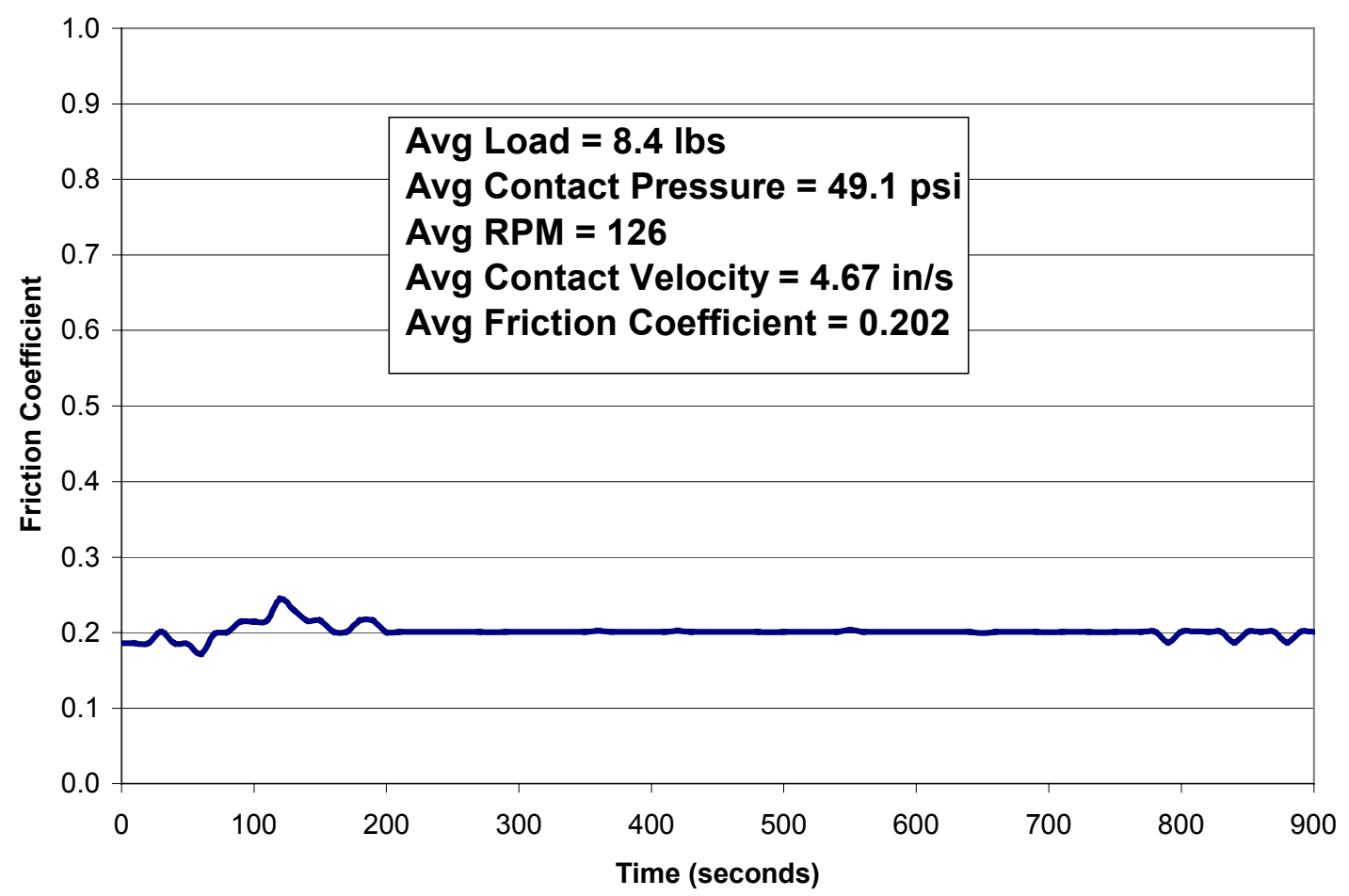

Figure C.6: Zinc pot bearing material friction coefficient as a function of time, for test $1 B$ in preliminary water test. 


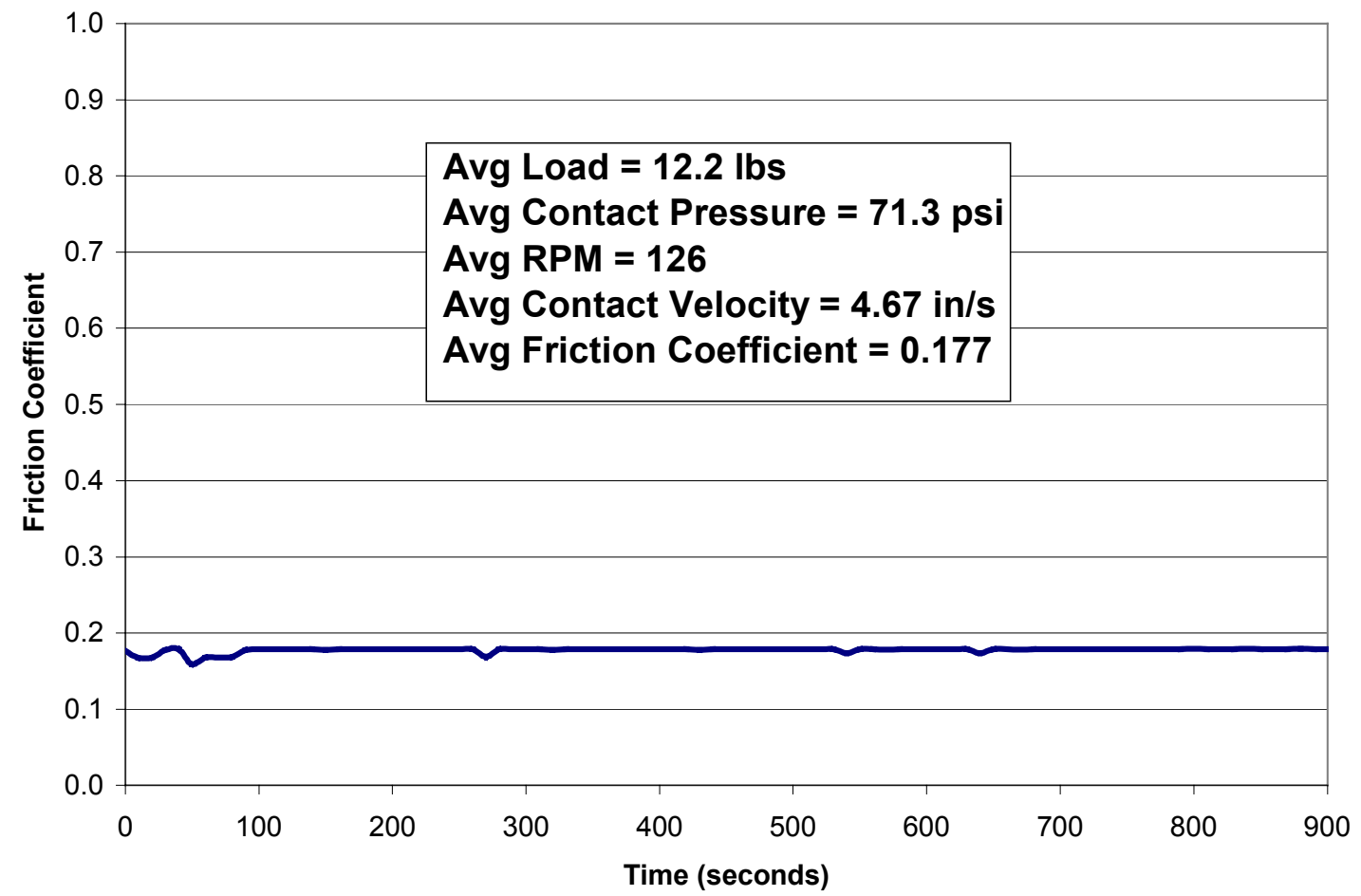

Figure C.7: Zinc pot bearing material friction coefficient as a function of time, for test $1 \mathrm{C}$ in preliminary water te 
Appendix D: Raw Test Data Hot Zinc Pot Tests 


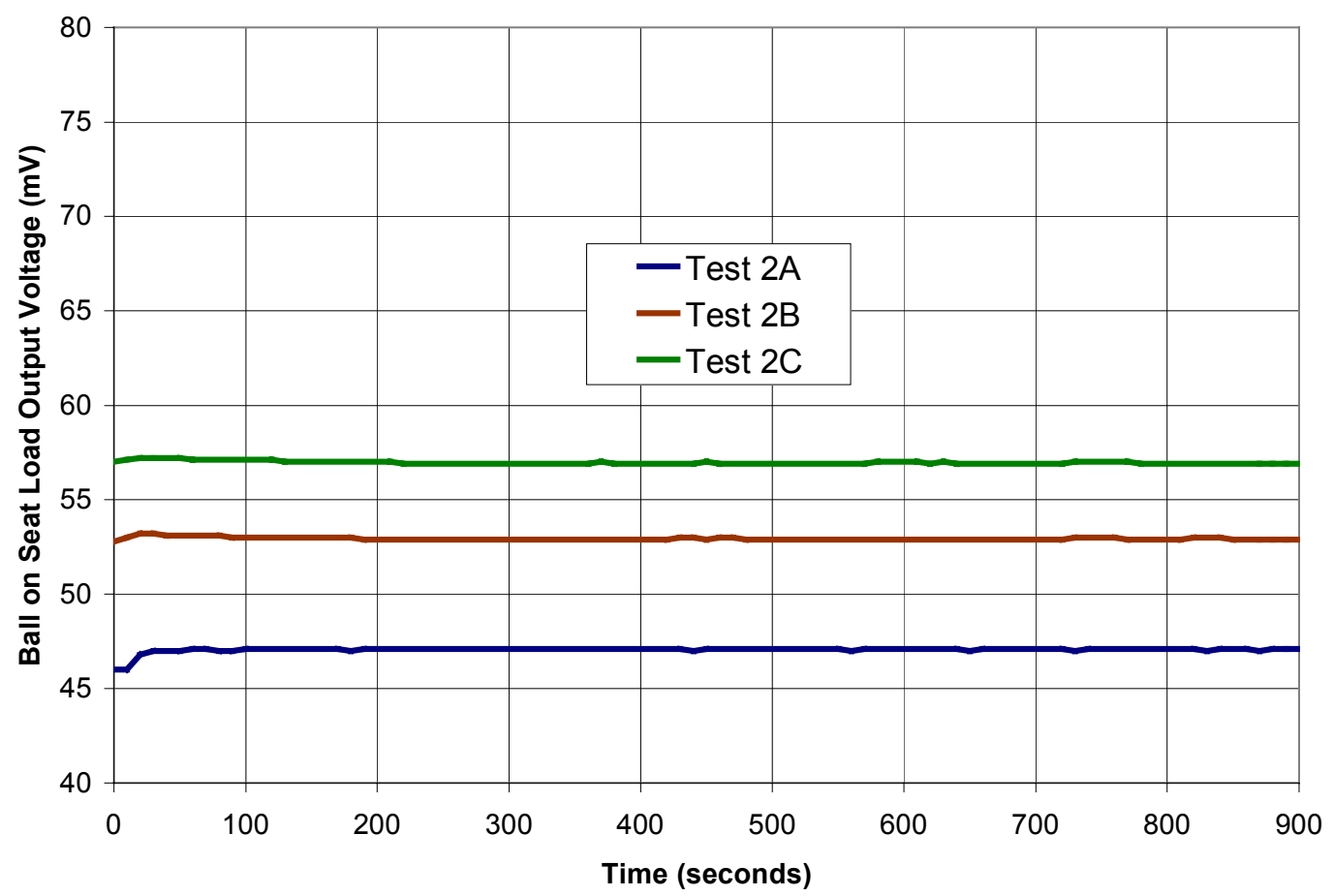

Figure D.1: Ball/seat load output voltage as a function of time in hot zinc test 2A, $2 B$, and $2 C$.

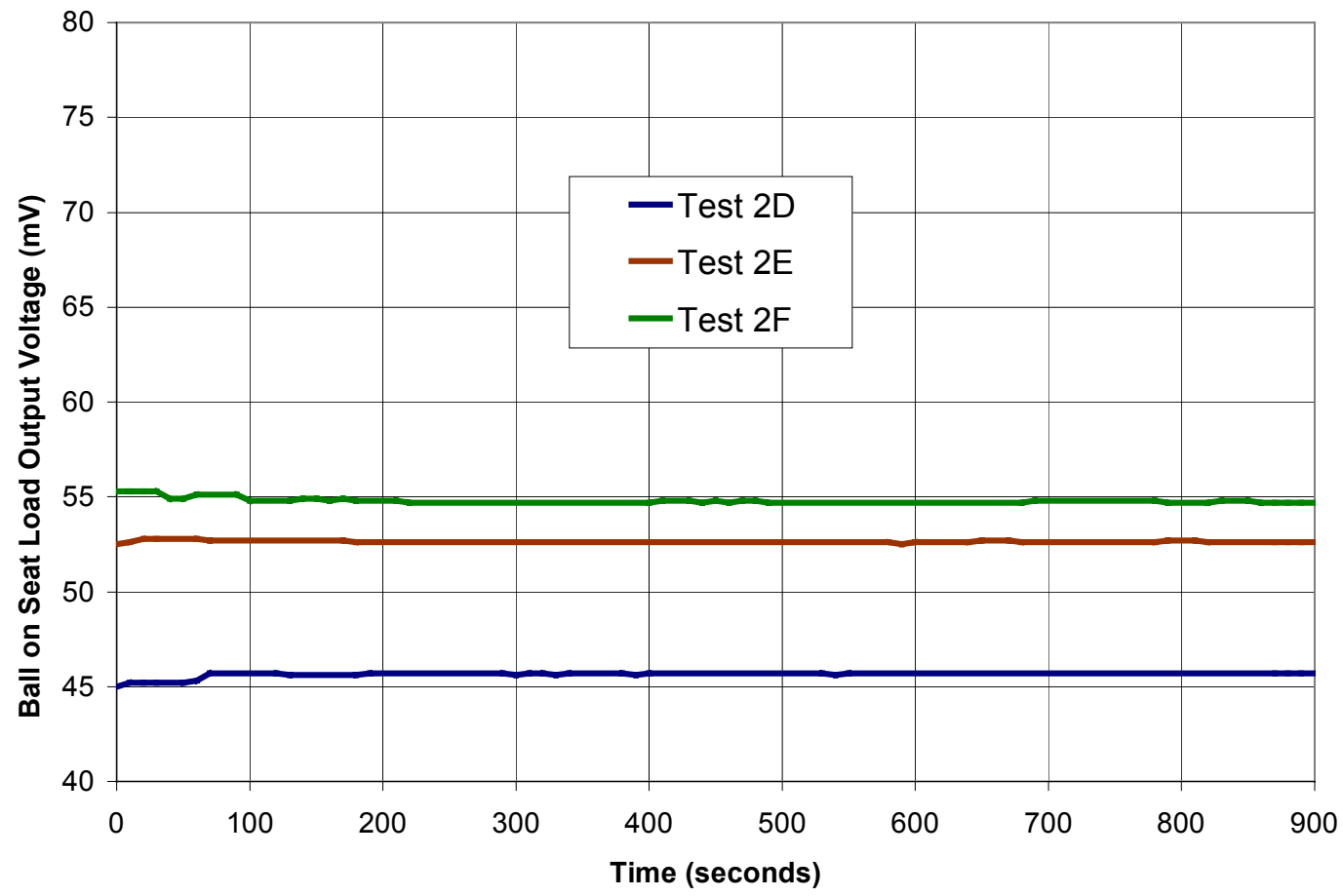

Figure D.2: Ball/seat load output voltage as a function of time in hot zinc test 2D, 2E, and $2 \mathrm{~F}$. 


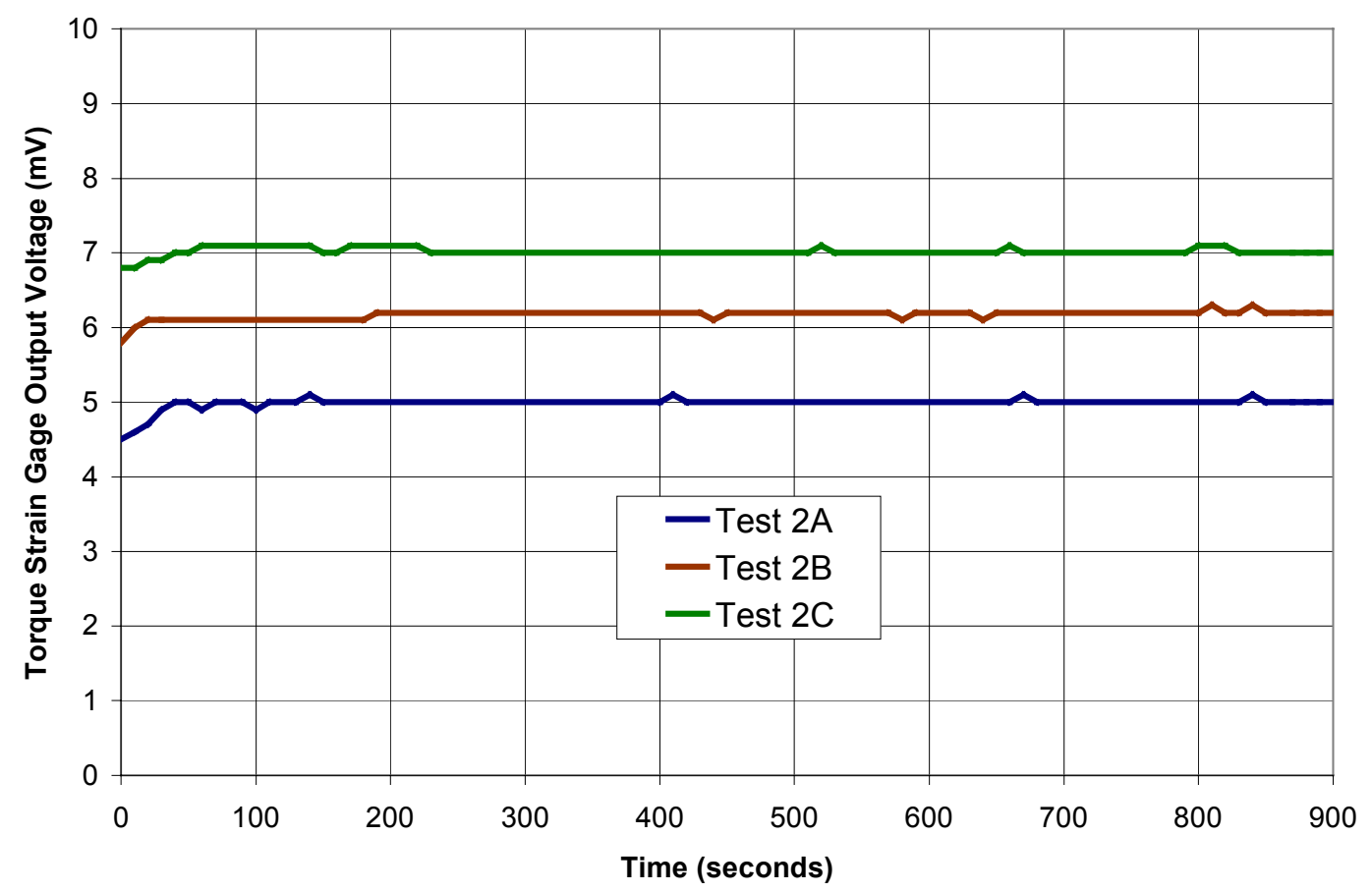

Figure D.3: Torque strain gage output voltage as a function of time in hot zinc test $2 \mathrm{~A}, 2 \mathrm{~B}$, and $2 \mathrm{C}$.

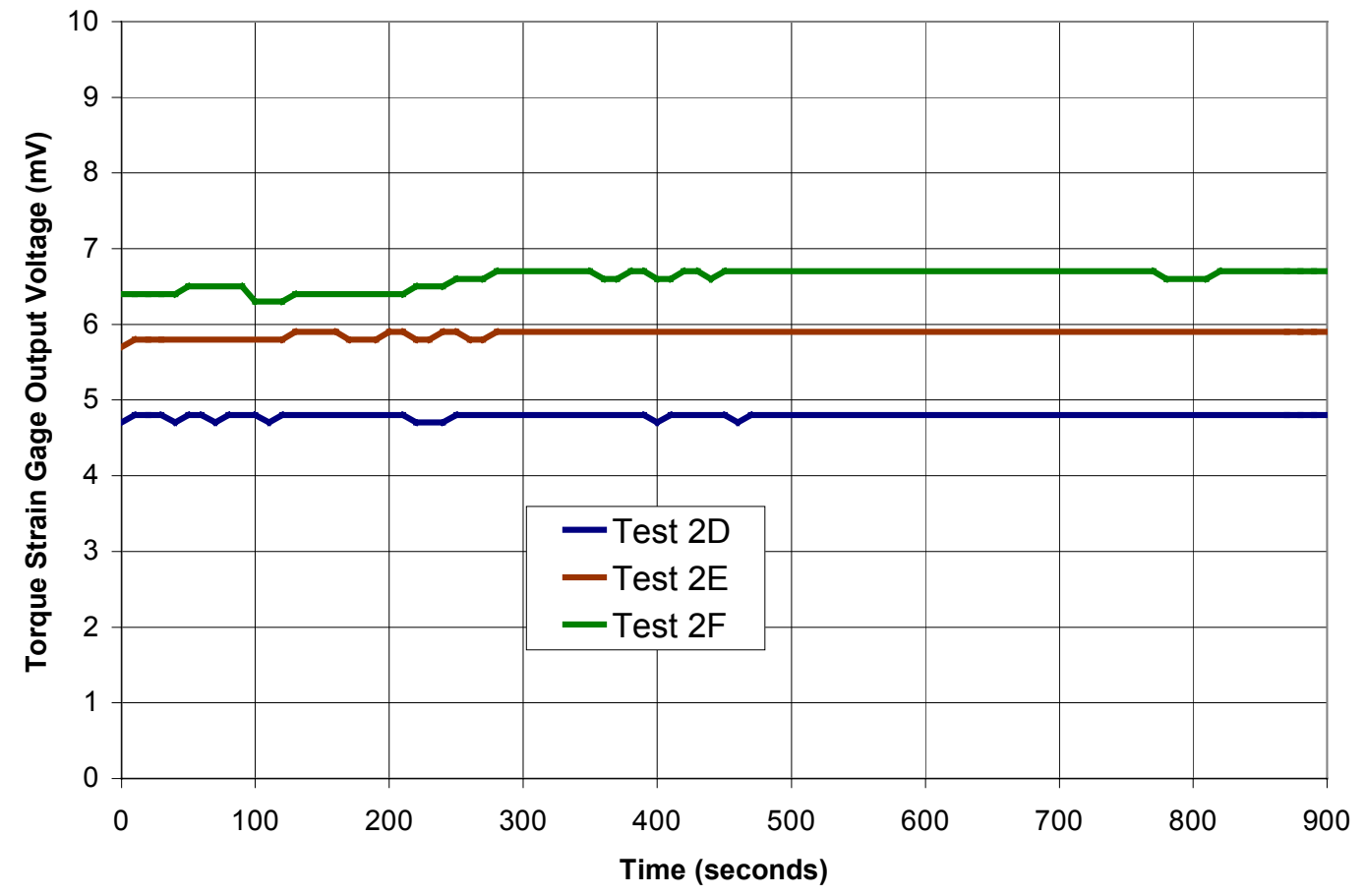

Figure D.4: Torque strain gage output voltage as a function of time in hot zinc test 2D, $2 \mathrm{E}$, and $2 \mathrm{~F}$. 


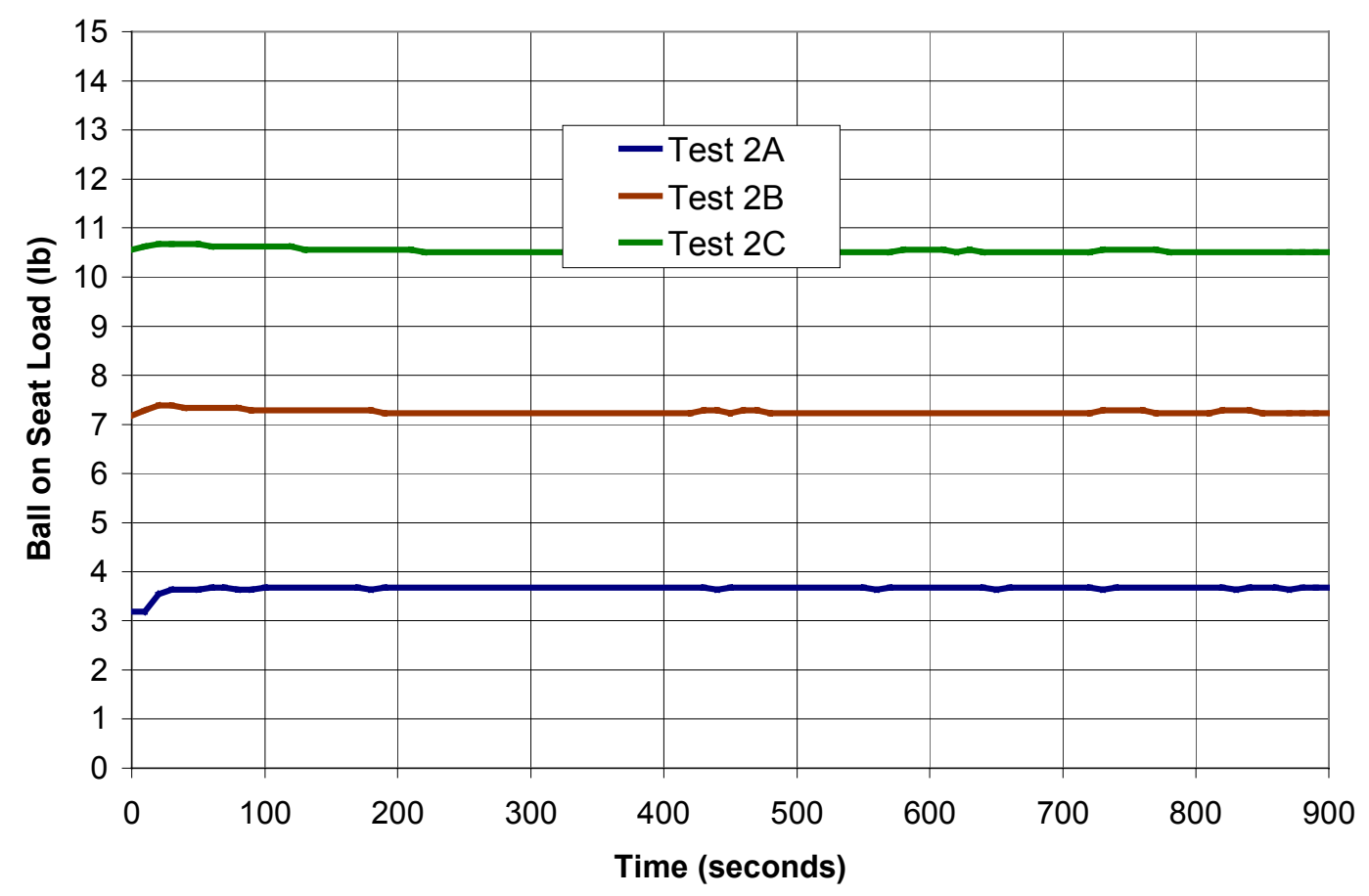

Figure D.5: Ball/seat load as a function of time in hot zinc test 2A, 2B, and 2C.

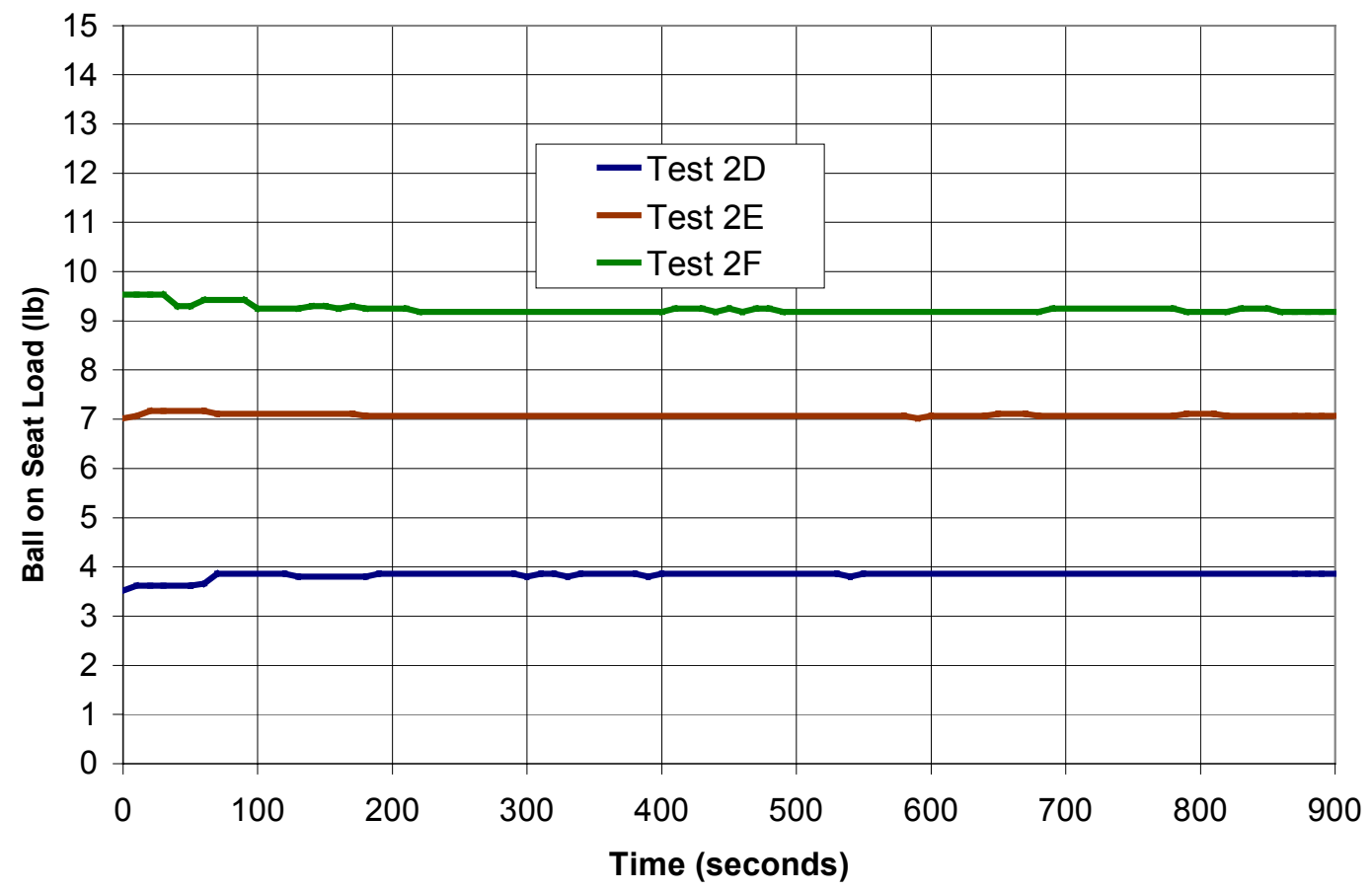

Figure D.6: Ball/seat load output voltage as a function of time in hot zinc test 2D, $2 \mathrm{E}$, and $2 \mathrm{~F}$. 


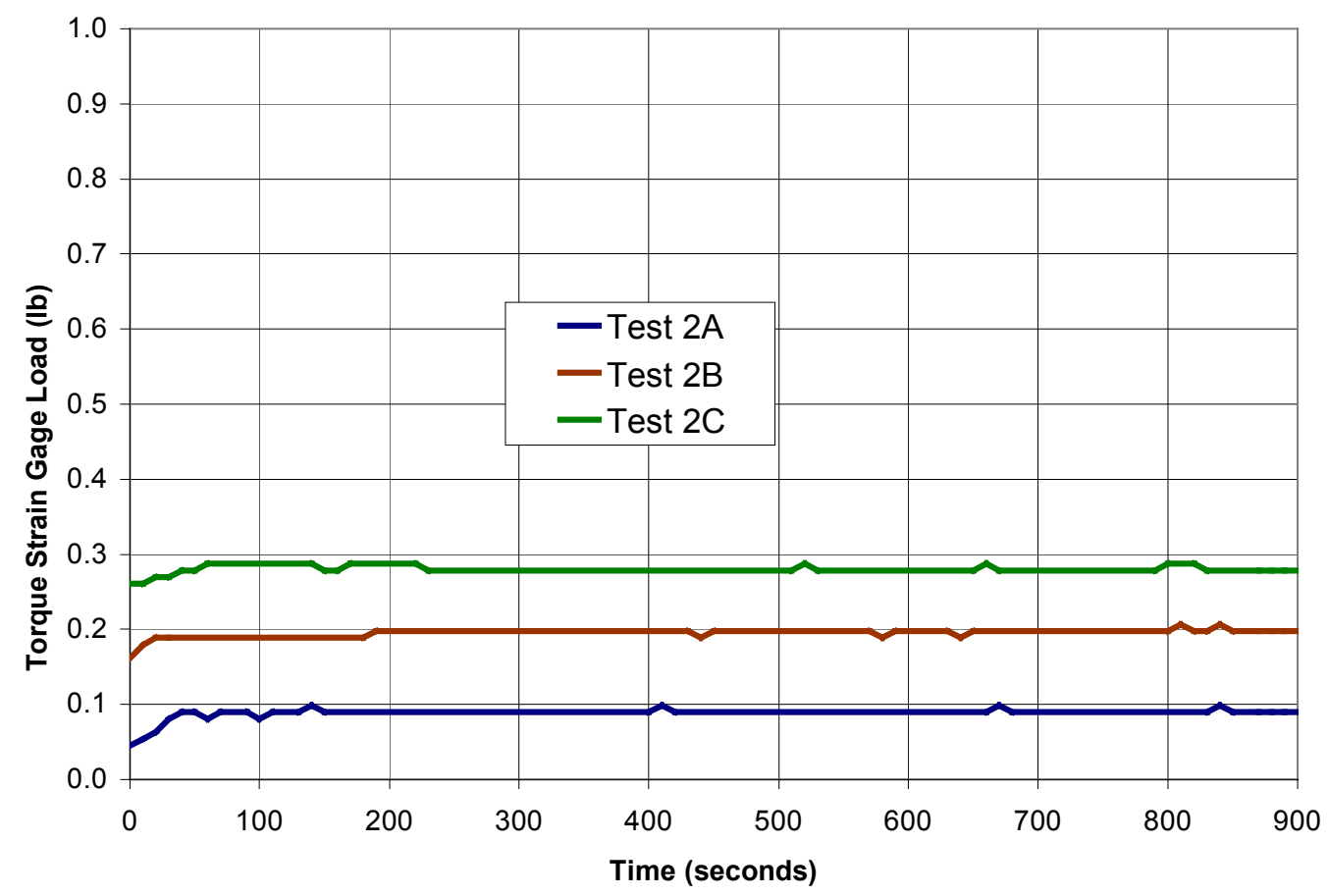

Figure D.7: Torque strain gage load as a function of time in hot zinc test 2A, 2B, and $2 \mathrm{C}$.

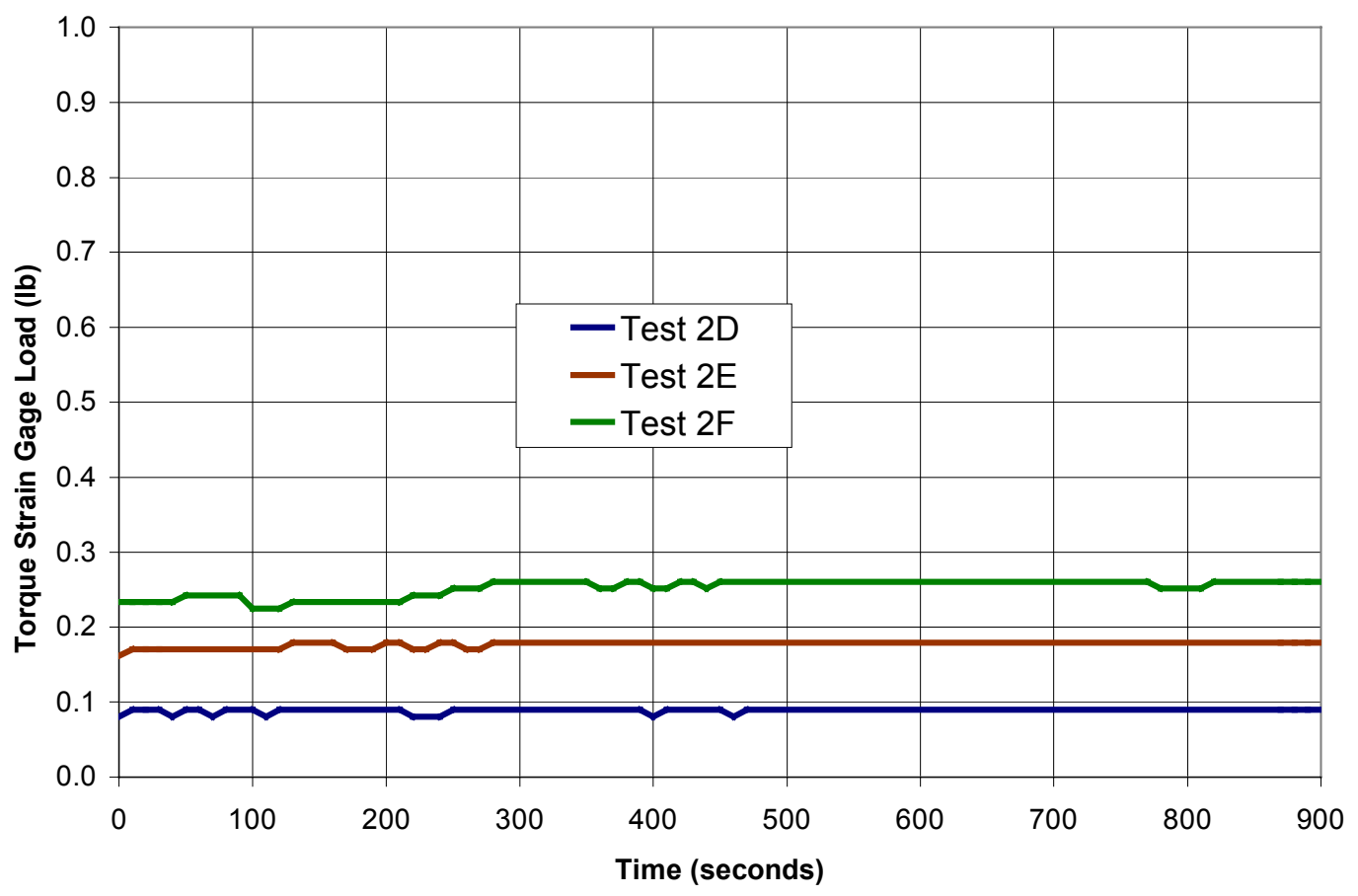

Figure D.8: Torque strain gage load as a function of time in hot zinc test 2D, 2E, and $2 \mathrm{~F}$. 


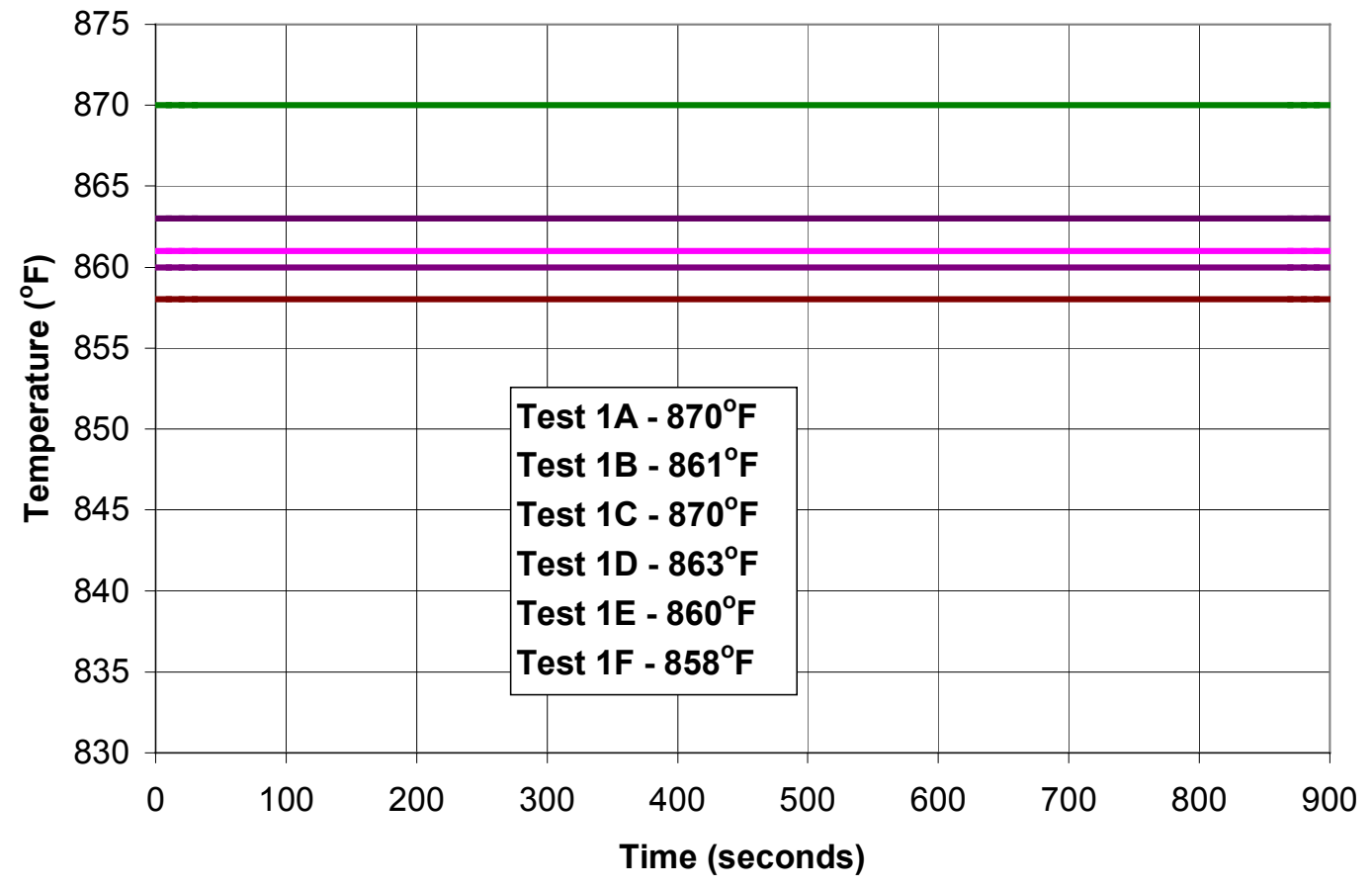

Figure D.9: Temperature as a function of time in hot zinc test $2 \mathrm{~A}, 2 \mathrm{~B}, 2 \mathrm{C}, 2 \mathrm{D}, 2 \mathrm{E}$, and $2 \mathrm{~F}$.

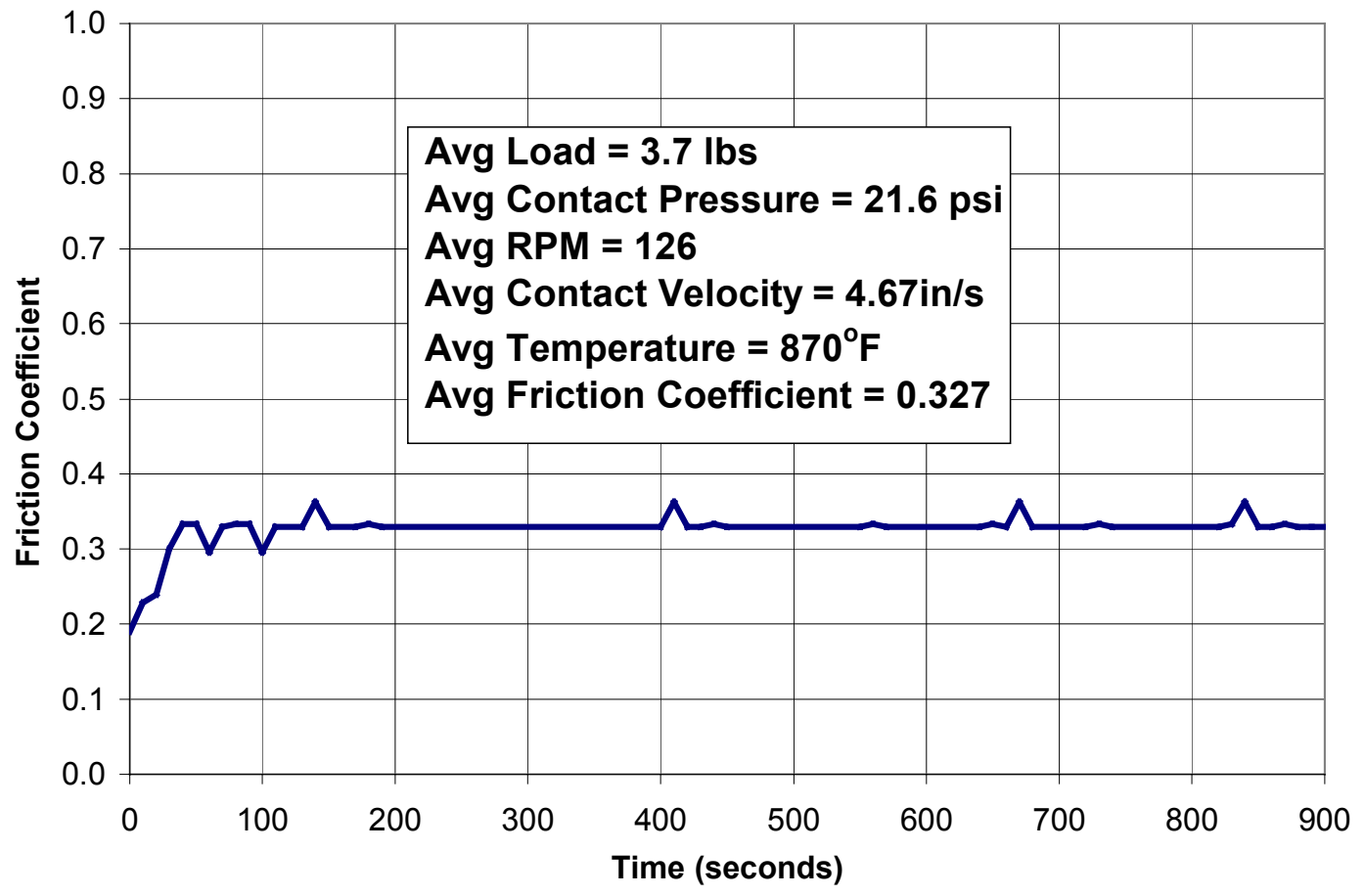

Figure D.10: Zinc pot bearing material friction coefficient as a function of time, for test $2 \mathrm{~A}$ in hot zinc test. 


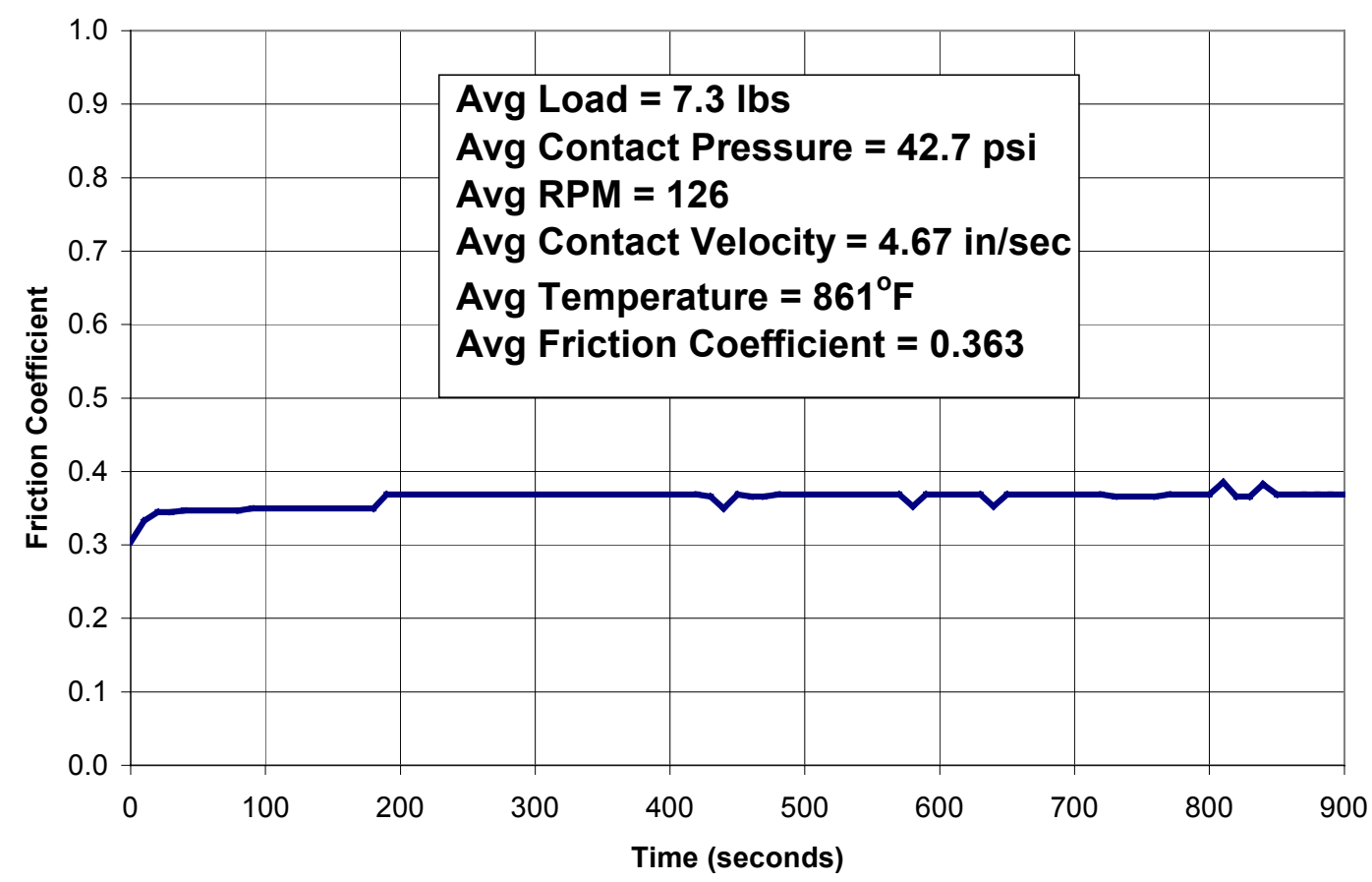

Figure D.11: Zinc pot bearing material friction coefficient as a function of time, for test $2 B$ in hot zinc test.

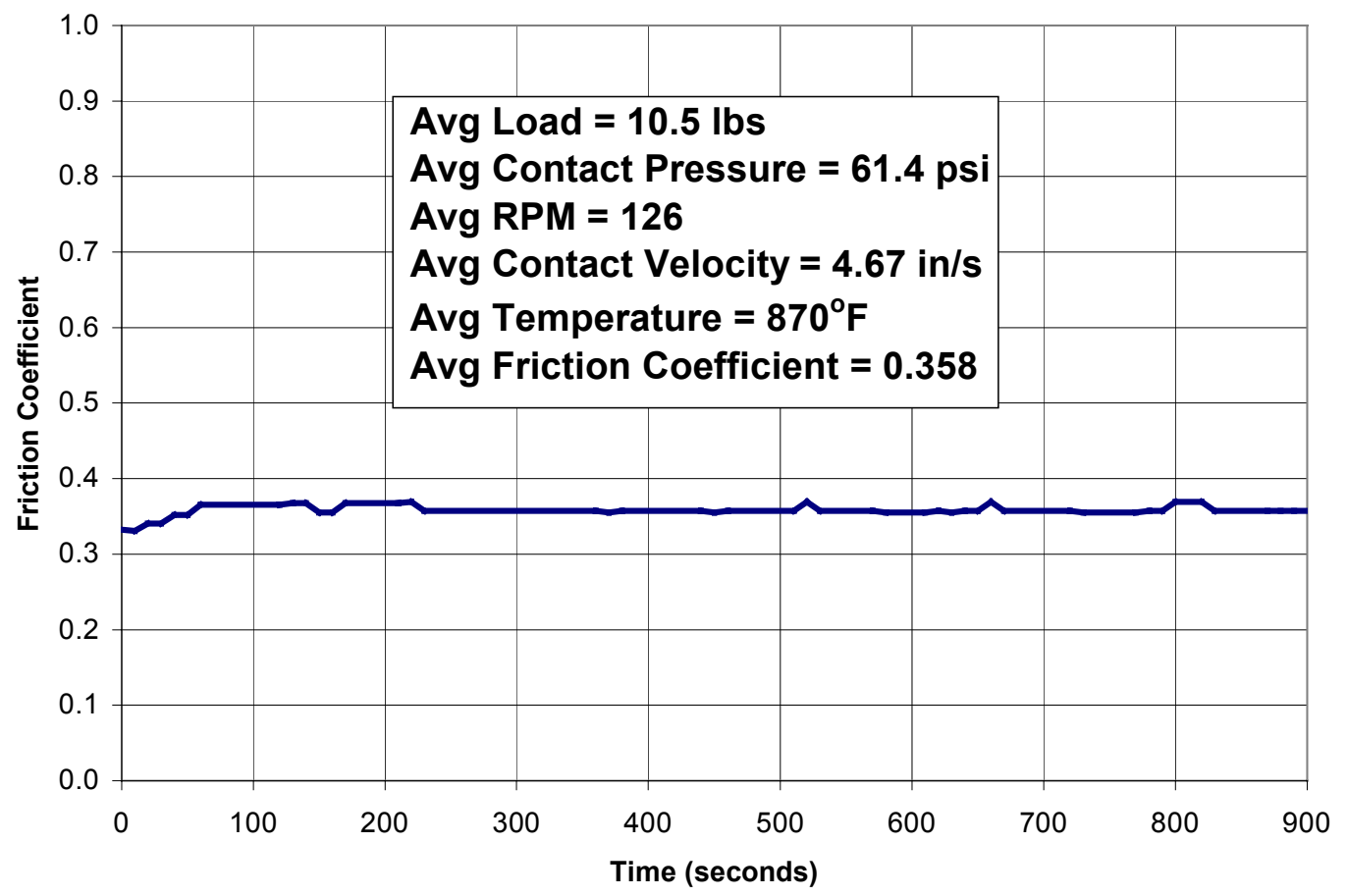

Figure D.12: Zinc pot bearing material friction coefficient as a function of time, for test $2 \mathrm{C}$ in hot zinc test. 


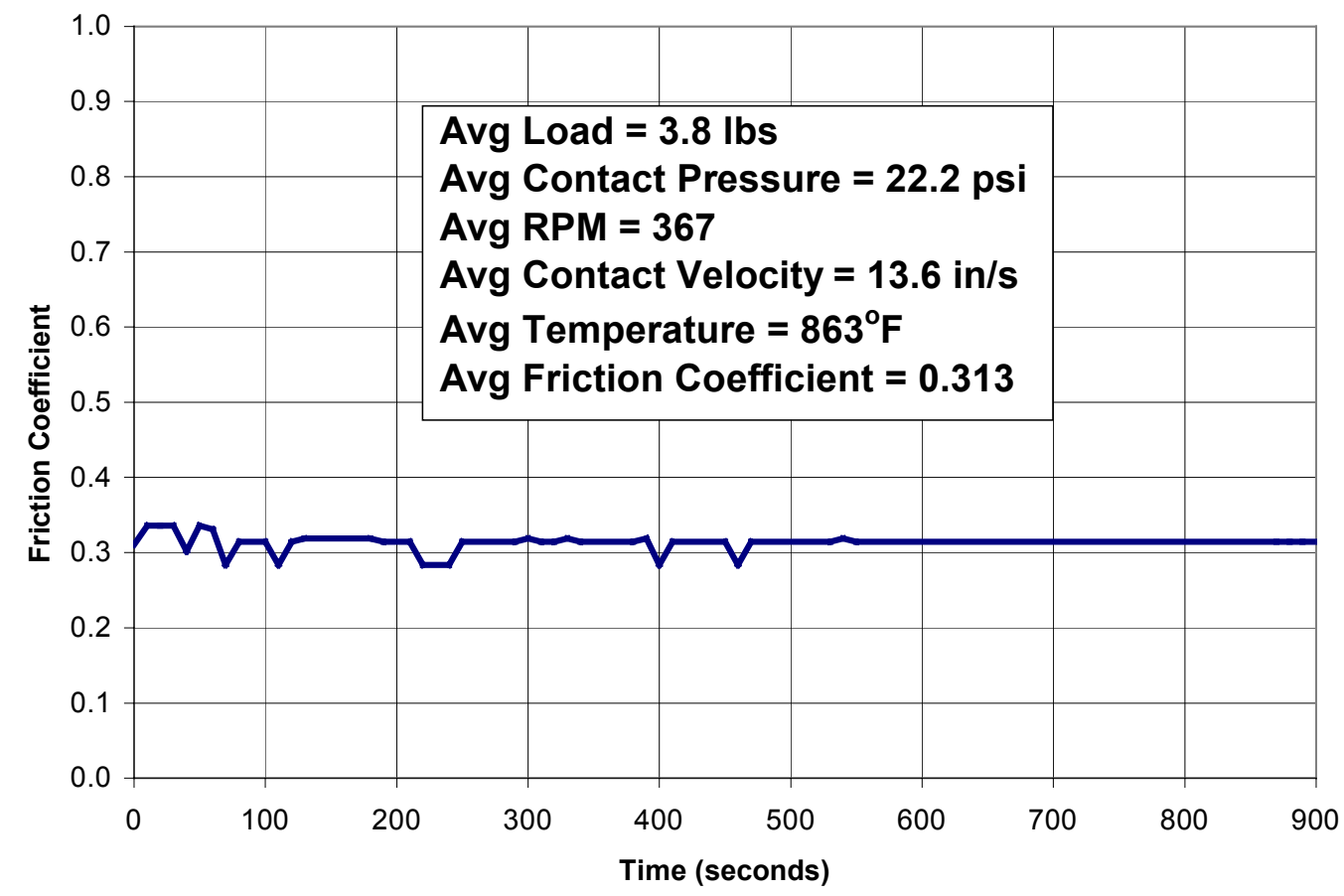

Figure D.13: Zinc pot bearing material friction coefficient as a function of time, for test 2D in hot zinc test.

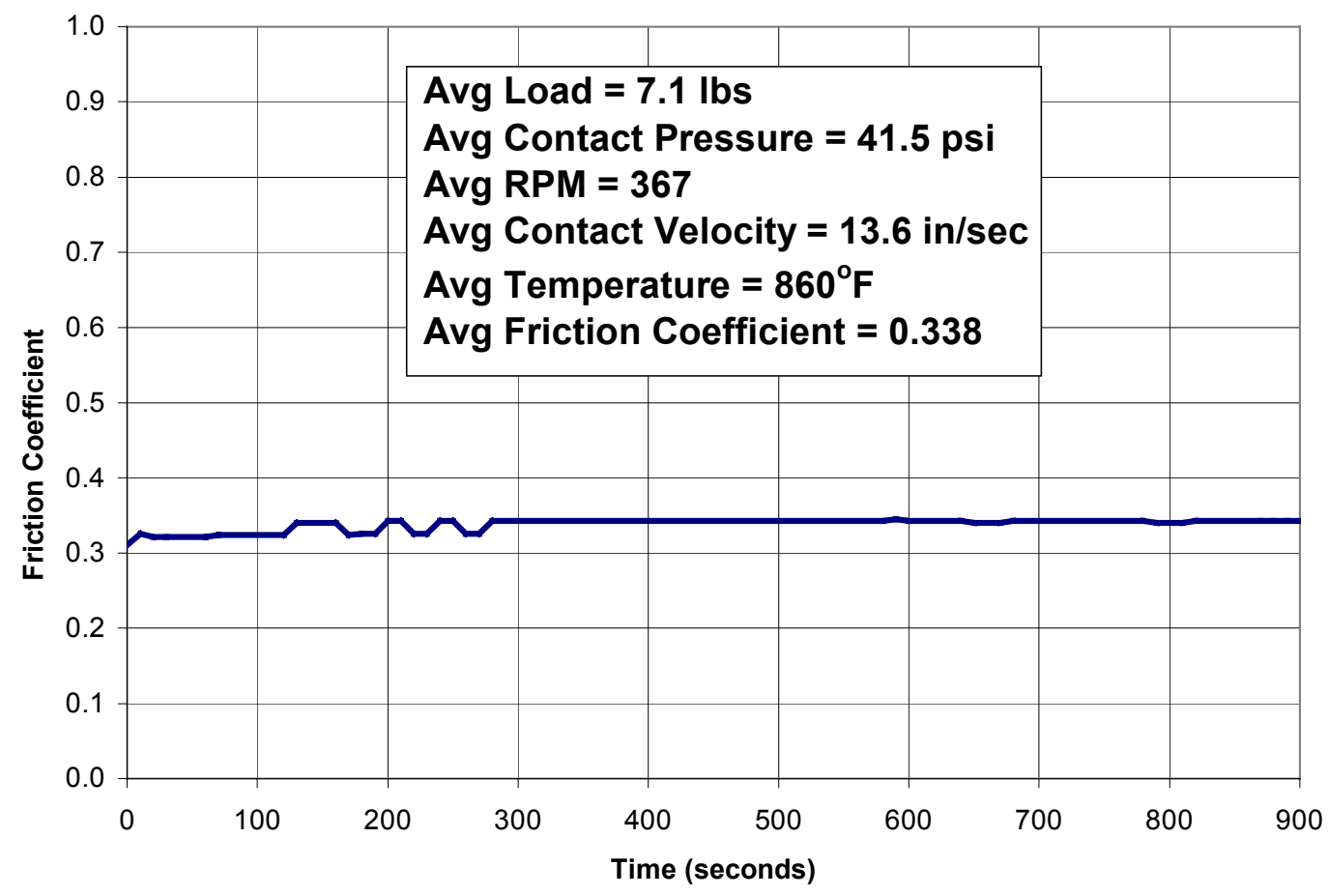

Figure D.14: Zinc pot bearing material friction coefficient as a function of time, for test $2 \mathrm{E}$ in hot zinc test. 


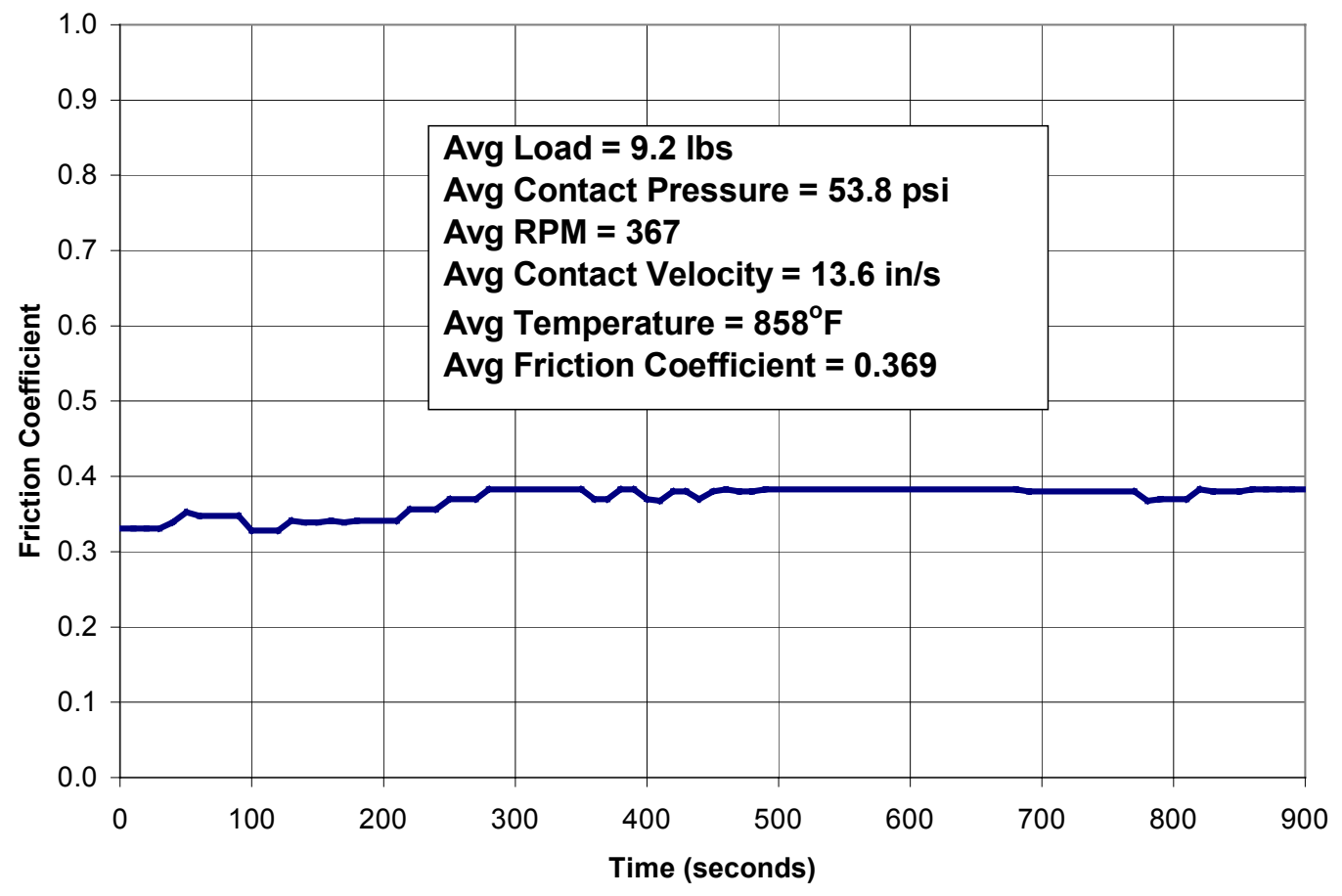

Figure D.15: Zinc pot bearing material friction coefficient as a function of time, for test $2 \mathrm{~F}$ in hot zinc test. 


\section{Appendix E Wiring Diagram for Power Supply}

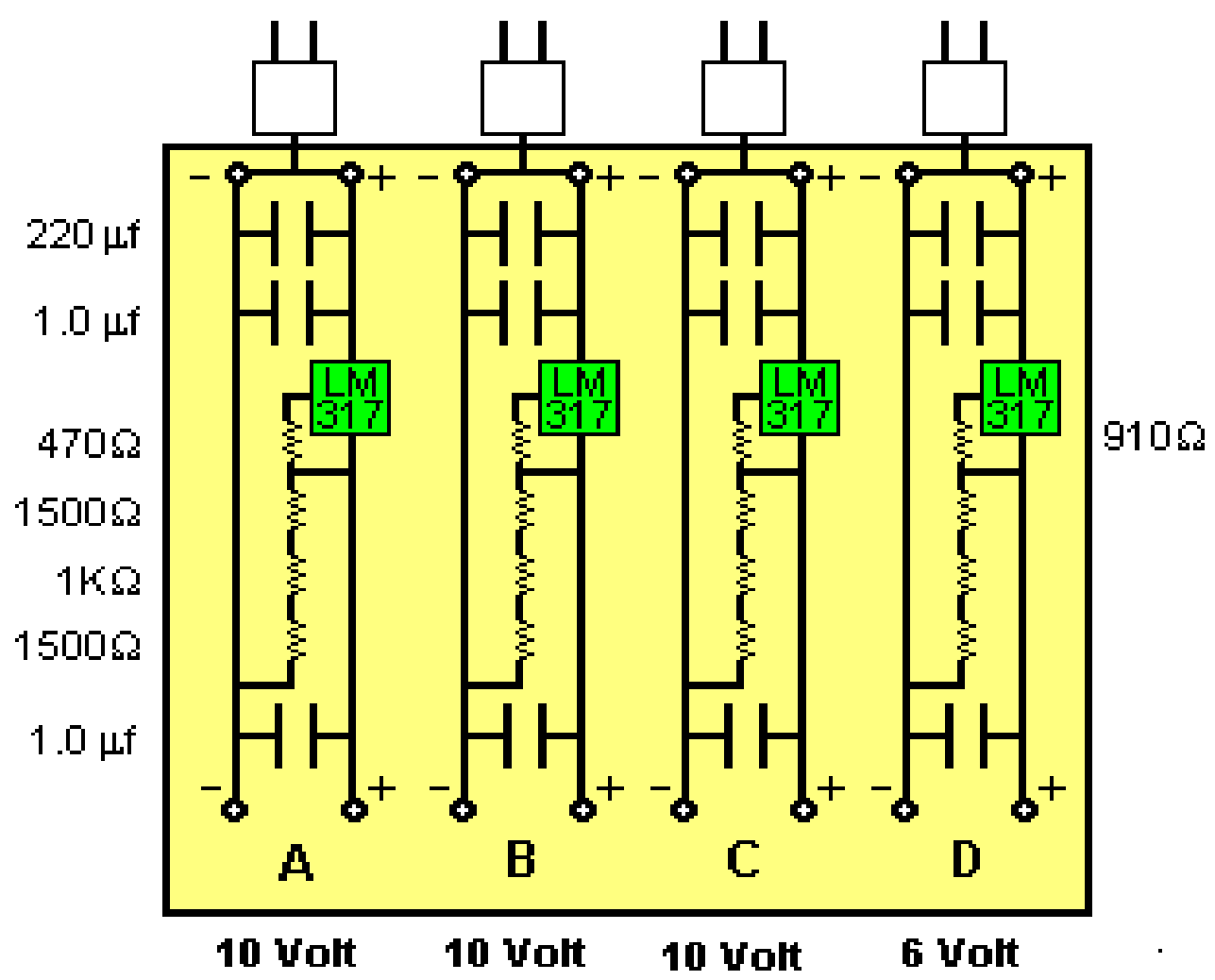

Figure E.1: Wiring diagram for power supply 


\section{Appendix F Zinc Composition for Testing}

Table F.1: Chemical composition analysis for molten zinc used in testing.

\begin{tabular}{|l|l|l|l|l|l|l|l|}
\hline & $\begin{array}{l}\mathrm{Al} \\
\%\end{array}$ & $\begin{array}{l}\mathrm{Cu} \\
\%\end{array}$ & $\begin{array}{l}\mathrm{Fe} \\
\%\end{array}$ & $\begin{array}{l}\mathrm{Pb} \\
\%\end{array}$ & $\begin{array}{l}\mathrm{Cd} \\
\%\end{array}$ & $\begin{array}{l}\mathrm{Si} \\
\%\end{array}$ & $\begin{array}{l}\mathrm{Zn} \\
\%\end{array}$ \\
\hline \multicolumn{7}{|l|}{} \\
\hline Zinc Start-up Material \\
\hline Bulk Material & 0.1593 & 0.0005 & 0.0131 & 0.0019 & 0.0010 & $<0.0003$ & 99.82 \\
\hline \multicolumn{7}{|l|}{} \\
\hline Static Test \\
\hline Alloy 4 500h & 0.1688 & 0.0005 & 0.0156 & 0.0022 & 0.0010 & $<0.0003$ & 99.81 \\
\hline Alloy 4-1 500h & 0.1689 & 0.0004 & 0.0163 & 0.0021 & 0.0008 & $<0.0003$ & 99.81 \\
\hline Alloy 4-2 500h & 0.1674 & 0.0004 & 0.0147 & 0.0020 & 0.0007 & $<0.0003$ & 99.81 \\
\hline Alloy 4-4 500h & 0.1723 & 0.0005 & 0.0167 & 0.0022 & 0.0010 & $<0.0003$ & 99.81 \\
\hline \multicolumn{7}{|l|l|}{} \\
\hline Dynamic Test
\end{tabular}

Average $(n=3)$ 


\section{Appendix G Heat Transfer Calculations}

The rate of heat flow, from the portion of the spindle submerged in the molten zinc bath at $\mathrm{T}_{1}=460^{\circ} \mathrm{C}$ to the water-cooled aluminum disk mounted on top of the spindle at $\mathrm{T}_{2}=20^{\circ} \mathrm{C}$ was calculated. From one-dimensional heat conduction find the heat flow along the spindle as:

$$
\dot{Q}_{\text {Max }}=A_{\text {Spindle }} * K *\left(\frac{d T}{d X}=\frac{T_{1}-T_{2}}{L}\right)
$$

Where the thermal conductivity (K) of type 316 stainless steel is $13 \frac{\mathrm{W}}{\mathrm{mK}}$, and the length of the spindle $(\mathrm{L})$ is 8 -inch $=0.203 \mathrm{~m}$. The cross-sectional area of the spindle $\left(\mathrm{A}_{\text {Spindle }}\right)$ was calculated, using the outer diameter $\left(D_{0}\right)$ and the inside diameter $\left(D_{i}\right)$ of the stainless steel tubing, by:

$$
A_{\text {Spindle }}=\left(\frac{\pi}{4}\right) *\left[\left(D_{O}^{2}-D_{i}^{2}\right)=\left(0.75^{2}-0.51^{2}\right)\right]=0.238 \operatorname{in}^{2}=1.54 * 10^{-4} \mathrm{~m}^{2}
$$

From the one-dimensional heat conduction equation:

$$
\begin{gathered}
\dot{Q}_{\text {Max }}=\left(1.54 * 10^{-4} \mathrm{~m}^{2}\right) *\left(13 \frac{\mathrm{W}}{\mathrm{mK}}\right) *\left(\frac{733.15^{0} \mathrm{~K}-293.15^{\circ} \mathrm{K}}{0.203 \mathrm{~m}}\right) \\
\dot{Q}_{\operatorname{Max}}=4.34 \mathrm{~W}
\end{gathered}
$$

The rate of heat flow along the spindle is found to be acceptably small. The ratio between the water-cooled disk and the fixed spindle disk:

$$
\frac{A_{\text {Disk }}}{A_{\text {Spindle }}}=\frac{0.0119 \mathrm{~m}^{2}}{1.54 * 10^{-4} \mathrm{~m}^{2}}=77
$$

The ratio between the area of two disks is so great, it is not necessary to calculate the heat transfer between them. 


\section{Appendix H: Calibration Calculations and Curves}

The torque strain gage and load cells are calibrated to transfer the known output signal to a force. Known weights are placed on the cup torque transfer plate, and the output voltage is read. Curves are generated to give an equation for force as a function of output voltage.

The torque strain gage was calibrated the same way. Weights hang from a small wire that is attached to the strain gage vertical beam. The wire is attached to a pulley, which transfers the force in the horizontal direction. Figures H.1 and H.2 show the calibration curves used.

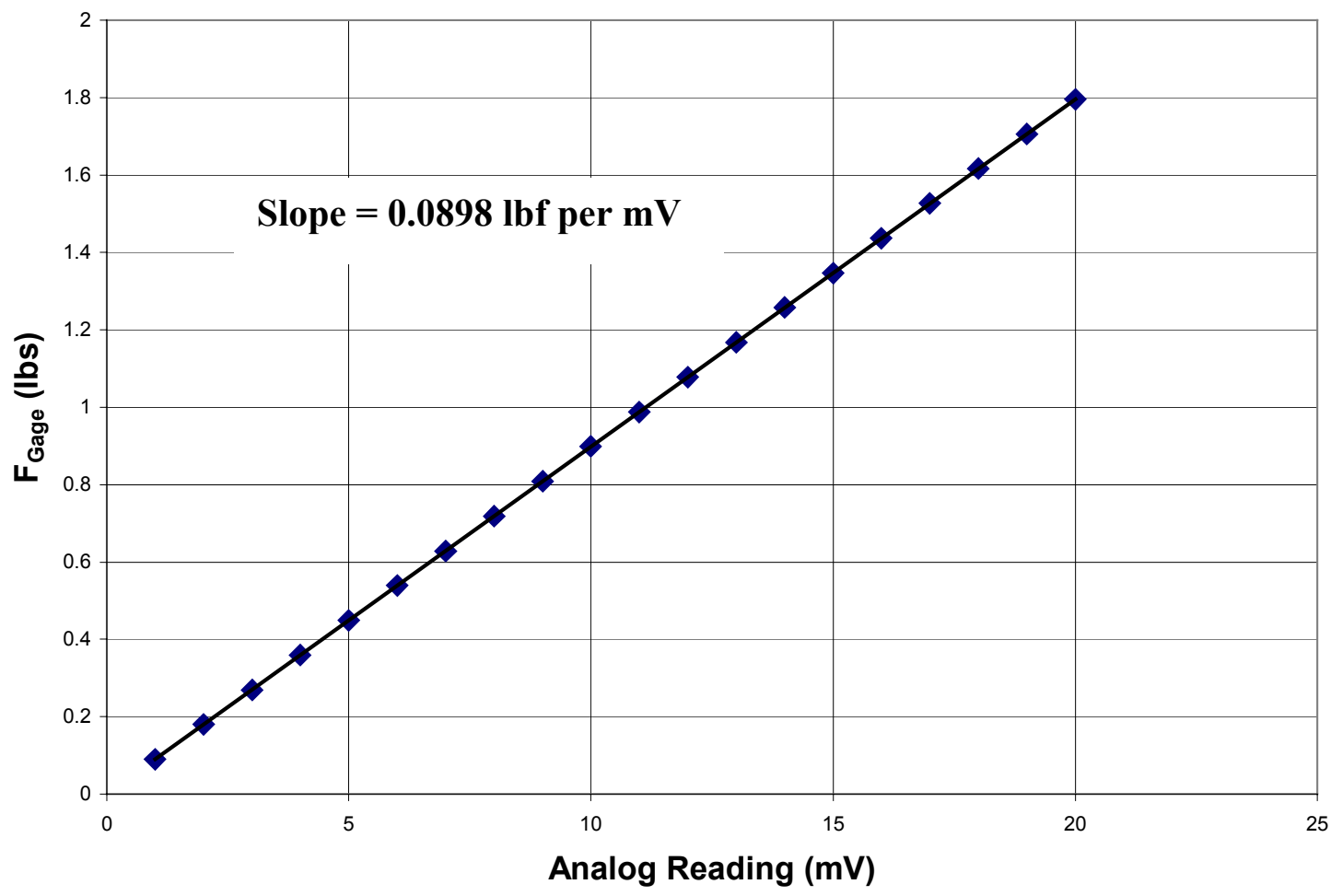

Figure H.1: Calibration curve for strain gage beam $\mathbf{F}_{\text {Gage }}$ with moment arm $l_{\text {Gage }}=6.75$-inch. 


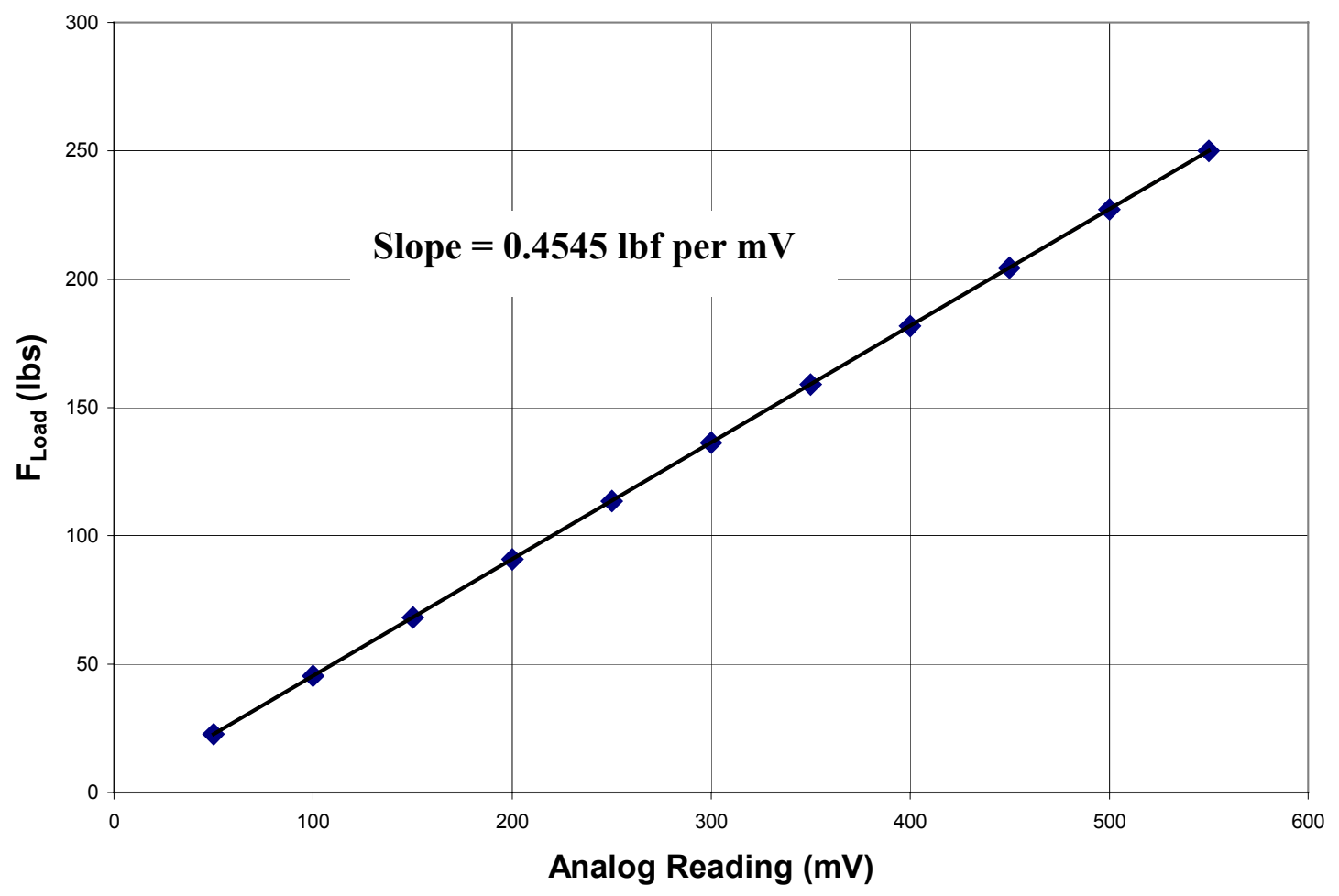

Figure H.2: Calibration curve for load cells. 